\title{
Elucidating the cellular effects of MDMA on the serotonin transporter (SERT)
}

\author{
ANA HOLLEY
}

A thesis submitted to Victoria University of Wellington in fulfillment of the requirements for the degree of Master of Biomedical Science

May 2012 


\begin{abstract}
Serotonin (5-HT) is a neurotransmitter with an integral role in regulating mood. Dysregulation of this system is implicated in disorders such as depression and withdrawal from drugs of abuse. 3,4- methylenedioxymethamphetamine (MDMA) or 'Ecstasy' is a commonly abused drug which primarily targets the serotonin transporter (SERT) and competes with 5-HT for uptake into the pre-synaptic neuron. This study focused on the cellular effects MDMA has on SERT, and how it is able to regulate SERT function. Previous studies have shown that MDMA is able to down-regulate SERT expression from the cell surface to intracellular vesicles, thereby decreasing 5-HT transport. How MDMA targets this regulatory pathway is unclear. Protein Kinase $\mathrm{C}(\mathrm{PKC})$ is a well-known regulator of SERT, and activation of PKC causes phosphorylation of SERT, targeting the transporter for internalization. Using rotating disc electrode voltammetry (RDEV) we show that MDMA causes a significant functional decrease of SERT in HEK-293 and $\mathrm{N}_{2}$ A cells expressing GFPhSERT. This MDMA-induced down-regulation was not observed when cells were pretreated with PKC inhibitor, Bis I. This data suggests that the MDMA-induced down-regulation of SERT occurs via PKC signaling pathways. Further investigations into the kinetics of the serotonin transporter did not show a change in the $\mathrm{V}_{\max }$ or $\mathrm{K}_{\mathrm{m}}$ values between the control and the MDMA-treated samples. This suggests that the functional down-regulation observed after MDMA treatment was not due to a decrease in SERT expression at the cell surface.
\end{abstract}




\section{Acknowledgements}

The following people have played a major role in seeing to the completion of this project:

First and foremost, my supervisor, Dr. Bronwyn Kivell, for her perseverance and support, endless research ideas and numerous proofreading of the drafts.

To my parents who have been my champions from the very start, I can never say thank you enough,

To Bridget Simonson, Kirsty Danielson, Peter Bosch and Fraser Putt for teaching me everything that I know and putting up with the bouts of insanity and providing the inspiration to carry on.

Students and staff of the School of Biological Sciences.

And to Victoria University of Wellington and the Neurological foundation for funding and providing the opportunity to undertake this project. 


\section{TABLE OF CONTENTS}

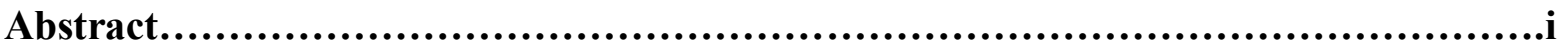

Acknowledgments.................................................................................

Table of Contents..............................................................................ii

List of Figures.................................................................................

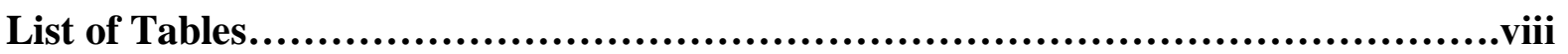

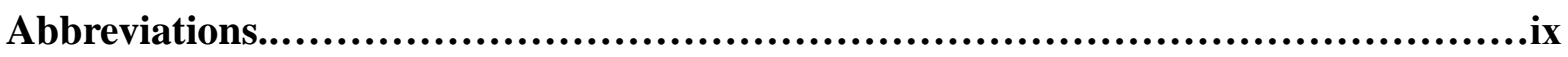

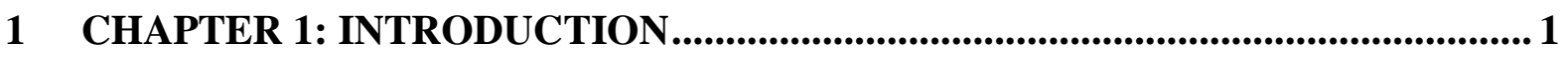

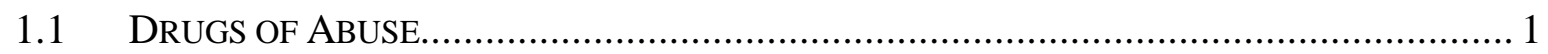

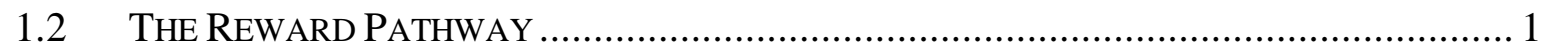

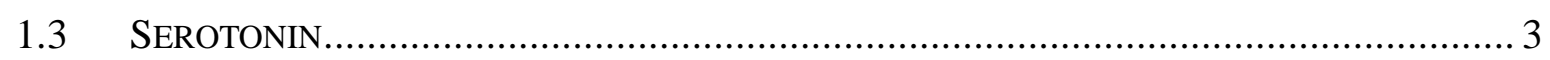

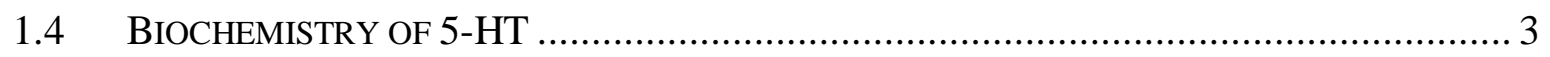

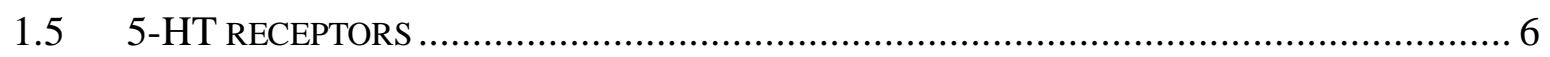

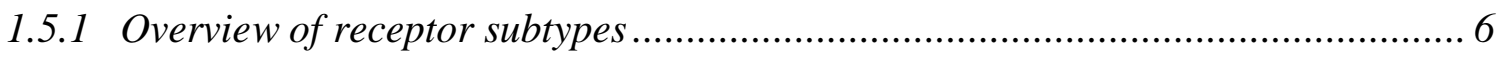

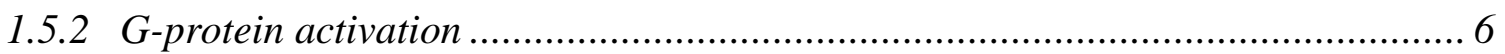

1.5.3 5-HT receptor subtypes: ......................................................................... 7

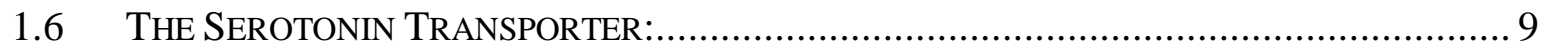

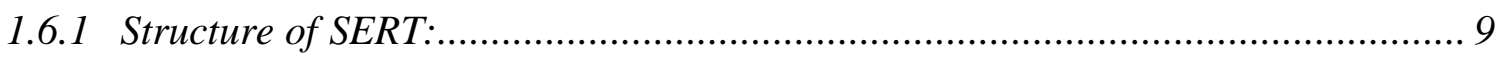

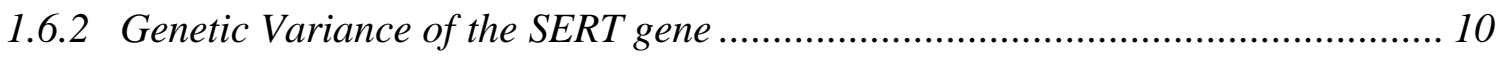

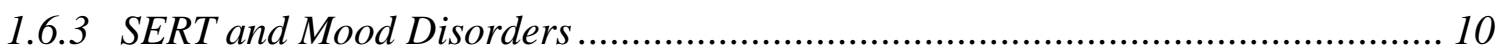

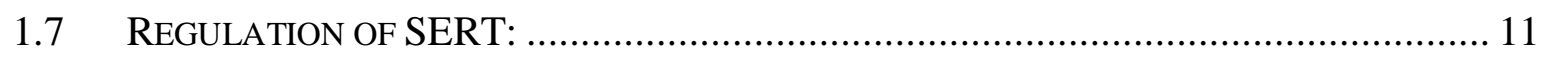

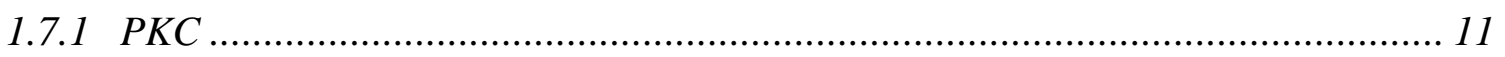

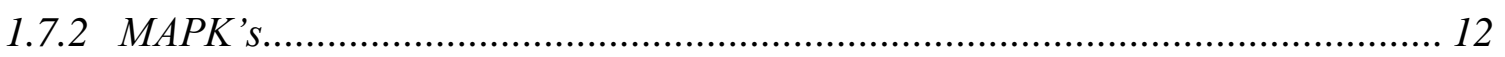

1.7 .3 PKA

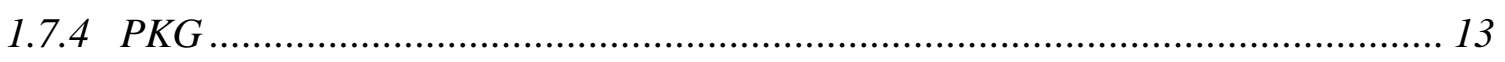

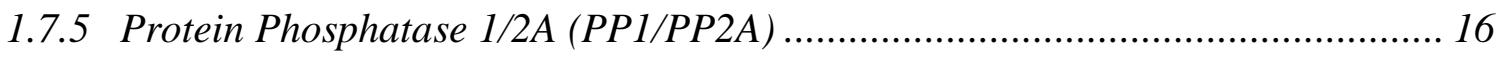

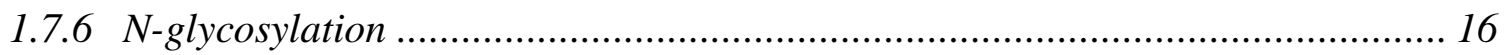

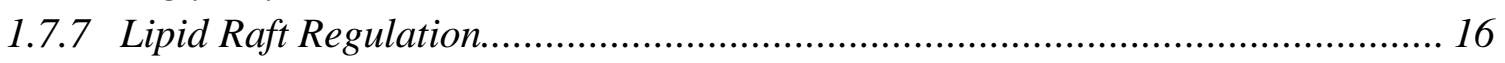

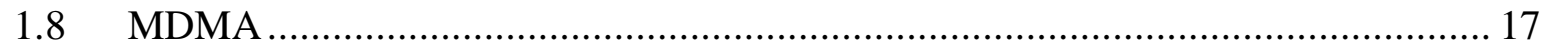

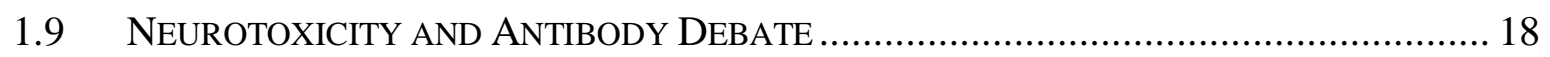

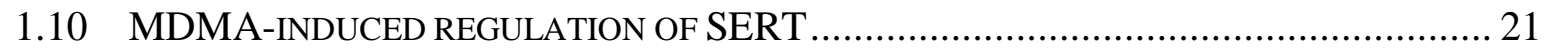

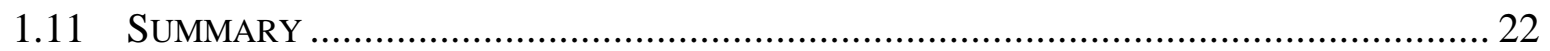

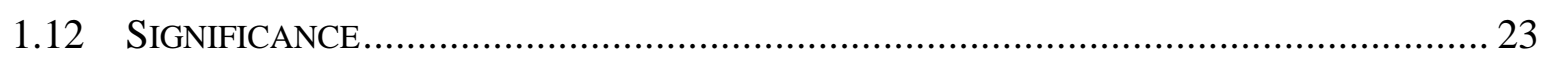

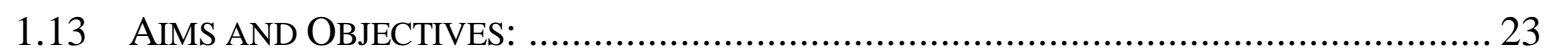

2 CHAPTER 2: MATERIALS AND METHODS …................................................

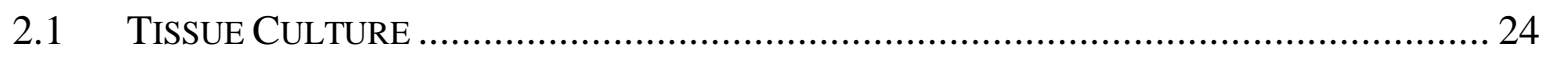

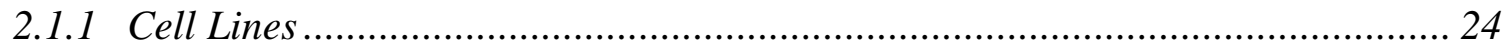

2.1.2 Cell growth and passaging ..................................................................... 25 


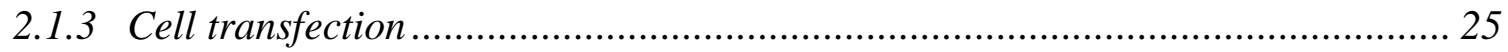

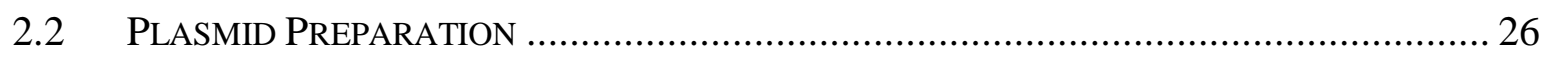

2.2.1 Luria Broth (LB) kanamycin agar plates........................................................ 26

2.2.2 Transformation of MAX Efficiency ${ }^{\circledR}$ DH5 $\alpha^{T M}$ Competent Cells ......................... 26

2.2.3 Cultivation of Escherichia coli (E.coli)............................................................ 26

2.2.4 Plasmid purification using the Qiagen hiSpeed Maxi Kit .................................. 26

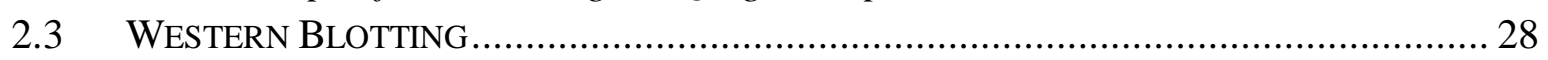

2.3.1 Protein lysate preparation ............................................................................. 28

2.3.2 SDS polyacrylamide gel electrophoresis and transfer of protein to PDVF

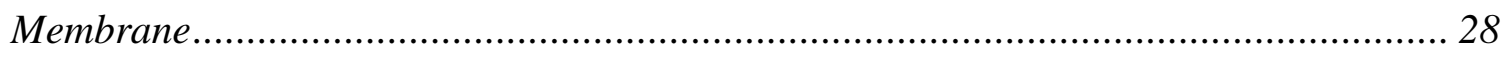

2.3.3 Probing for the protein of interest: GFP-hSERT ............................................. 29

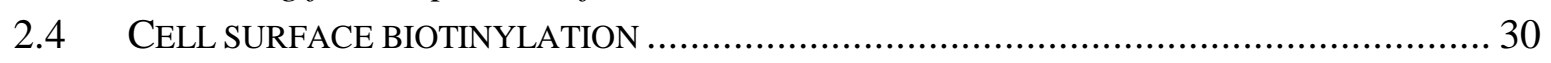

2.5 TOTAL INTERNAL REFLECTION FLUORESCENCE MICROSCOPY (TIRFM) .................. 32

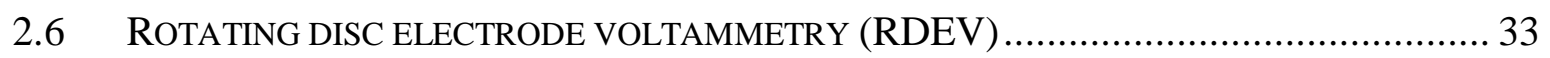

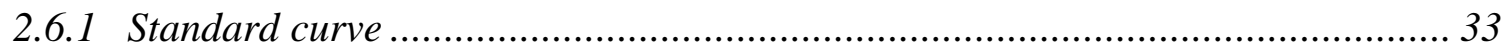

2.6.2 Preparation of GFP-hSERT transfected HEK-293 and $N_{2} A$ cells for RDEV ....... 34

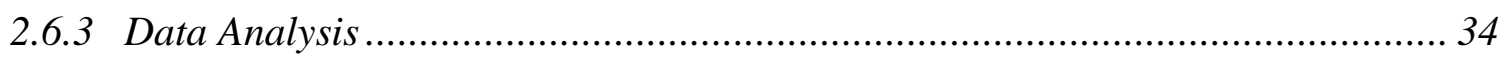

3 CHAPTER 3: VALIDATION OF SERT ANTIBODY SPECIFICITY .................. 35

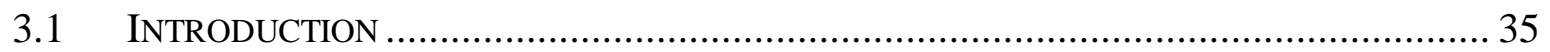

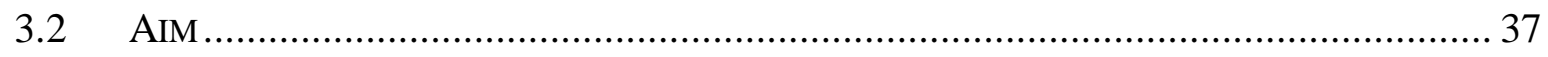

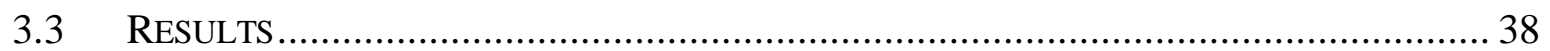

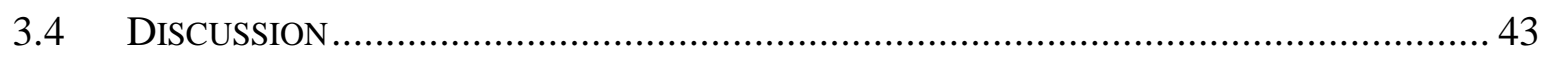

4 CHAPTER 4: INVESTIGATING THE EFFECTS OF MDMA ON SERT

FUNCTION IN A CELL MODEL ................................................................................... 45

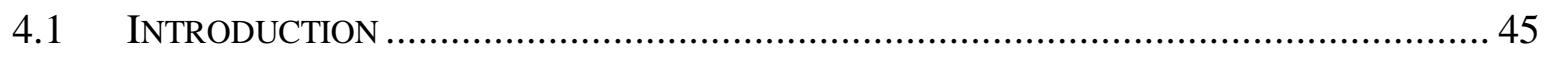

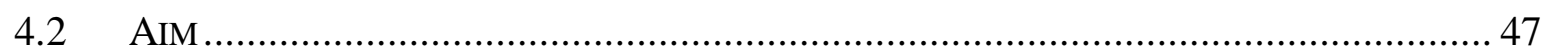

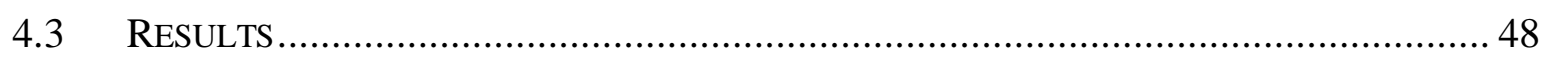

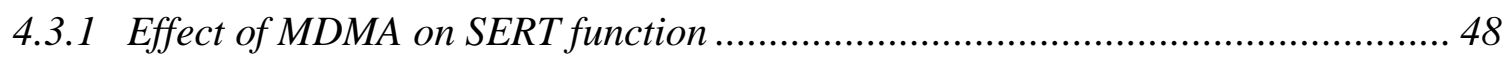

4.3.2 Effect of PKC activator $\beta$-PMA on SERT function ............................................ 51

4.3.3 Effect of MDMA on 5-HT uptake after PKC inhibition..................................... 53

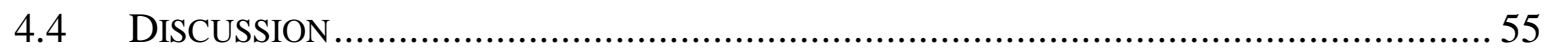

5 CHAPTER 5: INVESTIGATING THE EFFECT MDMA HAS ON THE SURFACE EXPRESSION OF SERT IN A CELL MODEL.........................................5 57

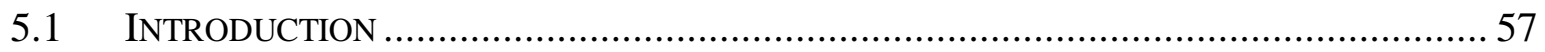

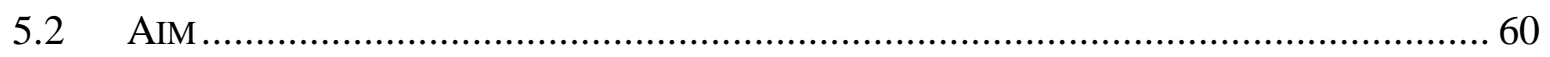

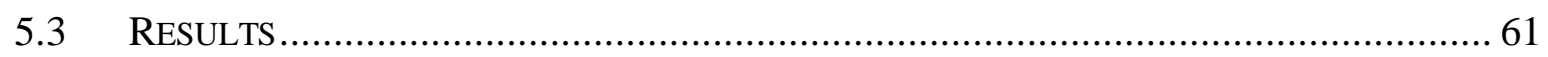

5.3.1 Determination of SERT kinetics in cells transfected with GFP-hSERT following

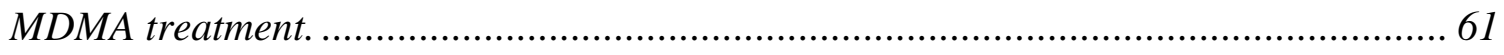

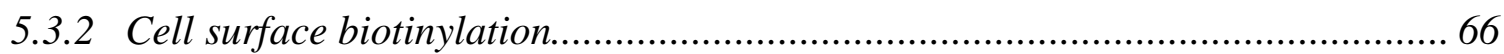

5.3.3 Total Internal Reflection Fluorescence Microscopy (TIRFM) ............................ 76

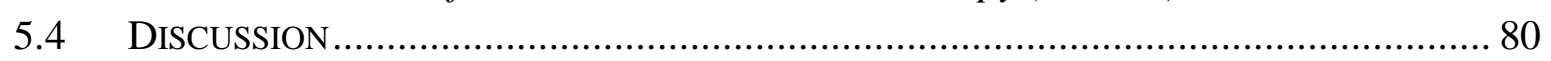


6 CHAPTER 6: FINAL DISCUSSION ........................................................................ 86

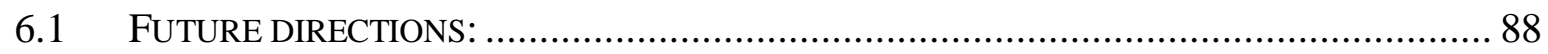

7 APPENDIX 1: SOLUTIONS ......................................................................................90

8 APPENDIX 2: BCA PROTEIN ASSAY ............................................................... 95

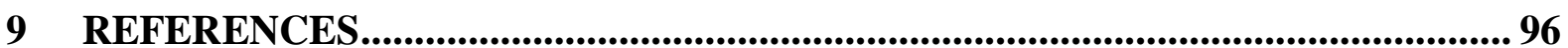




\section{LIST OF FIGURES}

Figure 1:1: The brain's natural reward pathway....................................................... 2

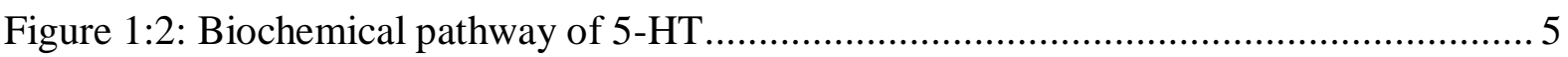

Figure 1:3: Overview of SERT regulation by the major protein kinases........................... 15

Figure 3:1: Western blot of HEK-293 cells transfected with GFP-hSERT and probed with

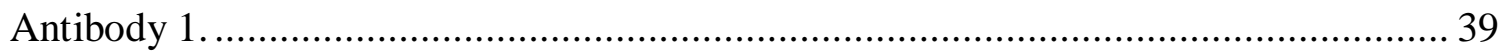

Figure 3:2: Western blot of HEK-293 cells transfected with GFP-hSERT and probed with

Antibody 2.

Figure 3:3: Western blot of $\mathrm{N}_{2}$ A cells transfected with GFP-hSERT and probed with

Antibody 2 at a dilution of $1: 1000$.

Figure 4:1: MDMA wash-out control.

Figure 4:2: Effect of MDMA on 5-HT uptake in HEK-293 and $\mathrm{N}_{2} \mathrm{~A}$ cells transfected with GFP-hSERT. 50

Figure 4:3: The effect of the PKC activator $\beta$-PMA on 5-HT uptake in HEK-293 and $\mathrm{N}_{2} \mathrm{~A}$ cells transfected with GFP-hSERT.

Figure 4:4: Effect of MDMA on 5-HT uptake after PKC inhibition by Bis I in HEK-293 and

$\mathrm{N}_{2}$ A cells transfected with GFP-hSERT. 54

Figure 5:1: Uptake of 5-HT in non-transfected and GFP-hSERT transfected HEK-293 cells.

Figure 5:2: The effect of MDMA on SERT function in HEK-293 cells transiently transfected with GFP-hSERT.

Figure 5:3: Uptake of 5-HT in non-transfected and GFP-hSERT transfected $\mathrm{N}_{2} \mathrm{~A}$ cells.

Figure 5:4: The effect of MDMA on SERT function in $\mathrm{N}_{2} \mathrm{~A}$ cells transiently transfected with

GFP-hSERT.

Figure 5:5: No change seen in GFP-hSERT cell surface fraction following MDMA treatment

in HEK-293 cells.

Figure 5:6: No change seen in GFP-hSERT cell surface fraction after MDMA treatment in

$\mathrm{N}_{2} \mathrm{~A}$ cells.

Figure 5:7: No change seen in GFP-hSERT cell surface fraction after $\beta$-PMA treatment in HEK-293 cells.

Figure 5:8: No change in GFP-hSERT cell surface fraction after $\beta$-PMA treatment in $\mathrm{N}_{2} \mathrm{~A}$

cells but significant decrease after treatment with Ionomycin and $\beta$-PMA. 72 
Figure 5:9: No change seen in GFP-hSERT expression after BisI and/or MDMA treatment in HEK-293 cells.

Figure 5:10: No change seen in GFP-hSERT expression following Bis I and/or MDMA treatment in $\mathrm{N}_{2} \mathrm{~A}$ cells.

Figure 5:11: MDMA does not significantly alter cell surface expression of GFP-hSERT expressed in HEK-293 cells. 77

Figure 5:12: Cell Surface Expression of GFP-hSERT during 10 min incubation with MDMA in $\mathrm{N}_{2} \mathrm{~A}$ cells. 78

Figure 5:13: Cell Surface Expression of GFP-hSERT during a 30 min incubation with $\beta$ PMA in $\mathrm{N}_{2} \mathrm{~A}$ cells. 79

Figure 8:1 Standard curve for BCA assay. 95 


\section{LIST OF TABLES}

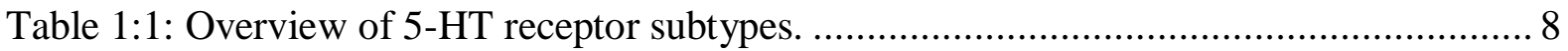

Table 2:1: List of Antibodies used in Western blotting experiments .................................. 30

Table 3:1: Literature review of the molecular characteristics of SERT.............................. 36

Table 5:1: Kinetic data from RDEV for control and MDMA treated cells.......................... 63 


\section{ABBREVIATIONS}

5-HT Serotonin (5-Hydroxytryptophan)

5-HIAA 5-hydroxyindoleacetic acid

AC Adenylate cyclase

AFU Arbitrary fluorescent unit

$\mathrm{AR}_{3} \quad$ Adenosine receptor

ATP Adenosine triphosphate

Bis I Bisindolylmaleimide I

CaMKII $\quad \mathrm{Ca}^{2+} /$ calmodulin-dependent kinase II

cAMP Cyclic adenosine monphosphate

DAG Diacylglycerol

DAT Dopamine transporter

DMEM Dulbeccos Modified Eagle's Medium

DMSO Dimethyl sulfoxide

FCS Fetal calf serum

FSCV Fast scan cyclic voltammetry

GAPDH Glyceraldehyde 3 phosphate dehydrogenase

GFAP Glial fibrillary acidic protein

GFP-hSERT Green fluorescent protein tagged-human serotonin transporter

GPCR G protein coupled receptor

HDC Hydroxytryptophan decarboxylase

HEK-293 Human embryonic kidney-293 cells

HSC High-speed chronoamperometry

$\mathrm{IP}_{3} \quad$ Inositol triphosphate

LB Luria broth

MAO Monoamine oxidase

MAPK Mitogen-activated protein kinase 
MDMA 3,4-methylenedioxymethamphetamine

$\mathrm{N}_{2} \mathrm{~A} \quad$ Mouse neuroblastoma cells

NAc Nucleus accumbens

NET Norepinephrine transporter

OCT Organic cation transporter

PAGE Polyacrylamide gel electrophoresis

PBS Phosphate-buffered saline

PFC Prefrontal cortex

PKA Protein kinase A

PKC Protein kinase C

PKG Protein kinase G

PMA Phorbol 12-myristate 13-acetate

PMAT Plasma membrane transporter

PP Protein phosphatase

PVDF Polyvinylidine difluoride

RDEV Rotating disc electrode voltammetry

RN Raphe nuclei

RPMI Roswell Park Memorial Institute

SDS Sodium dodecyl sulphate

SERT Serotonin transporter

SN Substantia nigra

SSRI Selective serotonin reuptake inhibitors

TBS Tris-buffered saline

TIRFM Total internal reflection fluorescence microscopy

TPH Tryptophan hydroxylase

VMAT Vesicular monoamine transporters

VTA Ventral tegmental area 


\section{Chapter 1: Introduction}

\subsection{Drugs of Abuse}

In New Zealand it is estimated that $30 \%$ of the population abuse drugs such as nicotine, alcohol, psychostimulants and opioids (M.O.H. 2007), which have a large impact on social and economic costs. Currently there are no pharmacotherapies available to treat abuse of psychostimulants such as cocaine, ecstasy, amphetamine or methamphetamine. The 2010 World Drug Report states that the Oceania region has one of the highest annual prevalence rates of ecstasy, with New Zealand reporting a $2.6 \%$ rate of annual prevalence in a population of 15-64 year olds (UNODC 2010). Drug abuse and dependence is of major concern with further research needed to determine the mechanistic effect drugs of abuse have on the brain so that potential therapeutics that prevent or reverse these changes can be investigated.

\subsection{The Reward Pathway}

The natural reward pathway in the brain is activated upon events such as eating, drinking or sex (Adinoff 2004). It is targeted by drugs of abuse which leads to a dysregulation of the neuro-circuitry involved (Koob 2001). Dopaminergic neurons make up the core of this natural reward system, with other monoamine systems such as the serotonergic system feeding into it, creating what is known as the limbic pathway. The ventral tegmental area is the center of the pathway, with dopamine cell bodies located here which project forward to the basal forebrain. The basal forebrain consists of the nucleus accumbens (NAc), pre-frontal cortex (PFC) and amygdala which all play a role in reward stimuli (Robinson and Berridge 2000). Figure 1:1 shows how the serotonergic system innervates the limbic system with cell bodies located in the raphe nuclei $(\mathrm{RN})$ which project forward to the forebrain (Hensler 2006). 


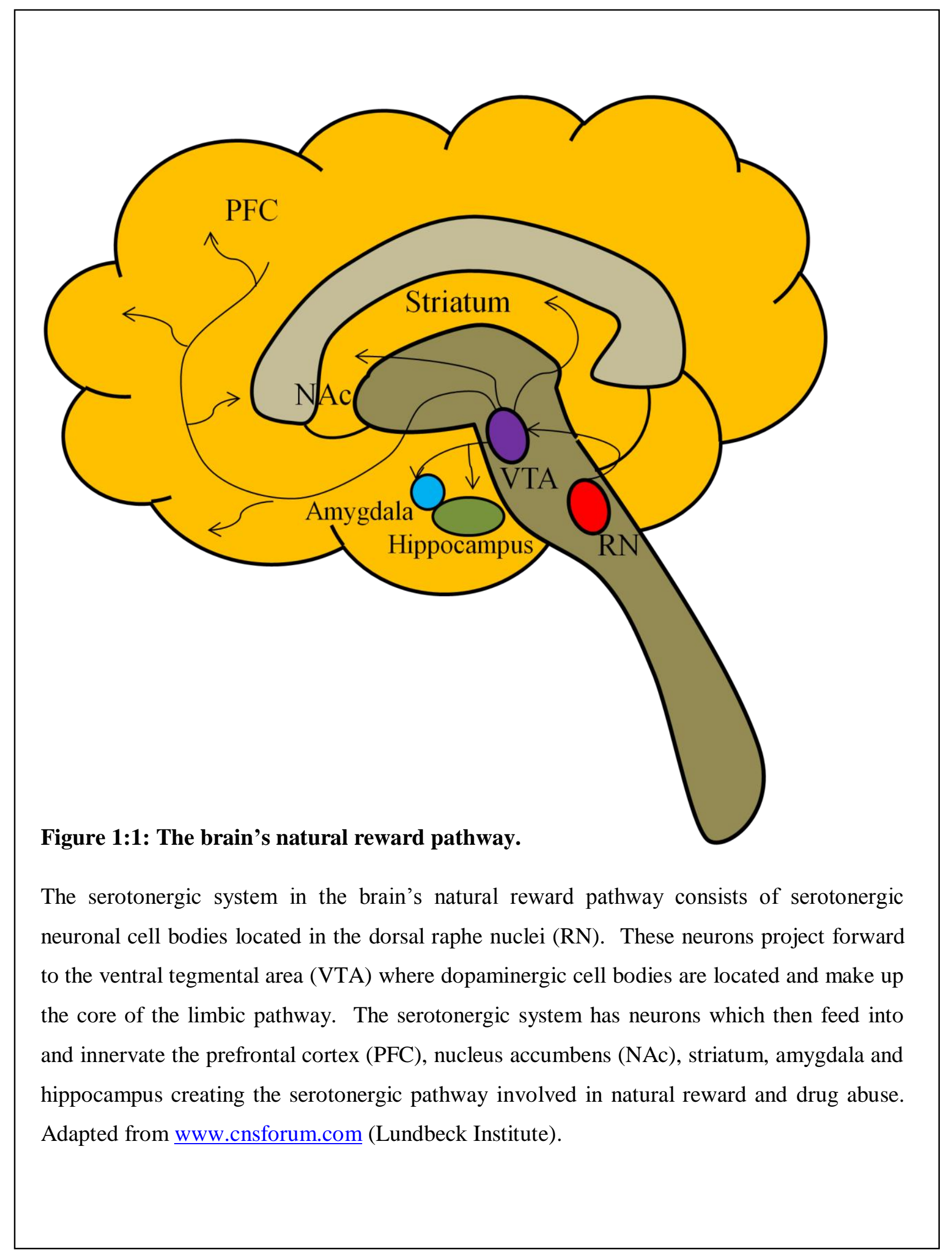




\subsection{Serotonin}

Serotonin (5-HT) is a monoamine neurotransmitter located in the brain and non-neuronal tissues such as the placenta, intestinal epithelial cells and platelets (Hoyer et al. 2002; Murphy et al. 2004; Jayanthi and Ramamoorthy 2005). In the brain, the serotonergic system (Figure 1:1) projects from the raphe nuclei in the brainstem, feeding into the ventral tegmental area with neurons extending to the pre-frontal cortex, basal ganglia, including the nucleus accumbens and striatum, as well as innervating the hippocampus and amygdala (Howell and Kimmel 2008). An individual's emotional response is partly regulated by the serotonergic tone which is determined by the levels of 5-HT in the brain. 5-HT plays an important role in the modulation of mood, sleep, appetite, anxiety and reward (Howell and Kimmel 2008; Murphy et al. 2008). Altered 5-HT signaling leads to an imbalance in 5-HT levels and is implicated in mood disorders such as depression and anxiety (Owens and Nemeroff 1994; Lesch et al. 1996), as well as other conditions such as obsessive compulsive disorder, alcoholism and substance abuse (Melo et al. 1996; Hoyer et al. 2002).

\subsection{Biochemistry of 5-HT}

5-HT synthesis is catalyzed by tryptophan hydroxylase (TPH), an enzyme which converts tryptophan to 5-hydroxytryptophan (5-HTP). 5-hydroxytryptophan is then converted to 5-HT by the enzyme hydroxytryptophan decarboxylase (HDC). As shown in Figure 1:2, 5-HT is stored in secretory vesicles within serotonergic neurons to prevent degradation by monoamine oxidases (MAO) located on mitochondria (Jorgensen 2007; Nichols and Nichols 2008). An action potential which depolarizes the nerve cell leads to an influx of calcium, causing vesicle release. 5-HT is released from the pre-synaptic nerve terminal into the synaptic cleft where it binds to 5-HT receptors located on the pre- and post-synaptic membranes. Binding to the receptors on the post-synaptic membrane causes the cell to depolarize, propagating the action potential down the neuron. Second messenger signaling systems are subsequently triggered and become activated in such a way that the signal is chemically propagated down the post-synaptic neuron (Hoffman et al. 1998; Nichols and Nichols 2008). 5-HT is cleared from the synaptic cleft either by diffusion or re-uptake by the serotonin transporter (SERT) located on the pre-synaptic membrane. These transporters effectively terminate further 5-HT signaling. Upon entry back into the pre-synaptic cell, 5HT is either recycled into synaptic vesicles for future re-release or targeted for degradation by monoamine oxidases (MAO). MAO A and B are the primary enzymes for degradation of 5- 
HT via deamination into its metabolite 5-hydroxyindoleacetic acid (5-HIAA) (Nichols and Nichols 2008). 


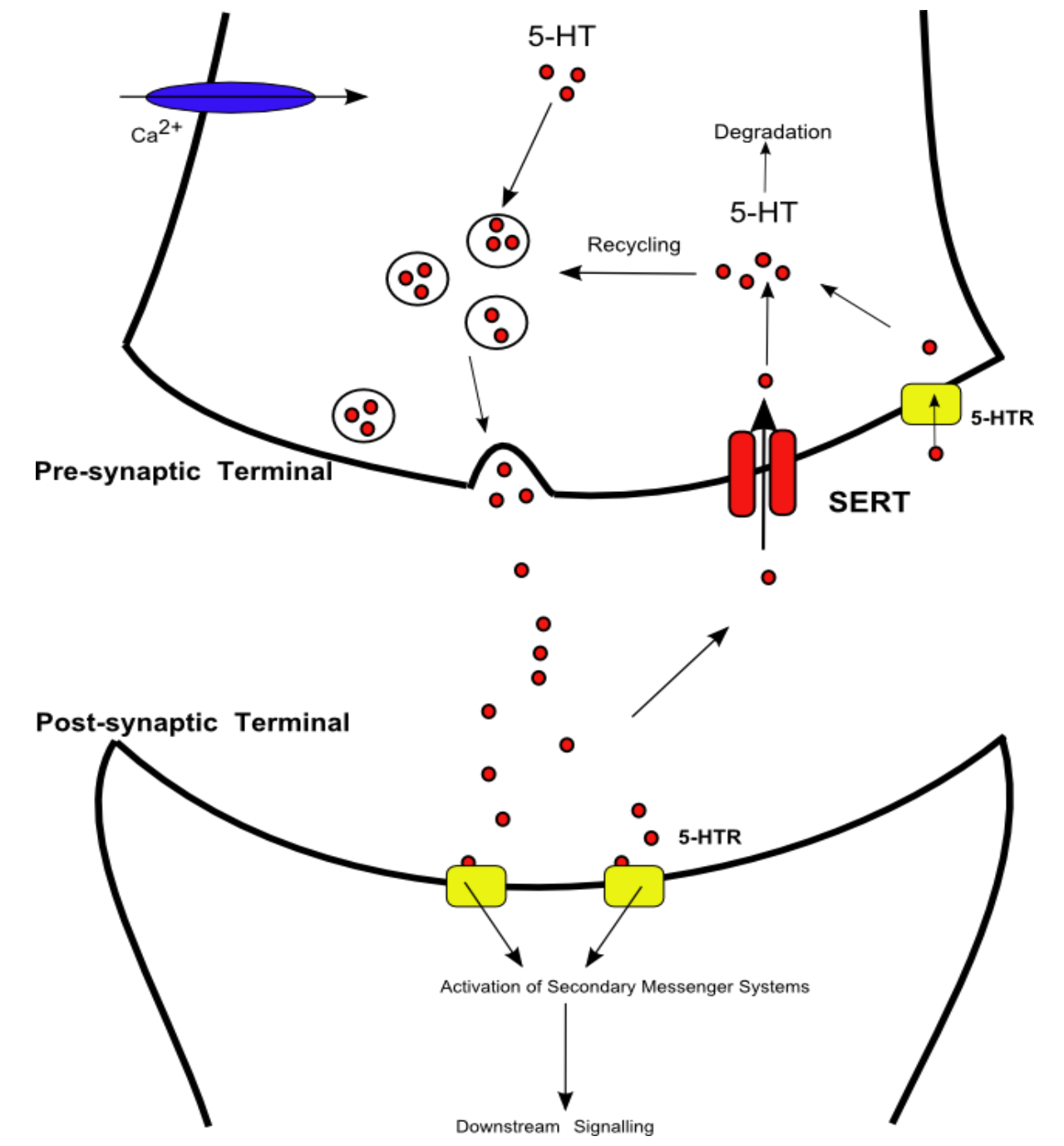

\section{Figure 1:2: Biochemical pathway of 5-HT}

5-HT is synthesized via a series of enzyme-mediated steps with the final product being stored in secretory vesicles in the pre-synaptic terminal. An action potential depolarizes the terminal leading to an influx of $\mathrm{Ca}^{2+}$, which causes the vesicles to be released into the synaptic cleft. 5-HT binds to receptors located on the pre- and post-synaptic terminals. 5-HT binding to the post-synaptic receptors causes the terminal to become depolarized therefore propagating the action potential. Activation of second messenger systems are triggered in the post-synaptic terminal. SERT is responsible for reuptake of 5-HT from the synaptic cleft, effectively terminating 5-HT function. Following uptake by SERT, 5-HT is recycled into vesicles or is targeted for degradation by monoamine oxidases. Key: 5-HT, 5hydroxytryptamine; SERT, serotonin transporter; 5-HTR, 5-HT receptor; $\mathrm{Ca}^{2+}$, calcium ions. Figure adapted from Nichols et al. (2008). 


\section{$1.5 \quad 5$-HT receptors}

\subsubsection{Overview of receptor subtypes}

Once in the synapse, 5-HT binds to and activates 5-HT receptors located on the post-synaptic membrane. 5-HT auto-receptors located on the pre-synaptic membrane can also respond to 5-HT and play a role in regulating synthesis and release within the pre-synaptic neuron (Nichols and Nichols 2008). There are seven different types of 5-HT receptors; six belong to the G-protein coupled receptor (GPCR) family, and one, $5-\mathrm{HT}_{3}$, is an ion channel (Nichols and Nichols 2008). There are 15 subtypes of 5-HT receptors which include 5-HT $\mathrm{HA}_{1 \mathrm{~A}}, 5-\mathrm{HT}_{1 \mathrm{~B}}$, $5-\mathrm{HT}_{1 \mathrm{D}}, 5-\mathrm{HT}_{1 \mathrm{E}}, 5-\mathrm{HT}_{1 \mathrm{~F}}, 5-\mathrm{HT}_{2 \mathrm{~A}}, 5-\mathrm{HT}_{2 \mathrm{~B}}, 5-\mathrm{HT}_{2 \mathrm{C}}, 5-\mathrm{HT}_{3 \mathrm{~A}}, 5-\mathrm{HT}_{3 \mathrm{~B}}, 5-\mathrm{HT}_{4}, 5-\mathrm{HT}_{5 \mathrm{~A}}, 5-\mathrm{HT}_{5 \mathrm{~B}}$, $5-\mathrm{HT}_{6}$ and $5-\mathrm{HT}_{7}$. G-protein coupled receptors are the largest family of signaling receptors and become activated by a vast array of extracellular ligands. They are able to relay the signal down through many second messenger signaling cascades in the cytoplasm (Marinissen and Gutkind 2001).

\subsubsection{G-protein activation}

5-HT receptors are coupled to different types of G-proteins, which when activated, dissociate from the GPCR and interact with effector molecules which further stimulate downstream biochemical signaling pathways. Activation of stimulatory G-proteins $\left(\mathrm{G}_{\mathrm{s}}\right)$ by binding of 5HT to specific receptor subtypes leads to activation of an enzyme called adenylate cyclase (AC) which converts adenosine triphosphate (ATP) to cyclic adenosine monophosphate (cAMP). cAMP is an intracellular second messenger which interacts with target effector molecules such as Protein Kinase A (PKA), an important signaling protein. Effector molecules of $\mathrm{G}_{\mathrm{s}}$-proteins are known to regulate calcium ion influx and membrane excitability, and PKA is able to phosphorylate specific target proteins leading to changes in gene expression (Nichols and Nichols 2008).

Activation of 5-HT receptors coupled to inhibitory G-proteins $\left(\mathrm{G}_{\mathrm{i}}\right)$ leads to an inhibition of AC. This results in a decreased cAMP production and subsequent decrease in PKA activity. Activation of these types of GPCR causes membrane hyper-polarisation which decreases the rate of neuronal firing (Nichols and Nichols 2008).

The other type of G-proteins act to cleave membrane phosphoinositides leading to formation of diacylglycerol (DAG) and inositol phosphates such as inositol triphosphate $\left(\mathrm{IP}_{3}\right)$. These molecules, along with cAMP, lead to downstream stimulation of Protein Kinase C (PKC) and 
p38 MAPKs which are important effector molecules. $\mathrm{IP}_{3}$ also stimulates an increase in intracellular $\mathrm{Ca}^{2+}$ levels adding to the second messenger effect (Nichols and Nichols 2008).

\subsubsection{5-HT receptor subtypes:}

The different 5-HT receptor subtypes and their important functions are outlined in Table 1:1. Homeostasis of 5-HT is maintained through an intricate balance between receptor activation of stimulatory and inhibitory G-proteins. Disruption of this system leads to changes in second messenger pathways which inadvertently affect the phosphorylation of effector molecules such as PKC, p38MAPK, PKA and PKG, among others. Dysregulation of this system is implicated in a host of mood disorders related to changes in the phosphorylation state of SERT (Murphy et al. 2008). 
Table 1:1: Overview of 5-HT receptor subtypes.

Literature review of 5-HT receptor characteristics from Nichols et al. (2008) and Jorgensen et al. (2007)

\begin{tabular}{|c|c|c|c|c|c|}
\hline $\begin{array}{l}\text { Receptor } \\
\text { class }\end{array}$ & $\begin{array}{l}\text { Receptor } \\
\text { subtype }\end{array}$ & Location & $\begin{array}{l}\text { G- } \\
\text { protein }\end{array}$ & $\begin{array}{l}\text { Effector } \\
\text { molecules }\end{array}$ & Function \\
\hline \multirow[t]{5}{*}{$5-\mathrm{HT}_{1}$} & $5-\mathrm{HT}_{1 \mathrm{~A}}$ & $\begin{array}{l}\text { Pre- and } \\
\text { post- } \\
\text { synaptic }\end{array}$ & $\mathrm{Gi}$ & $\begin{array}{l}\text { Decreases } \\
\text { cAMP, } \\
\text { decreases PKA }\end{array}$ & $\begin{array}{l}\text { Membrane hyper-polarisation, } \\
\text { inhibits neuronal firing, } \\
\text { facilitates psychostimulant } \\
\text { addiction }\end{array}$ \\
\hline & $5-\mathrm{HT}_{1 \mathrm{~B}}$ & $\begin{array}{l}\text { Pre- } \\
\text { synaptic }\end{array}$ & $\mathrm{Gi}$ & $\begin{array}{l}\text { Decreases } \\
\text { cAMP, } \\
\text { decreases PKA }\end{array}$ & Learning and memory \\
\hline & $5-\mathrm{HT}_{1 \mathrm{D}}$ & & $\mathrm{Gi}$ & $\begin{array}{l}\text { Decreases } \\
\text { cAMP, } \\
\text { decreases PKA }\end{array}$ & Target for anti-migraine therapy \\
\hline & $5-\mathrm{HT}_{1 \mathrm{E}}$ & & $\mathrm{Gi}$ & $\begin{array}{l}\text { Decreases } \\
\text { cAMP, } \\
\text { decreases PKA }\end{array}$ & Cognition and memory processes \\
\hline & $5-\mathrm{HT}_{1 \mathrm{~F}}$ & & Gi & $\begin{array}{l}\text { Decreases } \\
\text { cAMP, } \\
\text { decreases PKA }\end{array}$ & Target for anti-migraine therapy \\
\hline \multirow[t]{3}{*}{$5-\mathrm{HT}_{2}$} & $5-\mathrm{HT}_{2 \mathrm{~A}}$ & $\begin{array}{l}\text { Pre- and } \\
\text { post- } \\
\text { synaptic }\end{array}$ & $\mathrm{Gq}$ & $\begin{array}{l}\text { Increases } \mathrm{Ca} \\
\text { DAG, IP3 }\end{array}$ & $\begin{array}{l}\text { Membrane depolarization, } \\
\text { vasoconstriction, synaptic } \\
\text { plasticity }\end{array}$ \\
\hline & $5-\mathrm{HT}_{2 \mathrm{~B}}$ & & $\mathrm{Gq}$ & $\begin{array}{l}\text { Increases Ca, } \\
\text { DAG, IP3 }\end{array}$ & $\begin{array}{l}\text { Behavioral, auditory system, } \\
\text { heart and brain development }\end{array}$ \\
\hline & $5-\mathrm{HT}_{2 \mathrm{C}}$ & & $\mathrm{Gq}$ & $\begin{array}{l}\text { Increases Ca, } \\
\text { DAG, IP3 }\end{array}$ & $\begin{array}{l}\text { Appetite, target for treating } \\
\text { psychostimulant abuse, anxiety }\end{array}$ \\
\hline \multirow[t]{2}{*}{$5-\mathrm{HT}_{3}$} & $5-\mathrm{HT}_{3 \mathrm{~A}}$ & & & & Cation-selective ion channel \\
\hline & $5-\mathrm{HT}_{3 \mathrm{~B}}$ & & & & Cation-selective ion channel \\
\hline $5-\mathrm{HT}_{4}$ & & & Gs & $\begin{array}{l}\text { Increases } \\
\text { cAMP, } \\
\text { increases PKA }\end{array}$ & $\begin{array}{l}\text { Calcium ion influx, long-term } \\
\text { depression (LTD), learning and } \\
\text { memory }\end{array}$ \\
\hline $5-\mathrm{HT}_{5}$ & $5-\mathrm{HT}_{5 \mathrm{~A}}$ & & Gi & $\begin{array}{l}\text { Decreases } \\
\text { cAMP, } \\
\text { decreases PKA } \\
\text { Unknown }\end{array}$ & $\begin{array}{l}\text { Higher cortical and limbic } \\
\text { functions }\end{array}$ \\
\hline $5-\mathrm{HT}_{6}$ & & $\begin{array}{l}\text { Post- } \\
\text { synaptic }\end{array}$ & Gs & $\begin{array}{l}\text { Increases } \\
\text { cAMP, } \\
\text { increases PKA }\end{array}$ & $\begin{array}{l}\text { Higher cognitive processes, } \\
\text { target for Alzheimer's and } \\
\text { schizophrenia treatment }\end{array}$ \\
\hline $5-\mathrm{HT}_{7}$ & & & Gs & $\begin{array}{l}\text { Increases } \\
\text { cAMP, } \\
\text { increases PKA }\end{array}$ & $\begin{array}{l}\text { Sleep patterns, circadian rhythm } \\
\text { and regulation of overall mood }\end{array}$ \\
\hline
\end{tabular}




\subsection{The Serotonin Transporter:}

Along with the dopamine (DAT) and norepinephrine (NET) transporter, SERT belongs to the $\mathrm{Na}^{+} / \mathrm{Cl}^{-}$coupled transporter family (Nelson 1998). These transporters exploit the sodium gradient that already exists across the cell membrane to drive transport of neurotransmitters from the synaptic cleft back into the pre-synaptic compartment (Murphy et al. 2004; Sitte and Freissmuth 2010). The primary function of SERT is to re-accumulate released 5-HT from the synaptic cleft, therefore, effectively terminating signaling caused by $5-\mathrm{HT}$. The $\mathrm{Na}^{+} / \mathrm{Cl}^{-}$ gradient drives this secondary active-transport mechanism and it is the most rapid and economical way to remove and recycle 5-HT (Murphy et al. 2004; Sitte and Freissmuth 2010). As well as being expressed in serotonergic neurons in the central nervous system, SERT is distributed in the peripheral tissue. SERT is expressed in gastrointestinal cells, placental tissue, lungs and in red blood cells and platelets (Ramamoorthy et al. 2011).

\subsubsection{Structure of SERT:}

It is predicted that SERT consists of 12 hydrophobic transmembrane domains, with intracellular cytoplasmic $\mathrm{NH}_{2}$ and $\mathrm{COOH}$ termini, and a binding site located on the extracellular loop. Crystal structures of the bacterial homolog, $\mathrm{LeuT}_{\mathrm{Aa}}$, have allowed further insight into the conformation and transport process of the monoamine transporters. Although the overall homology is low with only $20-25 \%$ identical residues, the conservation around the binding site is high (50\% identical) (Yamashita et al. 2005; Sitte and Freissmuth 2010). It is thought that in SERT undergoes a conformational change following the simultaneous binding of $\mathrm{Na}^{+}, \mathrm{Cl}^{-}$and 5-HT. This allows 5-HT molecules to be transferred from the synapse into the cytosol. Once the three molecules are liberated from the binding site, $\mathrm{K}^{+}$takes their place, allowing the transporter to return back to their original conformation (Murphy et al. 2004). The maintenance of the ion gradient across the cell membrane by $\mathrm{Na}^{+}-\mathrm{K}^{+}$-ATPases is crucial for the SERT transport process. Quaternary structure evidence supports the formation of dimers or higher-ordered oligomers of the SERT molecules (Kilic and Rudnick 2000; Sitte et al. 2004). Some studies show evidence that the transport process is not affected when the transporter molecule is rendered monomeric (Scholze et al. 2002), whereas others argue that the oligomeric structure is necessary, especially for the action of amphetamines and related drugs on the monoamine transporters (Sitte and Freissmuth 2010). Oligomer formation has also shown to be necessary for correct exiting from the endoplasmic reticulum and travelling the secretory pathway to the plasma membrane (Sitte and Freissmuth 2010). 


\subsubsection{Genetic Variance of the SERT gene}

Coded by the SLC6A4 gene, the human SERT gene is comprised of fourteen exons encoding a protein of 630 amino acids (Murphy et al. 2004). There is a polymorphic region upstream of the transcription start site which is termed the 5-HTT gene-linked polymorphic region (5HTTLPR). There are two variants of this polymorphism that differentially modulate transcriptional activity of the SERT promoter termed the 'short' or 'S' allele or 'long' or 'L' allele. These are composed of either fourteen or sixteen repeated elements respectively. Identification of variants in the SERT coding region have been implicated in the anxiety and mood disorders (Murphy et al. 2004). This illustrates the significance of impaired regulation and the implication that is has in human disease conditions. The $\mathrm{S}$ allele is associated with decreased expression of SERT at the cell surface and decreased 5-HT uptake. The relationship between the low expressing $\mathrm{S}$ variant of the 5-HTTLPR and correlation to drug abuse and mental disorders is poorly understood (Ramamoorthy et al. 1993).

\subsubsection{SERT and Mood Disorders}

Dysfunction of the SERT protein is implicated in many mood disorders such as depression and anxiety, as well as being associated with substance abuse (Murphy et al. 2004; Ramamoorthy et al. 2011). Selective serotonin reuptake inhibitors (SSRI), such as fluoxetine $\left(\right.$ Prozac $\left.^{\mathrm{TM}}\right)$, citalopram $\left(\right.$ Celexa $\left.^{\mathrm{TM}}\right)$, paroxetine $\left(\right.$ Paxil $\left.^{\mathrm{TM}}\right)$ and sertraline $\left(\right.$ Zoloft $\left.^{\mathrm{TM}}\right)$, act as SERT antagonists. By binding to SERT they effectively prevent 5-HT re-uptake and cause an increase in 5-HT in the synapse. SSRI's are therefore the most commonly prescribed drug to treat depression. Response to SSRI's varies between individuals with no certain explanation as to why some patients respond better than others. An association between the SERT 5HTTLPR polymorphism and therapeutic response to SSRI's has been postulated. A study showed that possessing the ' $\mathrm{L}$ ' allele was predictive of a better antidepressant efficacy in patients with symptoms of mood and anxiety disorders (Murphy et al. 2004). Further pharmacogenetic studies are needed before a clinical use for 5HTTLPR genotyping is considered relevant.

Drugs of abuse similarly act as SERT substrates. 3 4-methylenedioxymethamphetamine (MDMA) or 'Ecstasy', is able to bind to SERT where it is then transported inside the cytoplasm and able to exert complex cellular effects (see Section 1.8 MDMA). Long-term use of drugs of abuse can lead to symptoms resembling those of the mood disorders mentioned above. 


\subsection{Regulation of SERT:}

Monoamine transporter cell surface expression and function is regulated through a series of post-translational modifications, including changes in the state of glycosylation and/or phosphorylation (Jayanthi and Ramamoorthy 2005). The importance in understanding the cellular mechanisms responsible for the regulatory processes of SERT is highlighted by the fact that this transporter is a key controller of 5-HT signaling and is involved in disease states as well as being a target for therapeutic drugs and psychostimulants (Ramamoorthy et al. 2011). Consensus sites for the binding of protein kinases and putative interactive motifs have been identified in the SERT protein, illustrating the role in which second-messenger systems play in post-translational regulation of SERT (Jayanthi and Ramamoorthy 2005).

One key molecular mechanism which will be focused on in this study is how the expression and functional properties of SERT are affected by transporter phosphorylation and how drugs of abuse interfere with this process (see Section 1.8 MDMA). Several kinase cascades are implicated in the regulation of SERT (Ramamoorthy et al. 2011). They help to maintain a relationship between transporter phosphorylation state, the level of 5-HT transport and SERT cell surface expression. It is suggested that increases in SERT phosphorylation at the membrane provides a signal for internalization of the protein, a change in the catalytic state of SERT, or both. It is not clear whether phosphorylation of the intracellular pool of SERT slows down recycling of the protein to the membrane or if the trafficking events of SERT are redirected to alter surface expression (Kivell et al. 2010). Substrate and antagonist binding act to influence transporter phosphorylation, trafficking and interaction with transporterassociating proteins, which all act to alter transport activity (Jayanthi and Ramamoorthy 2005; Ramamoorthy et al. 2011). Some of the key kinase proteins that are known to be involved in SERT regulation are outlined below, Figure 1:3 shows a schematic diagram of the interaction between the various kinase proteins:

\subsubsection{PKC}

PKC has been shown to contribute to diverse biochemical processes within the 5-HT nerve terminal. These mechanisms include the acceleration of neurite extension during development, the enhancement of vesicular neurotransmitter release, and the modulation of 5-HT transporter activity (Qian et al. 1997; Kramer et al. 1998). Activation of the 5-HT $2,4,6,7$ receptors causes cleavage of the membrane-bound phosphatidylinositol biphosphate ( $\left.\mathrm{PIP}_{2}\right)$ protein into $\mathrm{IP}_{3}$ and DAG which act as effector molecules. $\mathrm{IP}_{3}$ raises the levels of intracellular $\mathrm{Ca}^{2+}$ which then binds to PKC in the cytoplasm, causing the kinase to translocate 
to the plasma membrane. The presence of DAG in the inner portion of the lipid bilayer stabilizes the interaction of PKC at the membrane and supports its catalytic state so that it can phosphorylate its target i.e. SERT (Kramer et al. 1998).

PKC activation is correlated with an increased level of SERT phosphorylation which causes a reduction in both SERT function and cell surface expression (Qian et al. 1997; Jayanthi and Ramamoorthy 2005; Jayanthi et al. 2005; Samuvel et al. 2005). Efforts into the study of the time-dependent molecular events associated with PKC activation have shown that regulation of SERT occurs in a biphasic manner. The initial phase occurs upon phosphorylation of a serine residue where a change in transporter function occurs causing a decrease in 5-HT uptake. This decrease in SERTs catalytic activity occurs independently of trafficking and occurs in a rapid manner (within $<5 \mathrm{~min}$ ). The second phase occurs when there is subsequent phosphorylation on a threonine residue which causes a loss of SERT from the cell surface via internalization. This phase occurs between the 5 and 60 min time period (Jayanthi et al. 2005).

\subsubsection{MAPK's}

The mitogen-activated protein kinase (MAPK) pathway includes several serine-threonine protein kinases which are composed of three hierarchical proteins; MAPKK kinase (MAPKKK), which then phosphorylates a MAPK kinase (MAPKK), which in turn phosphorylates and activates a MAPK. This signaling cascade is activated through ligand binding to the receptor at the plasma membrane where the signal is then transmitted downstream until a MAPK is activated. Types of MAPK that have been characterized in detail include extracellular signal-regulated kinases (ERKs), c-Jun N-terminal kinases (JNKs) and p38 MAPKs. These further regulate transcription factor activity or kinases downstream by phosphorylation, therefore altering gene regulation and other cellular processes (Ichijo 1999).

p38 MAPK is a particular protein of interest as its downstream targets include the SERT protein. It plays a role in a range of cellular functions including growth and differentiation as well as apoptosis. It is activated by inflammatory cytokines and cellular stresses such as ultra-violet (UV) light. The signal is relayed by the cell surface receptor to a divergent array of MAPKKK which activate two MAPKK proteins; MAPKK3 and MAPKK6. When the signal reaches p38 MAPK it activates it and in response, downstream targets are phosphorylated (Ichijo 1999). SERT activity is increased in response to p38 MAPK 
activation, with an increase in 5-HT transport, but no change in SERT trafficking observed (Samuvel et al. 2005). Inhibition of p38 MAPK leads to a decrease in 5-HT uptake but no change in SERT cell surface expression (Zhu et al. 2005). These results suggest that p38 MAPK plays a role in maintaining SERT basal phosphorylation, expression and function (Samuvel et al. 2005). Cellular stress affect SERT and subsequently 5-HT signaling and p38 MAPK is induced by stress. It is plausible that p38 MAPK-mediated SERT regulation may provide a novel pre-synaptic mechanism whereby 5-HT synaptic levels are maintained during stressful conditions (Ramamoorthy et al. 2011). The MAPK pathway can be activated from upstream PKC, but can also be activated independent of PKC through PKA (Marinissen and Gutkind 2001).

There is evidence supporting both trafficking-dependent and independent mechanisms of p38 MAPK-mediated SERT regulation (Ramamoorthy et al. 2011). Taking into consideration that activation of PKC increases SERT phosphorylation and rate of internalization, and inhibition of p38 MAPK decreases SERT basal phosphorylation and membrane insertion, these two kinases must work on different phosphorylation sites. These two kinases may directly phosphorylate SERT, but at different cellular locations (Ramamoorthy et al. 2011).

\subsubsection{PKA}

PKA is bound in its inactive state until interaction with cAMP. This allows the regulatory units to dissociate, leaving the catalytic kinase domain able to bind and phosphorylate its targets. Previous studies have shown that PKA activation in human embryonic kidney cells (HEK-293 cells) expressing human SERT (hSERT) causes an increase in SERT basal phosphorylation levels (Ramamoorthy et al. 1998). However there was no change in 5-HT transport so the authors concluded that PKA does not have a functional effect on the SERT protein.

\subsubsection{PKG}

Previous studies have shown that activation of PKG stimulates 5-HT uptake (Zhu et al. 2004; Ramamoorthy et al. 2007). Whether there is SERT surface re-distribution following PKG activation is unclear. A review of the literature reports that under certain experimental conditions and depending on what cell type is used, PKG-mediated SERT regulation and trafficking can occur through alternative pathways (Ramamoorthy et al. 2011). It is possible that PKG and p38 MAPK may work together to regulate the function and expression levels of SERT at the cell surface. An increase in 5-HT uptake and SERT cell surface expression is observed with PKG or p38 MAPK following stimulation of the adenosine receptor $\left(\mathrm{AR}_{3}\right)$ at 
the cell surface in CHO-1 and RBL-2H3 cells (Zhu et al. 2004; Ramamoorthy et al. 2011). Inhibition of $\mathrm{p} 38$ MAPK prevented the increase in SERT function after $\mathrm{AR}_{3}$ activation, but not the increase in SERT surface expression. This suggests that $\mathrm{AR}_{3}$ stimulates an increase in SERT surface expression in a PKG-dependent manner, and increases SERT function in a p38 MAPK-dependent mechanism (Zhu et al. 2004). Mutation of a threonine residue in SERT expressed in CHO-1 cells abolished PKG-mediated activation of the transporter. This study provided the first identification of a phosphorylation site on SERT and linked it to the activation of PKG and subsequent increase in 5-HT uptake (Ramamoorthy et al. 2007). 


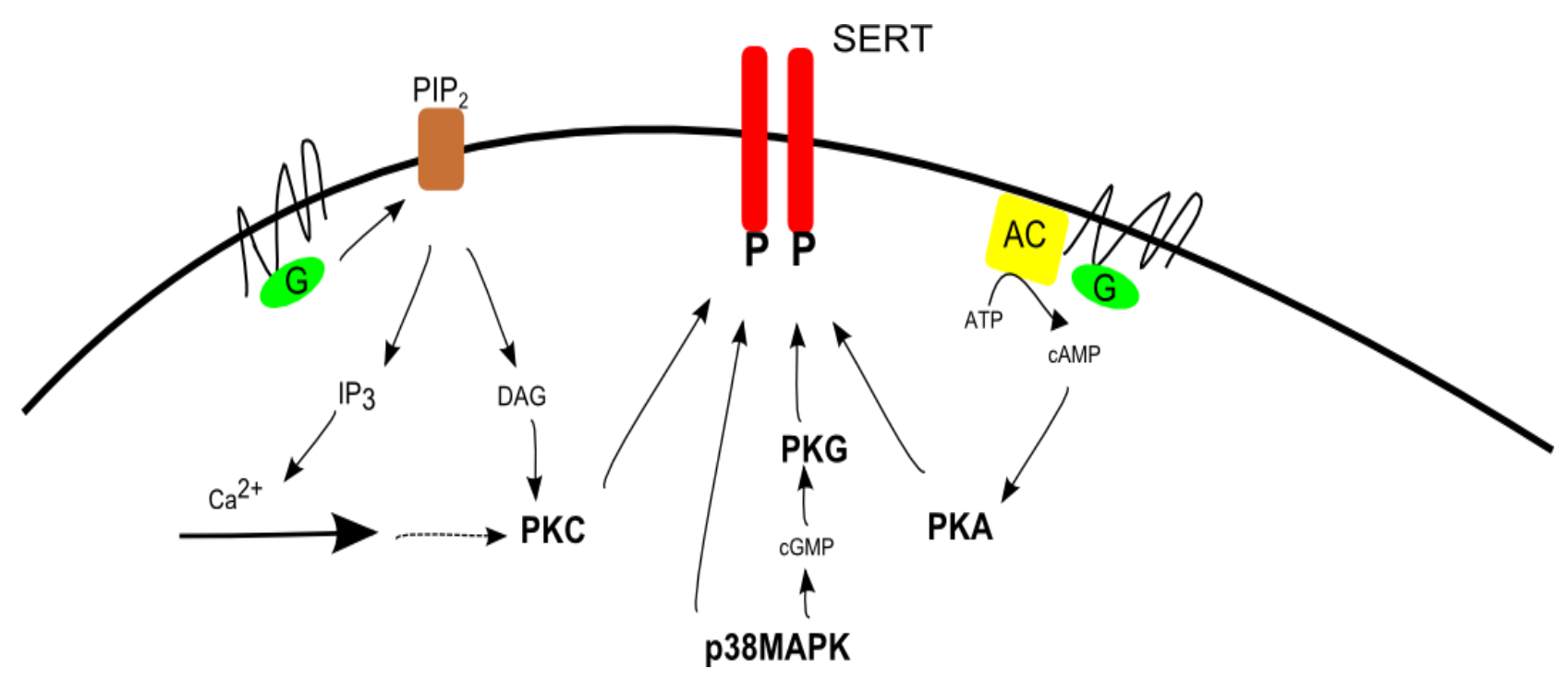

Figure 1:3: Overview of SERT regulation by the major protein kinases.

Simplified illustration of the most common protein kinases known to regulate SERT cell surface expression and function. Activation of GPCR by 5-HT binding causes changes in cAMP levels inside the cell. This triggers activation of PKA which is known to regulate SERT. Stimulation of GPCR's also causes cleavage of $\mathrm{PIP}_{2}$ to Dag and $\mathrm{IP}_{3}$, increasing intracellular calcium levels. DAG and calcium trigger PKC activation which is well-known regulator of SERT. Activation of PKC and PKA can activate p38 MAPK which is known to regulate SERT expression and function. In addition, PKG can be activated by increases in cGMP which is influenced by p38 MAPK and PKA. 


\subsubsection{Protein Phosphatase 1/2A (PP1/PP2A)}

It appears that inactivation of protein phosphatases reduces transporter activity and downregulates surface expression (Vaughan 2004). In particular, inhibition of protein phosphatase 1/2A (PP1/PP2A) by okadaic acid leads to a down-regulation of SERT activity. SERT phosphorylation levels are increased which lead to a subsequent decrease in 5-HT uptake. It is suggested that there is a physical association of the PP1/PP2A complex with SERT which is regulated by the activity of downstream kinases. Okadiac acid and PKC activators have been shown to disrupt the SERT/PP2A complex, and 5-HT acts as a stabilizing agent (Bauman et al. 2000; Vaughan 2004; Jayanthi and Ramamoorthy 2005).

\subsubsection{N-glycosylation}

SERT has been shown to contain two N-glycosylation sites which are implicated in maintaining proper protein folding allowing the transporter to be trafficked to and from the plasma membrane efficiently (Blakely et al. 1994; Tate and Blakely 1994). Glycosylation does not appear to be essential in regulating transporter function as non-glycosylated mutant form of SERT was able to bind and transport 5-HT (Tate and Blakely 1994). Addition of an oligosaccharide (sugar residue) to the transporter begins in the endoplasmic reticulum (ER) and is completed in the Golgi apparatus, where the protein can then be directed to the plasma membrane for insertion (Sorkina et al. 2003). SERT is differentially N-glycosylated in the brain and in platelets, yet it still proves to be an essential process for maintaining efficient protein trafficking and proper protein folding (Blakely et al. 1994).

\subsubsection{Lipid Raft Regulation}

There is evidence to suggest that SERT and the other monoamine transporters, such as DAT and NET, are associated with lipid rafts which aid in regulation of these transporters. Raftassociated sorting has been linked to several cellular processes including signal transduction, protein sorting and membrane trafficking (Chamberlain and Gould 2002). One study showed that SERT is involved in raft-mediated internalization in PKC-mediated regulation (Samuvel et al. 2005). Interestingly this was not shown for p38 MAPK-mediated regulation. With SERT present in lipid rafts, it could be possible that signaling mechanisms specific for lipid rafts are affiliated with PKC-mediated down-regulation of SERT (Jayanthi and Ramamoorthy 2005). 


\subsection{MDMA}

3,4-methylenedioxymethamphetamine (MDMA) is a ring-substituted derivative of amphetamines which comprise a subclass of psychostimulants. It is a stimulant and induces hallucinogenic effects on users with feelings of euphoria and heightened perception being described (Green et al. 2003; Baumann et al. 2007; Capela et al. 2009; Steinkellner et al. 2011). More commonly known as 'Ecstasy', it is a drug of abuse popular among young people, being used recreationally since the 1980's especially in the 'rave' scene (Green et al. 2003). Short-term effects of MDMA include mild depression, hyperthermia, cardiac arrhythmia, hypertension, and memory loss (Baumann et al. 2007; Yamauchi et al. 2007). Prolonged or chronic use of MDMA is associated with long-term deficits in 5-HT levels and loss of 5-HT nerve cell integrity (Wang et al. 2007).

Amphetamines have a high affinity for the monoamine transporters. In particular MDMA exhibits the highest affinity for the SERT protein, with affinities for the dopamine (DAT) and norepinephrine (NET) transporter being tenfold less (Green et al. 2003). MDMA functions as a substrate-type releaser; it binds to SERT, competing for uptake with 5-HT into the nerve terminal (Green et al. 2003; Yamauchi et al. 2007; Howell and Kimmel 2008). Once inside the cell, it reverses SERT transport and inhibits uptake of 5-HT from the synaptic cleft, thereby causing an initial increase in the extracellular pool of 5-HT (Bengel et al. 1998; Green et al. 2003; Sitte and Freissmuth 2010; Steinkellner et al. 2011). MDMA interferes with vesicular storage of 5-HT by competing for uptake by the vesicular monoamine transporter (VMAT). Under physiological conditions, VMAT regulates the concentration of intracellular neurotransmitter by retrieving 5-HT from the cytosol into the synaptic vesicles. Interference with this regulation leads to more 5-HT being available for non-exocytotic release by SERT (Rudnick and Clark 1993; Sitte and Freissmuth 2010). Monoamine oxidase (MAO) rapidly degrades 5-HT that escapes the action of VMAT. Inhibition of MAO by MDMA also contributes to 5-HT being available for SERT-mediated transport into the synapse (Sitte and Freissmuth 2010). In addition MDMA has been shown to inhibit the ratelimiting enzyme involved in 5-HT synthesis, tryptophan hydroxylase (Schmidt and Taylor 1987). The cumulative effects of MDMA are that there is significant rapid efflux of 5-HT into the synaptic cleft leading to long-term depletions of 5-HT in the serotonergic system.

Previous work from our laboratory has shown that MDMA is able to rapidly internalize SERT from the cell surface of transfected cell cultures to the intracellular vesicles (Kivell et al. 2010). Additionally no change in SERT mRNA levels was observed in this study which 
suggests that MDMA targets only SERT function and distribution rather than total SERT protein expression (Kivell et al. 2010).

\subsection{Neurotoxicity and Antibody Debate}

It is well-documented that MDMA abuse causes long-term depletion of 5-HT, but there is still much discrepancy in the literature about whether the changes in the biochemical markers are indicative of neuronal damage or neuronal cell death in humans. Whether or not MDMA is a neurotoxic chemical with the ability to cause nerve cell degeneration, or whether MDMA leads to neuroadaptation remains debated throughout the literature. Early investigators labeled MDMA as neurotoxic primarily due to its ability to deplete 5-HT (Battaglia et al. 1987; Commins et al. 1987; Xie et al. 2006). This finding lead to speculation over whether 5HT deficiency leads to cell death or whether there is a state of neuroadaptation of 5-HT metabolism related to SERT trafficking displayed by neurons. The extent of neurotoxic effects is often measured through endpoints thought to be selective for the 5-HT nerve terminal. Tissue 5-HT concentration and SERT levels are commonly used to determine the integrity of 5-HT nerve terminals (Wang et al. 2007).

Subsequent Western blotting experiments were carried out to investigate whether the decrease in 5-HT levels following MDMA were due to a loss in SERT protein. Most of these studies report no change in SERT protein levels using anti-SERT antibodies following neurotoxic doses of MDMA, even when 5-HT depletion was seen (Rothman et al. 2003; Wang et al. 2005; Wang et al. 2007). However some studies argue that SERT protein density and function is decreased after MDMA administration (Battaglia et al. 1987; Xie et al. 2006; McLane et al. 2011). This discrepancy in the literature has arisen from the fact that there is a large inconsistency and uncertainty over the reported molecular size for SERT, with diverse patterns being reported for SERT expression (Xie et al. 2006; Wang et al. 2007; Kivell et al. 2010). Previous studies from our laboratory report that there is no change in the $50 \mathrm{kDa}$ SERT immunoreative band following MDMA treatment in the rat brain (Kivell et al. 2010). In a separate study from another laboratory, an alternative diffuse band was seen at 63-68 $\mathrm{kDa}$ and identified as SERT. This group has reported that there is a MDMA-induced downregulation of this SERT immunoreactive band in rats (Xie et al. 2006; McLane et al. 2011). There are a large number of SERT-specific antibodies available; however the specificity of these antibodies has been brought into question following these reports. There has been further investigation into whether MDMA is able to alter SERT binding and function without affecting SERT protein expression. A study carried out by Wang et al. (2005) reported that 
there was no change in SERT distribution between the plasma membrane and cytoplasmic fraction. However due to the questionable specificity of the SERT antibody, these results must be viewed with caution.

Studies from our laboratory used a cellular model where a fluorescent tag was used to identify SERT in an attempt to overcome the antibody confusion. We report that SERT is down-regulated from the surface of transfected HEK-293 cells with a corresponding increase in the cytoplasmic fraction. We report no change in mRNA or total SERT protein expression which is suggestive that SERT function is affected due to the internalization of the transporter after MDMA exposure (Kivell et al. 2010). These findings from our lab are supported by previous studies which show high dosing of MDMA results in a depletion of brain 5-HT and reduce SERT binding but does not alter expression of SERT (Wang et al. 2005; Wang et al. 2007). Similarly a previous study reported a loss in SERT surface signal intensity following MDMA treatment which is in support of our published findings (Kittler et al. 2010; Kivell et al. 2010).

In regards to the neurotoxic status of MDMA, research employing more sensitive and detailed techniques has been used in an attempt to determine the degree of neurotoxicity of MDMA. Various staining techniques and identification of common neurotoxic markers to investigate 5-HT deficiency and whether it leads to cell death have been reported on, and reviewed in recent literature (Green et al. 2003; Baumann et al. 2007; Steinkellner et al. 2011).

Silver staining is a sensitive indicator of damage caused by neurotoxic chemicals and is used to identify neuronal degeneration. It has been used to show that MDMA administration causes degeneration in nerve terminals, axons and cell bodies throughout the rat brain (Commins et al. 1987). However it must be noted that the pattern of degeneration observed by the stain did not correlate with the distribution of serotonergic neurons, indicating that only non-specific neuronal damage occurred rather than specific serotonergic cell death (reviewed by Baumann et al. 2007). The high-dosing regime used for MDMA administration (>25 mg/kg) is excessive and therefore unlikely to be physiologically relevant to humans.

Similarly, non-specific neuronal degeneration after MDMA administration was observed using another novel histological stain, Fluoro-Jade B. This is an anionic fluorescin derivative that selectively stains for degenerating terminals, axons and cell bodies. Rats that were administered MDMA doses over $20 \mathrm{mg} / \mathrm{kg}$ had detectable neural degeneration, however cells 
identified as damaged were not specifically serotonergic, and did not overlap the pattern of 5HT deficits (Schmued and Xu 2003; Baumann et al. 2007). Another factor noted in the study carried out by Schmued et al. (2003) was that neuronal degeneration was only observed in rats that displayed hyperthermia (temperatures $>41^{\circ} \mathrm{C}$ ). In rats that did not experience hyperthermia, no degeneration was seen; as detected by Fluoro-Jade B. This is suggestive of a link between elevated body temperatures and adverse effects of MDMA (Schmued and Xu 2003; Baumann et al. 2007). MDMA neurotoxicity is predominantly investigated in rats that are exposed to MDMA doses of $10 \mathrm{mg} / \mathrm{kg}$ or higher, whether as single or repeated injections. The debate of the neurotoxic potential of MDMA partially remains due to the disagreement over the interspecies scaling equation. Extrapolating data from animal models to humans about the relevance of MDMA doses is a point of controversy due to the validity and limitations of the equation. 5-HT depletions seen in rats occurs after MDMA doses of 10-20 $\mathrm{mg} / \mathrm{kg}$, whereas human recreational doses are between $1-3 \mathrm{mg} / \mathrm{kg}$, with users taking an average of two ecstasy tablets at one time (Baumann et al. 2007; Steinkellner et al. 2011). With rats, at the this high level of dosing it has been observed that significant hyperthermia occurs which can exacerbate 5-HT depletions, causing incorrect, or over-exaggerated conclusions about MDMA neurotoxicity (Baumann et al. 2007). MDMA-induced neurotoxicity and the link to the hyperthermic response still needs to be further investigated to establish the relationship they have on the serotonergic system. Other variables that affect MDMA response range from dose, species, ambient and body temperatures, as well as route of administration (Bai et al. 2001; Wang et al. 2005).

Glial fibrillary acidic protein (GFAP) is a glial-specific structural protein and its expression levels are used as a neurotoxic CNS marker. When neurons are damaged or killed, glial cells replicate to take over the space left behind. An increase in GFAP expression is indicative of the neurotoxicity state of the CNS. A study carried out by O'Callaghan et al. (1993) observed that when rats were administered $10-30 \mathrm{mg} / \mathrm{kg}$ MDMA, they were unable to induce an increase in GFAP expression, even though a depletion in 5-HT was seen throughout the brain. A separate group of rats from the same study were administered a higher MDMA dose at $75-150 \mathrm{mg} / \mathrm{kg}$, observed an increase in GFAP expression in various brain regions, but which did not, however, correlate with the degree of 5-HT depletion (O'Callaghan and Miller 1993). 5,7-dihydroxytryptamine (5,7-DHT), a 5-HT neurotoxin, was used to compare GFAP expression levels. At doses which caused comparable 5-HT depletions as MDMA, only 5,7DHT was able to induce GFAP expression (O'Callaghan and Miller 1993; Baumann et al. 
2007). Recent studies also show that MDMA failed to have an effect on measures of reactive gliosis as indicated by the lack of change in immunoreactive GFAP (Bai et al. 2001; Pubill et al. 2003; Baumann et al. 2007). However, in contrast to these studies, there has been findings published which report that MDMA is able to enhance histochemical staining for GFAP (Aguirre et al. 1999). The explanation for the discrepancies between the literatures is not clear; differences in experimental protocols may have a significant effect on the outcome of the findings for each study. Aguirre et al. (1999) administered a dosing regimen of a single injection of $20 \mathrm{mg} / \mathrm{kg}$ of MDMA, whereas Pubill et al. (2003) used multiple injections of 20 $\mathrm{mg} / \mathrm{kg}$ over a course of four days. Variation between the different rat strains, as well as the different brain regions examined could all impact on the observed neurotoxic effects of MDMA.

The majority of data in the literature that states MDMA causes a significant depletion in 5HT levels (whether it from a single or repeated doses), cannot reliably induce silver positive staining or markers of reactive gliosis. Wang et al. (2007) demonstrate that high-dose MDMA treatment which was able to reduce SERT binding by $90 \%$ left a significant number of functionally intact 5-HT nerve terminals. Interestingly they showed that MDMA-induced 5-HT depletion in rats could have 5-HT levels restored by the administration of the 5-HT precursor L-5-hydroxytryptophan (Wang et al. 2007). This suggests that MDMA effects were not neurotoxic, but demonstrated neuroadaptation to the drug. The extent of MDMAinduced decreases in SERT binding appears to be dependent on in vitro assay conditions. Until a consensus can be reached about the extent that MDMA induces neurotoxicity, it must be kept in mind that MDMA-induced 5-HT depletions may be due to persistent adaptive changes in protein expression and/or function.

\subsection{MDMA-induced regulation of SERT}

The mechanism by which MDMA is able to modulate SERT function and redistribution is unclear. PKC is an important regulator of SERT, and a plausible hypothesis is that PKC activation in the pre-synaptic terminal occurs in response to MDMA binding to SERT. MDMA binding to SERT is known to cause an increased influx of intracellular calcium (Kramer et al. 1997). An extended period of elevated intracellular calcium levels is necessary for the translocation and association of PKC to the neuronal membrane. It is an important cofactor for the binding of PKC to biological membranes under basal conditions (Kramer et al. 1998). Previous studies carried out in rat synaptosomes have shown that MDMA is unable to induce PKC translocation when synaptosomes are incubated in $\mathrm{Ca}^{2+}$-free 
conditions. This is surprising when taking into the account the $\mathrm{Ca}^{2+}$-independent mechanism of MDMA-induced 5-HT release. The exact mechanism of calcium entry into the cell by MDMA is not known (Kramer et al. 1998). In the same study it was also demonstrated that animals pre-treated with fluoxetine before MDMA treatment were unable to stimulate PKC translocation. Fluoxetine may inhibit PKC activation by competing with MDMA for SERT binding (Kramer et al. 1998). Prolonged activation of PKC has been implicated in several calcium-dependent neurodegenerative processes, and so its role in MDMA-induced neurotoxicity is of interest. It is suggested that long periods of PKC activation can lead to changes in the homeostatic function of 5-HT neurons, which could modulate local mechanisms in the nerve terminal increasing the cells susceptibility to damage by MDMA (Kramer et al. 1998). Whether amphetamines such as MDMA have an effect on SERT through a PKC-dependent mechanism is unknown, however studies conducted on the dopamine transporter (DAT) have shown that amphetamines can increase striatal PKC activity in rat synaptosomes (Giambalvo 1992; Giambalvo 1992). The mechanism behind the increases in PKC activity due to amphetamine treatment is still unclear. It was shown that the presence of intracellular calcium is essential for the amphetamine-mediated stimulation of PKC activity in the dopaminergic system. Rat synaptosomes treated with a calcium chelator showed that a depletion of intracellular calcium resulted in the attenuation of dopamine release induced by amphetamine treatment (Giambalvo 2003). In the serotonergic and dopamernergic systems the mechanism for the requirement of intracellular calcium is as yet unknown. Calcium plays an important role in the functioning of modulators such as calmodulin and calmodulin-dependent protein kinase II, which could indirectly alter PKC activity.

\subsection{Summary}

SERT down-regulation is controlled through a multitude of signaling networks present in the cell. These networks are made up of pathways which interlink and regulate one another, some of which are constitutively in place, while others are activated upon extracellular signals. For example, three major kinases, PKC, PKA and p38 MAPK are activated via separate pathways, yet act to regulate one another. This makes them responsible for SERT's phosphorylation state which dictates the rate of SERT insertion into the membrane, SERT function and SERT trafficking inside the cell. The specific residues responsible for regulation of SERT by molecules such as kinases are not completely understood. It appears that basal phosphorylation occurs at separate sites to those responsible for rapid regulation of 
SERT. How MDMA interacts and affects the signaling networks responsible for SERT regulation is unclear. One possible hypothesis that is explored in this study is whether MDMA is able to target PKC, thereby activating it and causing down-regulation of SERT.

\subsection{Significance}

Despite more than two decades of research, the mechanisms by which MDMA is able to exert its effect on the serotonergic system remains to be fully elucidated. Being able to determine the biochemical pathways that are affected by MDMA in the neuronal cell will help to fill a gap in knowledge about how MDMA regulates SERT. Further information will help identify if the effects of MDMA are reversible or preventable. When working in animal or cell models, limitations arise in SERT protein research due to the lack of accurate and specific antibodies to the SERT protein. This study attempts to use a cell model expressing human SERT (hSERT) tagged with green fluorescent protein (GFP) to overcome this limitation and confidently investigate MDMA-induced effects. Research into this field will help bridge the gap in the information that is currently available on the cellular effects of MDMA.

\subsection{Aims and Objectives:}

The overall aim of this study was to investigate whether MDMA exerted its regulatory effect on SERT function and cell surface expression through a PKC-dependent pathway. The specific objectives of this study were:

1) Evaluate two commercially available antibodies targeting SERT to validate antibody specificity,

2) Determine the effects of MDMA on cell-surface SERT expression and function,

3) Identify the cellular signaling mechanism of how MDMA regulates SERT by investigating the effects of PKC, a known regulator of SERT function. 


\section{Chapter 2: Materials and Methods}

\subsection{Tissue Culture}

Cell lines used in this study were grown and maintained under PC2 conditions in the School of Biological Sciences, Victoria University of Wellington. All cell work was carried out in a class II biological safety cabinet (AES Environment Pty LTD, Auburn, Australia) with HEPE air filters. Before use, sterilization with Ultraviolet (UV) light $\left(1390 \mathrm{~mW} / \mathrm{m}^{2}\right)$ for $15 \mathrm{~min}$ was carried out and all surfaces were wiped down with $70 \%$ ethanol. Cells stocks were grown in a Heracell incubator (Kendro Laboratory Products, GmbH, Germany) in a humid environment kept at $37^{\circ} \mathrm{C}$ and supplemented with $5 \% \mathrm{CO}_{2}$. Sterile plastic-ware used to carry out experiments was purchased from BD Biosciences and Greiner Bio One. Two different cell lines were used in this study: human embryonic kidney cells (HEK-293) and mouse neuroblastoma cells $\left(\mathrm{N}_{2} \mathrm{~A}\right)$. Both cell lines were purchased from American Type Culture Collection (ATCC, Manassas, VA, USA) and were used between passage number seven and one hundred.

\subsubsection{Cell Lines}

\subsubsection{Human embryonic kidney cells (HEK-293)}

Transformed with adenovirus 5, HEK-293 cells are an immortalized cell line derived from human embryonic kidney cells. They were maintained in Dulbeccos modified Eagle medium (DMEM) (Gibco, Invitrogen, Auckland, NZ) containing 10\% fetal calf serum (FCS, ICP biologicals, Auckland, NZ)), 1\% Penstrep antibiotic (Penicillin G sodium 5000 units/mL. Streptomycin sulphate 5000 units $/ \mathrm{mL}$ in $0.85 \%$ saline, Gibco, Invitrogen) and $200 \mu \mathrm{M} \mathrm{L-}$ glutamine (Gibco, Invitrogen). DMEM media containing no penstrep antibiotic (containing $200 \mu \mathrm{M}$ L-glutamine and 10\% FCS) was used for cell transfection experiments. For confocal microscopy and biotinylation experiments, $1 \mathrm{~mL}$ of cells were plated at a density of $1 \times 10^{6} / \mathrm{mL}$ in $35 \mathrm{~mm}$ dishes. Western blotting and rotating disc voltammetry experiments required $2 \mathrm{~mL}$ of cells to be plated out at a density of $1 \times 10^{6} / \mathrm{mL}$ in $60 \mathrm{~mm}$ dishes. In addition rotating disc electrode voltammetry used $7 \mathrm{~mL}$ of cells plated out at density of $1 \times 10^{6} / \mathrm{mL}$ in $100 \mathrm{~mm}$ dishes.

\subsubsection{Mouse neuroblastoma cells $\left(\mathrm{N}_{2} \mathrm{~A}\right)$}

Originating from Mus musculus, $\mathrm{N}_{2} \mathrm{~A}$ cells are adherent mouse brain neuroblastoma cells. They were maintained and cultured in Roswell Park Memorial Institute (RPMI) 1640 medium containing 10\% FCS and 1\% Penstrep antibiotic. RPMI medium containing no Penstrep (supplemented only with 10\% FCS) was used for cell transfection experiments. 
Cells were plated out at a density described for HEK-293 cells for Western blotting, biotinylation, confocal microscopy and rotating disc electrode voltammetry experiments.

\subsubsection{Cell growth and passaging}

Cryovials of cell stocks were stored in a liquid nitrogen dewar and thawed in a $37^{\circ} \mathrm{C}$ water bath for use in experiments. Defrosted cells were transferred to $75 \mathrm{~mL}$ flasks fitted with MIT filter screw caps (Greiner bio-one, Raylab, Auckland, NZ) containing $7 \mathrm{~mL}$ of culture medium and 1\% Penstrep. 24 hours later, the culture medium was removed and replaced with fresh growth medium.

Cells were passaged into $250 \mathrm{~mL}$ flasks when $80 \%$ confluency was reached. Cells were washed with sterile phosphate buffered saline (PBS, $137 \mathrm{mM} \mathrm{NaCl}, 2.7 \mathrm{mM} \mathrm{KCl}, 8.1 \mathrm{mM}$ $\mathrm{Na}_{2} \mathrm{HPO}_{4}, 1.5 \mathrm{mM} \mathrm{KH} \mathrm{PO}_{4}, \mathrm{pH}$ 7.4) before a 5 min incubation with $1 \mathrm{~mL}$ of TrpLE Express (Gibco, Invitrogen). Gentle mechanical agitation of the flask helped to detach cells which were then centrifuged at $300 \mathrm{~g}$ for $5 \mathrm{~min}$. The concentration of the pelleted cells was determined using a haemocytometer to count an aliquot of cells diluted in $0.4 \%$ tryphan blue (Sigma). The cells were then diluted 1:4 and reseeded in two separate $250 \mathrm{~mL}$ flasks; one to carry on the cell line, the other to be used to freeze down and replace stocks removed from the liquid nitrogen. $1 \mathrm{~mL}$ aliquots of $\log$ phase cells were frozen in liquid nitrogen at a concentration of $1 \times 10^{6}$ cells $/ \mathrm{mL}$ in their appropriate culture medium containing $10 \%$ dimethyl sulfoxide (DMSO).

\subsubsection{Cell transfection}

On day 1 cells were plated into dishes at a density respective of the experiment planned. On day 2, cells were transfected with the GFP-hSERT plasmid when growth reached 60-70\% confluency. Lipofectamine 2000 reagent (Invitrogen) and Optimum I medium (Invitrogen) were used to create the transfection mixture. For HEK-293 cells, $3 \mu \mathrm{L}$ of Lipofectamine 2000 was made up to $50 \mu \mathrm{L}$ of Optimem I per $1 \times 10^{6}$ cells, and incubated for $5 \mathrm{~min}$ at room temperature. In a separate tube, GFP-hSERT plasmid DNA (kindly donated by S. Ramamoorthy) was made up to $50 \mu \mathrm{L}$ with Optimem I per $1 \times 10^{6}$ cells to a final concentration of $0.5 \mu \mathrm{g} / \mathrm{mL}$. After an initial $5 \mathrm{~min}$ incubation, the two separate mixtures were added together and incubated for a further $20 \mathrm{~min}$. Dishes containing the cells to be transfected had old culture medium replaced with fresh penstrep-free medium and $100 \mu \mathrm{L}$ per $1 \times 10^{6}$ cells of the transfection mixture was added. Cells were used 48 hours after transfections. For $\mathrm{N}_{2} \mathrm{~A}$ cells, $4 \mu \mathrm{L}$ of Lipofectamine 2000 and $1 \mu \mathrm{g} / \mathrm{mL}$ of GFP-hSERT per $1 \times 10^{6}$ cells were used. 


\subsection{Plasmid Preparation}

\subsubsection{Luria Broth (LB) kanamycin agar plates}

LB-broth (10 g/L NaCl, $5 \mathrm{~g} / \mathrm{L}$ Yeast extract, $10 \mathrm{~g} / \mathrm{L}$ Bactotryptone) (Appendix) and LB-Agar (10 g/L NaCl, $5 \mathrm{~g} / \mathrm{L}$ Yeast extract, $10 \mathrm{~g} / \mathrm{L}$ Yeast agar, $10 \mathrm{~g} / \mathrm{L}$ Bactotryptone) (Appendix) were autoclaved at $121^{\circ} \mathrm{C}$ at $20 \mathrm{lb} / \mathrm{in}^{2}$ for $20 \mathrm{~min}$ to sterilize. Once cooled, a final concentration of $50 \mu \mathrm{g} / \mathrm{mL}$ of kanamycin antibiotic was added. Agar plates were poured, left to set and stored at $4^{\circ} \mathrm{C}$ until needed.

\subsubsection{Transformation of MAX Efficiency® DH5a ${ }^{\mathrm{TM}}$ Competent Cells} $100 \mu \mathrm{L}$ aliquots of MAX Efficiency ${ }^{\circledR}$ DH5 $\alpha^{\mathrm{TM}}$ Competent Cells (Invitrogen) were thawed on ice and divided into $50 \mu \mathrm{L}$ aliquots in microcentrigfuge tubes. One aliquot served as a negative control, while the other had $20 \mathrm{ng}$ of GFP-hSERT plasmid DNA added to it. Cells were incubated on ice for 1 hour, and then heat shocked at $42^{\circ} \mathrm{C}$ for 2 min in a heat block (Global Science). The tubes were then transferred to ice for a further $5 \mathrm{~min}$. $450 \mu \mathrm{L}$ of SOC medium (Invitrogen) was added to each tube and left to shake at $225 \mathrm{rpm}$ for 1 hour in a $37^{\circ} \mathrm{C}$ shaker (Bioline, Edwards Instrument Company, Australia). A 'lawn' culture was then created by spreading $100 \mu \mathrm{L}$ of each mixture on LB-agar plates containing antibiotic and left to incubate overnight at $37^{\circ} \mathrm{C}$ in a humid incubator.

\subsubsection{Cultivation of Escherichia coli (E.coli)}

From the previously described 'lawn' culture, single colonies of transformed DH5 $\alpha$ cells were streaked out onto new LB-agar plates containing antibiotic and incubated overnight at $37^{\circ} \mathrm{C}$. The negative control described previously was used as a reference to ensure that this procedure was only carried out if no growth was generated with the non-transformed bacteria. Growth would indicate a contamination of the bacterial stock, and a new transformation would have to be carried out. The following day, a single colony was picked from the plate using a sterile pipette tip and resuspended in $2 \mathrm{~mL}$ of LB-broth containing antibiotic to create an overnight culture. $12-18$ hours at $37^{\circ} \mathrm{C}$ with shaking at $225 \mathrm{rpm}, 200 \mu \mathrm{L}$ of the overnight culture was added to $200 \mathrm{~mL}$ of LB-broth containing antibiotic. This culture was incubated overnight in the same conditions, and the following day a plasmid purification was carried out (see Section 2.2.4).

\subsubsection{Plasmid purification using the Qiagen hiSpeed Maxi Kit}

GFP-hSERT plasmid DNA was extracted from the $200 \mathrm{~mL}$ bacterial culture following the manufacturer's protocol for the Qiagen hiSpeed Maxi kit (Biolab, Auckland, NZ). 
Briefly, the $200 \mathrm{~mL}$ culture was centrifuged at $6000 \mathrm{~g}$ for $25 \mathrm{~min}$ at $4^{\circ} \mathrm{C}$ in a Sorvall Evolution RC centrifuge (Kendro Laboratory Products, Bath, UK) and the supernatant removed. The bacterial pellet was resuspended in $10 \mathrm{~mL}$ of resuspension buffer containing RNase A (Buffer P1). Following this, $10 \mathrm{~mL}$ of Lysis buffer (Buffer P2) was added and mixed by inverting solution 4-6 times. After a 5 min incubation at room temperature, $10 \mathrm{~mL}$ of chilled neutralization buffer (Buffer P3) was added to halt the lysis reaction. The lysate was transferred to a QIAfilter Cartridge and incubated for $10 \mathrm{~min}$ at room temperature. A HiSpeed Maxi Tip was equilibrated by placing it over a waste container allowing $10 \mathrm{~mL}$ of Buffer QBT to flow through the filter. The lysate was filtered through the QIAfilter Cartridge into the HiSpeed Maxi Tip so the DNA binds to the filter resin. The tip containing the DNA was then washed with $60 \mathrm{~mL}$ of a wash buffer (Buffer QC), and the DNA eluted into a sterile $50 \mathrm{~mL}$ Falcon tube using Buffer QF. The resulting DNA was precipitated using $10.5 \mathrm{~mL}$ of molecular grade isopropanol (Sigma) for $5 \mathrm{~min}$. A $30 \mathrm{~mL}$ syringe attached to a QIAprecipitator Maxi Module was used to filter the isopropanol mixture, allowing the precipitator to capture the DNA strands. $2 \mathrm{~mL}$ of $70 \%$ ethanol (Ajax Chemicals, Auckland, NZ) was used to wash the DNA strands. Air was rapidly pushed through the syringe twice in order to air dry the filter to prevent any ethanol carry-over in the final DNA plasmid solution. A $5 \mathrm{~mL}$ syringe was then attached to the precipitator containing the DNA and placed over a sterile microcentrifuge tube. $500 \mu \mathrm{L}$ of endotoxin free buffer (Buffer TE) was added and allowed to run through the filter, eluting the DNA to be collected in the tube. The eluted DNA was transferred back to the syringe the process was repeated a second time to ensure all DNA from the precipitator was collected.

The concentration and purity of the plasmid DNA was determined using a Nanodrop ND1000 spectrophotometer (Biolab, Auckland, NZ). Ultrapure MilliQ water (Barnstead Easypure II, MA, USA) was used to initialize and blank the machine. $1 \mu \mathrm{L}$ of plasmid DNA sample was then placed on the sensor and a recording was measured using the package software (ND-100 v3.1.0). DNA yields over $250 \mathrm{ng} / \mu \mathrm{L}$ were deemed acceptable for use in transfection experiments. The purity measurement obtained from the absorbance $A_{260} / A_{280}$ ratio was between 1.6 - 2.0 for transfection experiments.

Transformed bacterial cultures $(2 \mathrm{~mL})$ were frozen at $-80{ }^{\circ} \mathrm{C}$ in $500 \mu \mathrm{L}$ aliquots in $20 \%$ glycerol for transformed bacterial stocks. Keeping stocks of adequate transformed bacteria meant that future plasmid purifications were able to be carried out without transforming 
further DH5 $\alpha$ cells. Instead scrapings could be made from the transformed bacterial stocks and streaked onto LB-agar plates containing antibiotic to create single colonies.

\subsection{Western Blotting}

\subsubsection{Protein lysate preparation}

For the antibody specificity experiments Western blotting techniques were carried out. Firstly the two different cell lines, HEK-293 and $\mathrm{N}_{2} \mathrm{~A}$, were plated and transfected as described previously (Section 2.1.1). HEK-293 cells were transfected over a range of 0.2-1 $\mu \mathrm{g}$ of GFP-hSERT plasmid DNA. Similarly $\mathrm{N}_{2}$ A cells were transfected over a range of $1 \mu \mathrm{g}$

- $4 \mu \mathrm{g}$ plasmid DNA. Non-transfected cells were run alongside each experiment for comparison in the Western blots. Protein was extracted from the cells by removal of the culture medium and replacing with $400 \mu \mathrm{L}$ of TrpLE Express to detach cells from the dishes. After gentle tapping, the liquid was transferred to a $1.5 \mathrm{~mL}$ sterile microcentrifuge tube and centrifuged at $300 \mathrm{~g}$ for $5 \mathrm{~min}$ at room temperature (Eppendorf 5415R, Global Science, NZ). The pellet was resuspended in Radioimmuno-precipitation assay (RIPA) buffer (10 mM TrisHCL, $150 \mathrm{mM} \mathrm{NaCl}, 1 \mathrm{mM}$ EDTA, $1 \%$ Triton-X-100, 0.1\% SDS, 1\% sodium deoxycholate, $\mathrm{pH} 7.5$ (Appendix)) containing $10 \mu \mathrm{L} / \mathrm{mL}$ of protease inhibitor to lyse the cells, with final volumes 180, 300 and $400 \mu \mathrm{L}$ being used. Cells were left to lyse in a rotating Labquake machine at $4^{\circ} \mathrm{C}$ for 1 hour. The DNA pellet was sucked out using a sterile pipette and discarded. The remaining whole protein lysate concentration was then quantified using a BCA protein assay (Pierce IL) as per the manufacturer's protocol. Briefly BCA protein standards were diluted to give a concentration range of $0.025-1.0 \mathrm{mg} / \mathrm{mL}$, so that a standard curve of the absorbances could be generated to determine the protein concentration of the lysate samples. Using the linear portion of the standard curve, the protein concentration of the whole cell lysates was able to be determined. The samples were then diluted so that a range of protein concentrations ranging from 2.5-75 $\mu \mathrm{g}$ could be loaded onto a SDSpolyacrylamide gel.

\subsubsection{SDS polyacrylamide gel electrophoresis and transfer of protein to PVDF Membrane}

Protein lysates were diluted using RIPA buffer to desired concentration, $50 \mu \mathrm{L}$ aliquots were mixed with $15 \mu \mathrm{L}$ of $5 \mathrm{x}$ reducing buffer (62.5 mM Tris-HCl, $\mathrm{pH}$ 6.8, 2\% SDS, $20 \%$ glycerol, $1 \%$ bromophenol blue (Appendix)) containing 10\% $\beta$-mercaptoethanol (Sigma). $20 \mu \mathrm{L}$ of each protein sample was loaded onto 10- or 15-well SDS-PAGE gels consisting of a $10 \%$ separating gel and 4\% stacking gel (Appendix). $1 \mu \mathrm{L}$ of Precision Plus Protein Standard 
Dual Colour Molecular Weight Marker (Biorad, CA, USA) was loaded onto each gel to serve as a ladder for determining band sizes. The protein lysates were separated out on the SDSPAGE gels by electrophoresis for $90 \mathrm{~min}$ at $120 \mathrm{~V}$ in $1 \mathrm{x}$ running buffer (3.5 mM SDS, 25 $\mathrm{mM}$ Tris base, $190 \mathrm{mM}$ glycine. Prior to Western blotting gels were scanned on a Fuji film laser scanner (Fujifilm FLA-5100, Tokoyo, Japan) using a $473 \mathrm{~nm}$ laser and BPB1 filter set at $800 \mathrm{~V}$, allowing visualization of GFP-hSERT which also serves as a loading control.

Following scanning, the gels were used for a Western Blot transfer. The proteins in the gel were transferred to a polyvinylidine difluoride (PVDF) $(0.2 \mu \mathrm{M}$ pore size, Millipore Corporation, MA) membrane. The membrane was hydrated by pre-soaking in methanol for 5 min, then in western transfer buffer before being placed in the Western blotting cassette. The transfer cassette was arranged so that the black side of the cassette faced the back, followed by the sponge, $3 \mathrm{MM}$ filter paper, SDS-gel, membrane, followed by another piece of $3 \mathrm{MM}$ filter paper, and sponge. The cassette was then inserted into the Bio-Rad Tetracell transfer set (Biorad) containing an ice-pack, and immersed in Western Transfer buffer (25 mM Tris, $0.2 \mathrm{M}$ glycine, $20 \%$ methanol, $1 \%$ SDS. The transfer was run at $4^{\circ} \mathrm{C}$ for 17 hours at $20 \mathrm{~V}$.

\subsubsection{Probing for the protein of interest: GFP-hSERT}

Following disassembly of the transfer cassette; the membranes were rinsed in Tris buffered saline (TBS, $50 \mathrm{mM}$ Tris base, $150 \mathrm{mM} \mathrm{NaCl}, \mathrm{pH} 7.5$ and blocked for one hour in the appropriate blocking solution (described in Table 2.1) at room temperature with gentle rocking. Following the blocking reaction, membranes were incubated with the primary antibody diluted in appropriate blocking buffer (described in Table 2.1) overnight at $4^{\circ} \mathrm{C}$ with constant shaking. The two primary antibodies investigated were either directed at the $\mathrm{N}$ terminal or the $\mathrm{C}$ terminal of the SERT protein. Antibody 1 is from Santa Cruz and is raised against the $\mathrm{C}$ terminal and Antibody 2 from Sigma Aldrich and targets the $\mathrm{N}$ terminal (aa 120). After incubation with the primary antibody, membranes were rinsed with $3 \mathrm{~mL}$ of TBS containing $0.1 \%$ Tween 20 (T-TBS) 3 times. They were then further incubated with $3 \mathrm{~mL}$ of T-TBS for $5 \mathrm{~min}$ intervals 3 times. The corresponding secondary antibody (described in Table 2.1) was diluted in T-TBS and added to membranes and incubated for 1 hour in the dark at room temperature with constant shaking. Detection of the $\mathrm{Cy}_{5}$ tagged secondary antibody was visualized using the Fuji laser scanner using a $635 \mathrm{~nm}$ laser at $400 \mathrm{~V}$ with the DBR1 filter. ImageJ software was used to investigate the pictures of the scanned membrane. 
Table 2:1: List of Antibodies used in Western blotting experiments

\begin{tabular}{|c|c|c|c|c|c|c|}
\hline & $\begin{array}{l}\text { Protein of } \\
\text { Interest }\end{array}$ & $\begin{array}{l}\text { Blocking } \\
\text { Agent }\end{array}$ & Primary Ab & Dilution & Secondary Ab & Dilution \\
\hline Antibody 1 & hSERT & $\begin{array}{l}5 \% \text { donkey } \\
\text { serum in } \\
\text { TTBS }\end{array}$ & $\begin{array}{l}\text { Goat polyclonal to } \mathrm{C} \\
\text { terminal } \\
\text { (Santa Cruz) }\end{array}$ & $\begin{array}{l}1: 500 \\
1: 1000\end{array}$ & $\begin{array}{l}\text { Dylite anti- } \\
\text { mouse } \mathrm{Cy}_{5}\end{array}$ & $1: 2500$ \\
\hline Antibody 2 & hSERT & $\begin{array}{l}5 \% \text { milk } \\
\text { powder in } \\
\text { TTBS }\end{array}$ & $\begin{array}{l}\text { Rabbit polyclonal to } \\
\text { N terminal (aa1-20) } \\
\text { (Sigma Aldrich) }\end{array}$ & $1: 1000$ & $\begin{array}{l}\text { Goat anti- } \\
\text { rabbit } \mathrm{Cy}_{5} \\
\text { (GE } \\
\text { Healthcare) }\end{array}$ & 1:3000 \\
\hline
\end{tabular}

\subsection{Cell surface biotinylation}

HEK-293 and $\mathrm{N}_{2} \mathrm{~A}$ cells were plated and transfected as described previously in section 2.1.1 and biotinylation experiments were carried out 48 hours after transfection. Methods used have been previously described (Bolan et al. 2007; Zapata et al. 2007).

$\beta$-PMA, MDMA, and ionomycin were dissolved in 1 x PBS $(1.4 \mathrm{M} \mathrm{NaCl}, 26.8 \mathrm{mM} \mathrm{KCl}$, $81.0 \mathrm{mM} \mathrm{Na}_{2} \mathrm{HPO}_{4}, 14.7 \mathrm{mM} \mathrm{KH}_{2} \mathrm{PO}_{4}, \mathrm{pH} 7.4$ ) so that final concentrations of $1 \mu \mathrm{M} \beta$-PMA, $10 \mu \mathrm{g} / \mu \mathrm{L}$ MDMA and $5 \mu \mathrm{M}$ ionomycin were added to $1 \mathrm{~mL}$ culture dishes. The inhibitor compound Bisindolylmaleimide I (Bis I) was dissolved in DMSO so that a final concentration of $200 \mathrm{nM}$ was added to the $1 \mathrm{~mL}$ cell culture dishes. The compounds were added for the required amount of time for maximal effect to occur to investigate the effects they have on SERT expression. Cells were then washed twice with ice-cold PBS/Ca-Mg (PBS containing $0.1 \mathrm{mM} \mathrm{CaCl}_{2}$ and $1 \mathrm{mM} \mathrm{MgCl}_{2}, \mathrm{pH}$ 8.0) and incubated with EZ link NHSSulfo-SS-biotin (Pierce) in PBS/Ca-Mg at a concentration of $1 \mathrm{mg} / \mathrm{ml}$ for $30 \mathrm{~min}$ at a temperature of $4^{\circ} \mathrm{C}$ in the dark with gentle shaking. Cells were washed $2 \mathrm{x}$ times and quenched by addition of $100 \mathrm{mM}$ glycine in PBS/Ca-Mg. This was carried out in the dark at temperature of $4^{\circ} \mathrm{C}$ for $20 \mathrm{~min}$ with gentle shaking. Lysing of the cells was achieved by addition of $400 \mu \mathrm{L}$ of RIPA buffer containing $10 \mu \mathrm{L} / \mathrm{mL}$ of protease inhibitor (Sigma) and incubated for 1 hour at $4^{\circ} \mathrm{C}$ with constant shaking. Lysate samples were then transferred to sterile microcentrifuge tubes and centrifuged at $16,000 \mathrm{~g}$ in a bench top centrifuge (Eppendorf, Eppendorf South Pacific, Australia) for $30 \mathrm{~min}$ at $4^{\circ} \mathrm{C}$. The resulting DNA pellet was discarded and a $50 \mu \mathrm{L}$ sample of the supernatant was collected and stored on ice as 
representative of the total protein fraction. $400 \mu \mathrm{L}$ of the supernatant was then incubated with $100 \mu \mathrm{L}$ of streptavidin beads (Pierce) in filter columns. These were incubated with gentle mixing in a rotating Labquake machine for 1 hour in the dark. Plugs were removed from the columns and centrifuged at $500 \mathrm{~g}$ for $1 \mathrm{~min}$ at $4^{\circ} \mathrm{C}$, and the liquid spun down into the collecting tube. $50 \mu \mathrm{L}$ samples representing the intracellular fraction were stored on ice in the dark until needed. The beads were then washed by passing $400 \mu \mathrm{L}$ of RIPA buffer through the columns $3 \mathrm{x}$ times, with centrifugation at $16,000 \mathrm{~g}$ for $1 \mathrm{~min}$ at $4{ }^{\circ} \mathrm{C}$ being carried out after each wash. Elution of the bound proteins from the beads was carried out by incubation with $40 \mu \mathrm{L}$ of $5 \mathrm{x}$ reducing buffer (Appendix 1: Solutions) containing 10\% $\beta$-mercaptoethanol for $30 \mathrm{~min}$ at room temperature in the rotating Labquake machine. A final centrifugation spin was carried out at $500 \mathrm{~g}$ for $1 \mathrm{~min}$ at $4^{\circ} \mathrm{C}$ to collect the sample which contains the cell surface fraction. To the total and intracellular fractions, $15 \mu \mathrm{L}$ of $5 \mathrm{x}$ reducing buffer containing $10 \%$ $\beta$-mercaptoethanol was added. The fractions were then analyzed by loading $20 \mu \mathrm{L}$ of each sample onto a 10\% SDS-PAGE gels and electrophoresis was carried out for 90 minutes at $120 \mathrm{~V}$. Gels were transferred onto Western blotting membranes as described in section 2.3.2. Using Western blotting techniques, HEK-293 and $\mathrm{N}_{2} \mathrm{~A}$ cells were probed for GAPDH (1:1000, Abcam) and actin (1:1000, Abcam) respectively for $1 \mathrm{hr}$ at room temperature. GAPDH and actin are two common housekeeping proteins which are expressed only in the intracellular fraction in the respective cell lines. GAPDH and actin therefore serve as internal references to ensure the cells were not lysed before the addition of biotin, validating the specific localization of SERT.

SERT expression was measured by the densitometry of the band size identified as GFPhSERT prior to Western transfer using a laser gel scanner at $473 \mathrm{~nm}$. Using Image-J software, the integrated density of each band was determined following subtraction of background readings. The background corrected cell surface and intracellular readings were then normalized to the total fractions for each corresponding treatment. For each treatment, the normalized cell surface and intracellular data were also normalized to the matching vehicle-treated samples in each gel. This allowed for between-gel comparisons to be made. Graphpad prism 4 software (GraphPad Software Inc, La Jolla, CA, USA) was used to graph the values and one-way ANOVA, followed by Bonferroni post tests, was conducted to test for significance between treatments. GAPDH and actin immunoblots were identified through detection of the $\mathrm{Cy}_{5}$ tagged secondary antibody using the Fuji laser scanner as described in Section 2.3.3. 


\subsection{Total Internal Reflection Fluorescence Microscopy (TIRFM)}

TIRFM experiments followed the protocol described in Furman et al. (Furman et al. 2009). HEK-293 and $\mathrm{N}_{2} \mathrm{~A}$ cells were plated and transfected as described previously for confocal microscopy in $35 \mathrm{~mm}$ glass-bottomed petri dishes coated with $0.5 \mathrm{mg} / \mathrm{mL}$ poly-d lysine. All experiments were performed 48 hours following transfection. TIRFM monitoring and imaging was carried out using an Olympus Flv 1000 confocal laser scanning microscope equipped with a QImaging Digital Camera 6.2.0.6 (QImaging ROLERA-MGI Fast1394; Surrey, BC, Canada). All experiments were performed at $37^{\circ} \mathrm{C}$. The microscope stage incubator (INU-21LCS-F1 model, Tokai Hit Co., Ltd, Japan) was equilibrated with a flow of carbogen $\left(95 \% \mathrm{O}_{2}, 5 \% \mathrm{CO}_{2}\right)$ to maintain the optimal $\mathrm{pH}$. A $300 \mu \mathrm{L}$ syringe was used to dispense the compound that was being tested directly into the dish containing the transfected cells though the inlet port of the chamber. Cells were left to equilibrate in the chamber for a minimum of 20 minutes before experimentation started. Using the $100 \mathrm{x}$ objective lens (Olympus, PLAPO 100x, OTIFM, NA 1.45) a region of mono-layer cells were chosen and focused on using FITC epi-florescence, the TIRFM camera and Image Pro Plus 7.0 acquisition software (MediaCybernetics, Bethesdus, MD, USA). TIRFM settings were used so that the microscope scanned a penetration depth of $100 \mathrm{~nm}$, a FS of $11 \mathrm{~nm}$ and a refractive index of the sample was 1.45. The microscope was set so that the focal plane focused on the part of the cell membrane that was adhered to the glass bottom of the dish. Cells were chosen so that a range of GFP-expression levels could be imaged, but could still clearly be seen at laser power settings ranging from $0.5-1.2 \%$ (473 nm laser, GFP filter). The camera (QImaging Digital Camera 6.2.0.6) was set to an acquisition area of $512 \times 512$ pixels with a capture depth of 14 bit mono (16 bit image class) and an exposure preview of $00.902 .508 \mathrm{~s}$ with a capture exposure time of $3 \mathrm{~s}$ using Image Pro Plus Sotfware.

For the longer time course experiments (40 min), the first image captured was time 0 , and subsequent images were captured every minute for the duration of the time course. The first 10 frames $(10 \mathrm{~min})$ were used as a baseline. Following this either MDMA (final concentration $10 \mu \mathrm{g} / \mathrm{mL}$ ) or $\beta$-PMA (final concentration $1 \mu \mathrm{M}$ ) was delivered into the dish using a syringe. To ensure no photo-bleaching of the cells occurred, the laser was blocked from the sample between scans. Controls were carried out to test for photo-bleaching and conditions set to ensure photo-beaching were not seen. In short-time experiment courses (up to $10 \mathrm{~min}$ ) images were set to capture every 5 seconds for a total of 70 frames. After capture 
of the first 10 baseline images, either MDMA or the control compound was delivered through the syringe.

Images collected were analysed using Image-J software. Each individual cell was selected around and the mean fluorescence intensity determined. This was done for each image frame of the scan. Each reading was normalized back to the first reading after the baseline period (arbitrary fluorescent unit $=1$ ) and the subsequent normalized pixel intensities were graphed in GraphPad Prism. Statistical analysis using two-way ANOVA, with Bonferroni post test, was applied to test for significance between treatments.

\subsection{Rotating disc electrode voltammetry (RDEV)}

Rotating disc electrode voltammetry (RDEV) is an electrochemical technique that has been previously used for the measurement of real time 5-HT uptake and release in tissue samples such as whole brain rat synaptosomes (Hagan et al. 2010). Here, RDEV is used to investigate the changes in SERT function as defined by rate of change of 5-HT uptake under different treatments in HEK-293 and $\mathrm{N}_{2} \mathrm{~A}$ cells. A rotating glassy carbon electrode (Pine Instruments, special order AFMDO3GC, Pennsylvania) is connected to a high-precision MSR rotator (Pine Instruments) and set to spin at $2000 \mathrm{rpm}$ which keeps the cell sample or buffer in the custom glass chamber mixed. Rotation rates were recorded and maintained by a digital laser tachometer. Connected to the glass chamber an $\mathrm{Ag} / \mathrm{AgCl}$ reference electrode was used to apply a $+450 \mathrm{mV}$ potential relative to the electrode by an eDAQ potentiostat EA161 (eDAQ, NSW, Australia) and a platinum wire was used as an auxiliary electrode. A PC computer with Chart software (eDAQ, NSW, Australia) was used to save the resulting currents recorded by an eDAQ recorder 210 (eDAQ, NSW, Australia).

\subsubsection{Standard curve}

Concentration response curves were created each day prior to performing experiments. Serotonin stock was diluted into KREB buffer (130 mM NaCl, $1.3 \mathrm{mM} \mathrm{KCl}, 2.2 \mathrm{mM} \mathrm{CaCl}$,

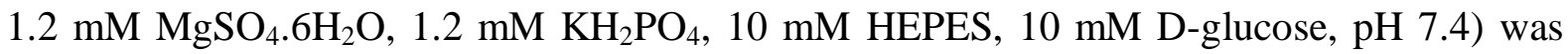
used to give 5-HT concentrations of $0.25,0.5,0.75,1.0,1.5,2.0,3.0$ and $5.0 \mu \mathrm{M}$. A linear regression was generated by calculating the increase in current (nA) at each 5-HT concentration, so that data collected from the cell samples can be transformed into $\mu \mathrm{M}$ based on the measured $\mathrm{nA}$ values. 


\subsubsection{Preparation of GFP-hSERT transfected HEK-293 and $\mathrm{N}_{2} \mathrm{~A}$ cells for RDEV}

Cells transfected with GFP-hSERT were treated with compounds so that their maximal effect on SERT was achieved, then washed $5 \mathrm{x}$ times with $37^{\circ} \mathrm{C}$ KREBs buffer saturated with $5 \% \mathrm{CO}_{2} / 95 \% \mathrm{O}_{2}$. They were harvested by mechanical agitation with the KREBs buffer and centrifuged at $300 \mathrm{~g}$ for $5 \mathrm{~min}$. The pellet of cells were then resuspended in either $1.2 \mathrm{~mL}$ or $300 \mu \mathrm{L}$ (depending on size of the dish, $100 \mathrm{~mm}$ and $60 \mathrm{~mm}$ respectively) of KREBs buffer saturated with carbogen $\left(5 \% \mathrm{CO}_{2} / 95 \% \mathrm{O}_{2}\right)$ and maintained at $37^{\circ} \mathrm{C}$ for up to $20 \mathrm{~min}$ until needed.

For 5-HT uptake experiments, $300 \mu \mathrm{L}$ of GFP-hSERT expressing cells were added to the glass chamber and the rotator lowered into the center and rotated at $2000 \mathrm{rpm}$ until a stable baseline recording was achieved. Single additions of 5-HT, from 0.25-5.0 $\mu \mathrm{M}$ were added to the cell suspension, and uptake recorded for $20 \mathrm{~s}$. A $10 \mu \mathrm{L}$ aliquot of cell suspension containing $0.4 \%$ tryphan blue was used to determine cell number using a haemacytometer. For the MDMA time points and activator/inhibitor experiments, a 5-HT concentration of 1.5 $\mu \mathrm{M}$ was used. For the kinetic experiments, a range of 5-HT concentrations was used, ranging from 0.25-5 $\mu \mathrm{M}$. Transfection percentages were calculated by visualization of GFP-hSERT positive cells using a fluorescent microscope (AX70, Olympus, Mt Waverly, Australia).

\subsubsection{Data Analysis}

5-HT uptake by SERT was determined from a $10 \mathrm{~s}$ period directly after addition of 5-HT. Microsoft Office Excel was used to plot the data and generate a linear regression. A linear regression with an $\mathrm{R}^{2}$ value less than 0.95 was discarded from this study. The change in current recorded from measurement period of 5-HT uptake by the cells was transformed into $\mu \mathrm{mol} / \mathrm{s}$ using the standard concentration curve generated at the beginning of the experiment. Using data generated from the standard curve and cell numbers SERT uptake was expressed in $\mathrm{pmol} / \mathrm{s} / 10^{6}$ cells. The values were then entered into GraphPad Prism to calculate the kinetic data. For HEK-293 cells a nonlinear regression (one-site binding hyperbole) was fitted to the data and $\mathrm{V}_{\max }$ and $\mathrm{K}_{\mathrm{m}}$ values could be calculated. Student t-tests and one-way ANOVA were used to determine the statistical significance. 


\section{Chapter 3: Validation of SERT antibody specificity}

\subsection{Introduction}

In recent years there has been increasing interest in the molecular characteristics and regulatory process of SERT. This has lead to the production of numerous SERT-specific antibodies. A review of the literature shows that there is much discrepancy and uncertainty over the identification of the molecular size of SERT, with a diverse pattern of SERT expression being reported (Table 3:1). The discrepancy in the literature has lead to speculation over the neurotoxicity of MDMA, as well as controversy over other SERTrelated findings. Whether or not MDMA has the potential to decrease SERT protein after MDMA treatment is debated throughout the literature, largely due to the fact that there is no consensus over which band represents SERT (Wang et al. 2005; Xie et al. 2006; Kivell et al. 2010). Reports from our lab show that there is no change in SERT abundance after MDMA treatment, instead we report that there is a redistribution of SERT from the plasma membrane to the intracellular compartment in cells transiently expressing SERT (Kivell et al. 2010). In contrast, reports from Wang et al. (2005) state that they did not observe any change in SERT distribution in brain tissue following MDMA administration. However images from their Western blot experiments show that the protein loaded in the gels were heavily overloaded and so may affect the analysis of their results. SERT heterologously expressed in cell lines is found at different molecular weights than SERT constitutively expressed in brain tissue or platelets. Some studies report a dominant non-glycosylated $60 \mathrm{kDa}$ form of SERT which is expressed endogenously and trafficked to the outer membrane (Chamba et al. 2008). Yet another study reports a diffuse 63-68 $\mathrm{kDa}$ immunoreactive band in rat brains (Xie et al. 2006). Endogenous SERT in the human brain and platelets have been also been identified as $76 \mathrm{kDa}$ and $94 \mathrm{kDa}$ respectively (Qian et al. 1995). Post-translational modifications have been attributed for the difference in mobility of the SERT protein. Mutational studies (Tate and Blakely 1994) and experiments (Melikian et al. 1996; Cai et al. 2005) on DAT and NET have shown increasing evidence for the importance of $\mathrm{N}$-glycosylation for correct folding of the transporters, therefore possibly playing a role in regulation and surface expression. A study on the rat brain identified a $70 \mathrm{kDa}$ glycosylated form of SERT which when deglycosylated creates a $50 \mathrm{kDa}$ species (Wang et al. 2005). SERT generated in cell lines such HEK-293 cells render a broad 85-95 kDa band which is N-glycosylated (Chamba et al. 2008). Despite a large number of studies, SERT-specific antibodies have not been able to characterize SERT at the protein level due to the lack of consensus regarding its size or 
isoform and general lack of specificity. For these reasons our laboratory utilizes a cell system where the GFP-tagged SERT can be directly visualized. This overcomes the limitations of the available antibodies (Kivell et al. 2010).

This chapter investigates the discrepancy between SERT antibodies by comparing two SERT-specific antibodies that are commercially available. Both are from polyclonal backgrounds, with one being directed to the N-terminal (Sigma Aldrich, USA), and the other to the C-terminal (Santa Cruz supplied by Thermofisher, Auckland, NZ) of the human SERT protein. Since our cellular system employs a GFP tag, we are able to directly visualize SERT using a laser scanner to read the fluorescent gels. This allows for a comparison between what bands the SERT-specific antibodies identify, and what bands are identified through the direct detection of SERT via fluorescent GFP. Detailed methods can be found in Section 2.3.

Table 3:1: Literature review of the molecular characteristics of SERT.

Table adapted from Chamba et al. (2008)

\begin{tabular}{lllll}
\hline Species & Cell type & Source & Size (kDa) & Reference \\
\hline Human & HEK-293 & cDNA & 96,76 & (Ramamoorthy et al. 1998) \\
Human & HEK-293 & cDNA & $85-95,60$ & (Frankhauser et al. 2006) \\
Human & $\mathrm{N}_{2} \mathrm{~A}$ & cDNA & 100,85 & (Kivell et al. 2010) \\
Human & HEK-293 & cDNA & $85-95,70,60$ & (Chamba et al. 2008) \\
Rat & Brain & Endogenous & 50 & (Kivell et al. 2010) \\
Rat & HeLa & cDNA & 61 & (Qian et al. 1995) \\
Rat & Brain & Endogenous & 70,50 & (Wang et al. 2005) \\
Rat & Brain & Endogenous & 70 & (Rothman et al. 2003) \\
Rat & Brain & Endogenous & $63-68$ & (Xie et al. 2006) \\
Rat & Platelet & Endogenous & 100 & (Jayanthi et al. 2005) \\
Human & HEK-293, & cDNA & 103,75 & This study \\
& $\mathrm{N}_{2} \mathrm{~A}$ & & & \\
\hline
\end{tabular}




\subsection{Aim}

This experiment aimed to investigate if there are discrepancies in SERT protein immunolabeling. To do this we immunolabeled Western blots using two different SERTspecific antibodies in both HEK-293 and $\mathrm{N}_{2} \mathrm{~A}$ cells transfected with GFP-hSERT. Immunolabeling from the antibodies was compared to direct detection of SERT via its GFP tag. 


\subsection{Results}

Figure 3:1 shows non-transfected HEK-293 cells (lanes 1 and 2) and transiently transfected GFP-hSERT HEK-293 cells (lanes 3, 4 and 5) probed with Antibody 1 at a dilution of 1:500 (a) and 1:1000 (b). Non-transfected HEK-293 cells were run as controls to test the antibodies for non-specific binding. From this Western blot it appears that there is residual immunolabeling in the non-transfected cells, whether this is evidence of non-specific binding is not clear (Figure 3:1). There is no difference in the pattern of staining using the two different antibody concentrations as seen in Figure 3:2. However loading protein concentrations above $50 \mu \mathrm{g}$ causes the blot to become saturated and the bands appear significantly more diffuse and undefined (Figure 3:1 and Figure 3:2).

Figure 3:2 shows that there is no significant difference in the pattern of staining between Antibody 1 and Antibody 2 (lanes 3, 4 and 5). Both antibodies identify a dominant band at $103 \mathrm{kDa}$ and $75 \mathrm{kDa}$, with the same pattern of non-specific binding. The molecular weight of SERT that Antibody 1 is predicted to identify is $70 \mathrm{kDa}$ according to the manufacturer's protocol. Antibody 2 is predicted to identify SERT at $83 \mathrm{kDa}$ according to the manufacturer's protocol. 
Fluorescent Gel

a)

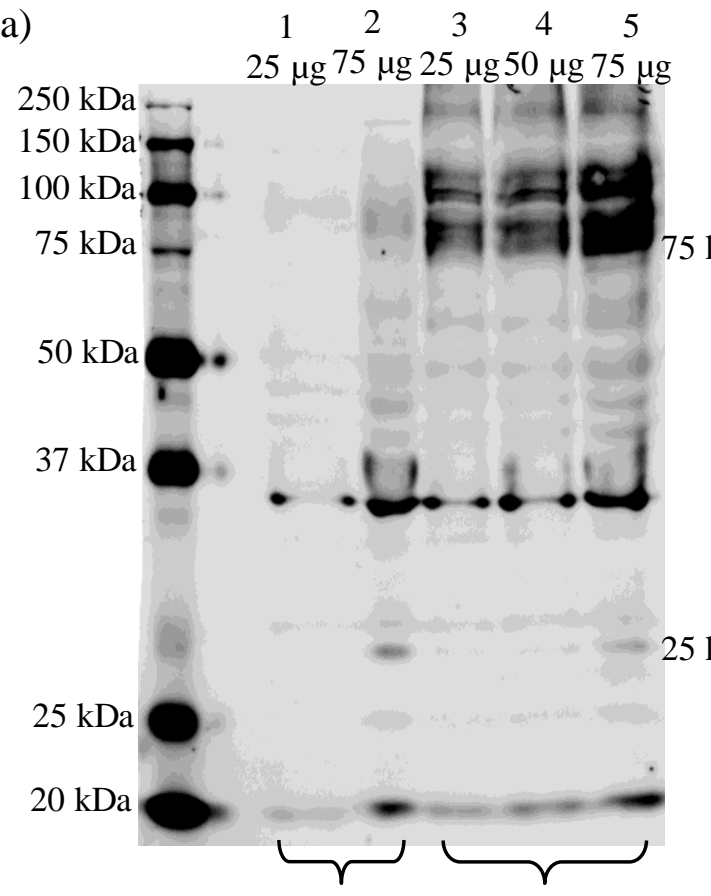

Non-transfected GFP-hSERT

b)

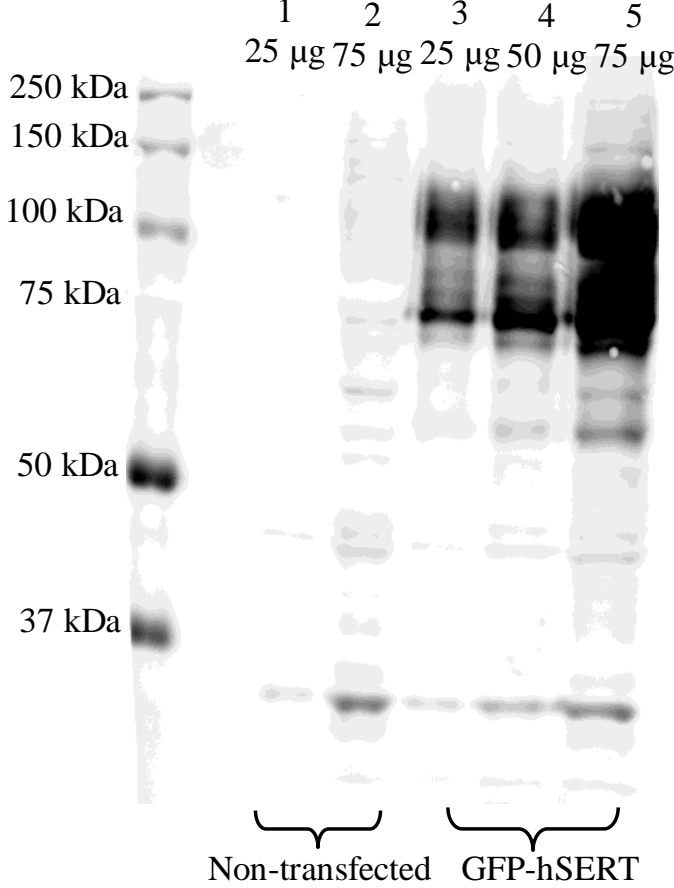

Immunoblot

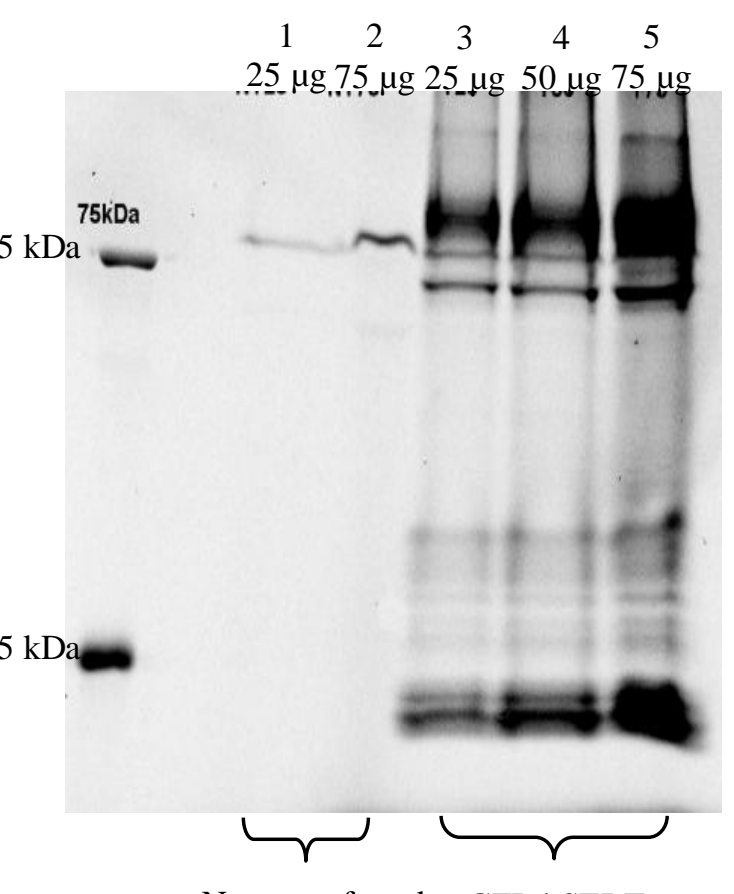

Non-transfected GFP-hSERT

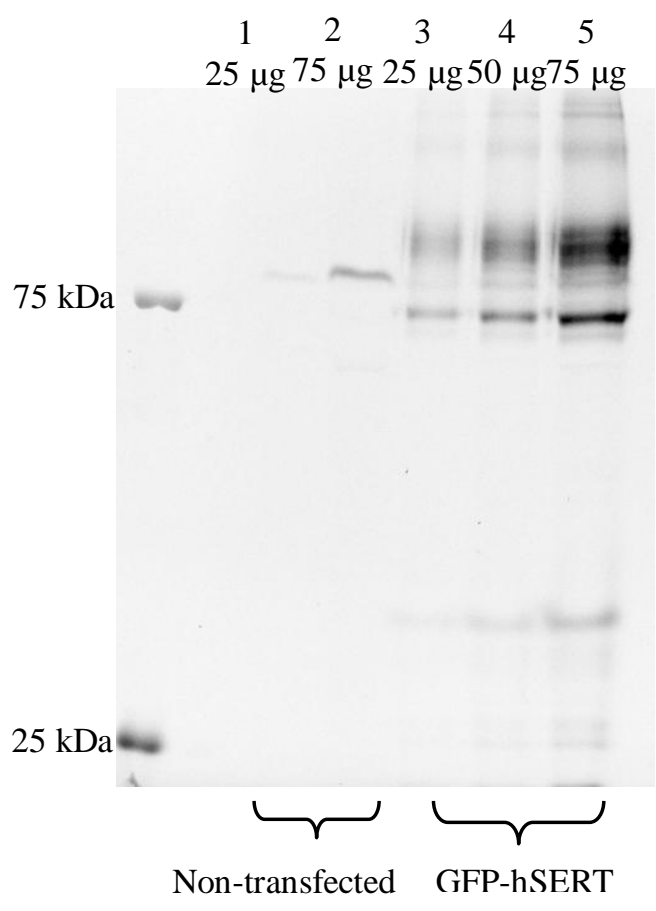

Figure 3:1: Western blot of HEK-293 cells transfected with GFP-hSERT and probed

with Antibody 1. A dilution of 1:500 (a) and 1:1000 (b) was used to probe the membranes. Pictured with the immunoblot (right) is the fluorescent gel (left) corresponding to the blot. Lanes are indicated with numbers (1-5) with the amount of protein loaded denoted underneath. Both non-transfected and GFP-hSERT transfected HEK-293 cells were loaded. 


\section{Fluorescent Gel}

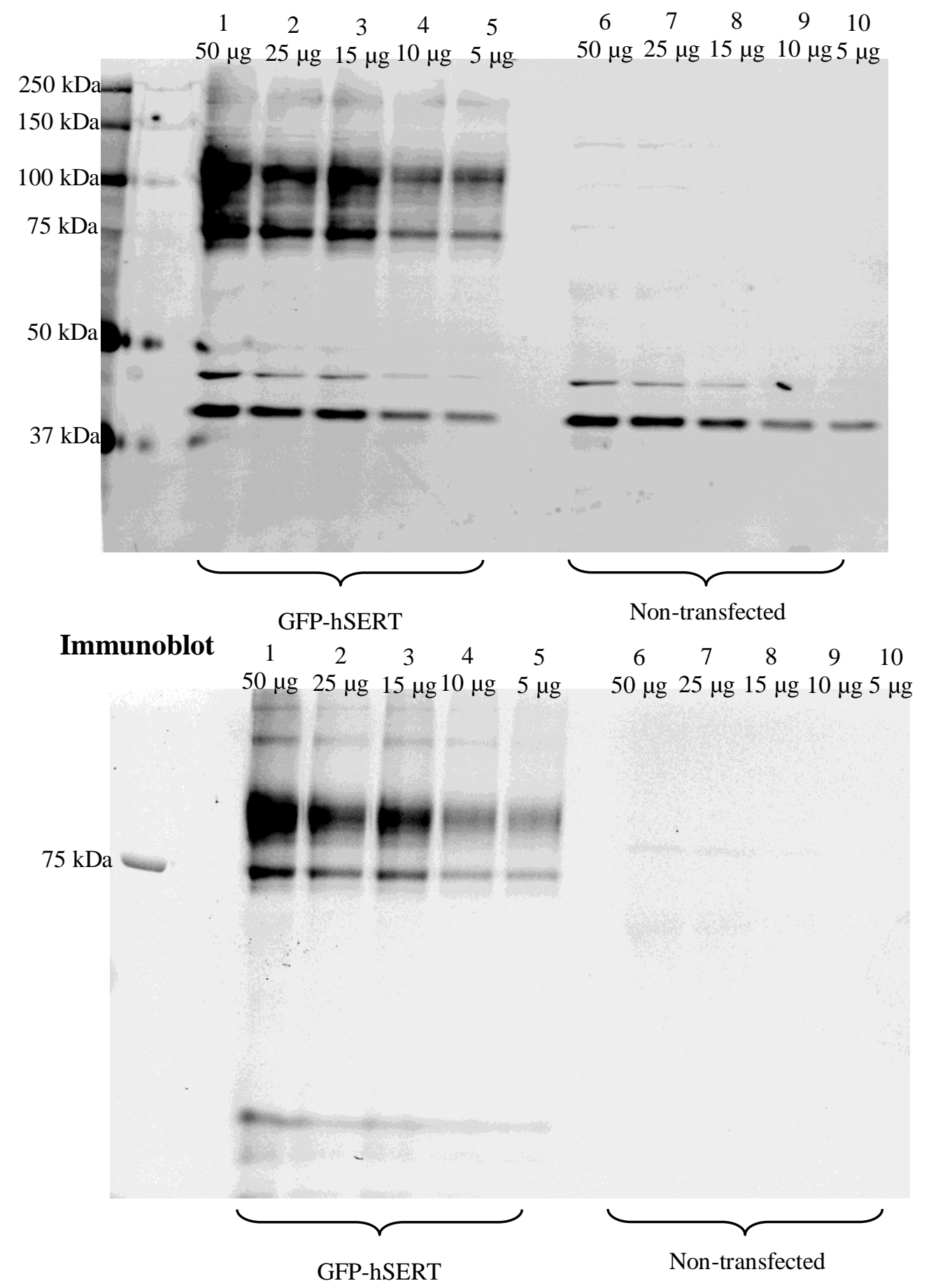

Figure 3:2: Western blot of HEK-293 cells transfected with GFP-hSERT and probed with Antibody 2.

A dilution of 1:1000 was used to probe the membranes. Pictured is the fluorescent gel corresponding to the immunoblot. Lanes are indicated with numbers (1-10) with the amount of protein loaded denoted underneath. Both non-transfected and GFP-hSERT transfected HEK-293 cells were loaded. 
Figure 3:3 shows a Western blot of $\mathrm{N}_{2} \mathrm{~A}$ cells either transfected with GFP-hSERT or nontransfected wild-type. Antibody 2 was used to probe the cell lysates at a dilution of 1:1000. With the difficulty encountered by poor transfection rates and inefficient transfer rates of the protein from the gel to the membrane, only this antibody was able to be investigated at this dilution. This antibody picked up a dominant immunoreactive band at $103 \mathrm{kDa}$ and $75 \mathrm{kDa}$ with the rest of the blot having a similar staining pattern to that of HEK-293 cells (Figure 3:1 and Figure 3:2). 


\section{Fluorescent Gel}
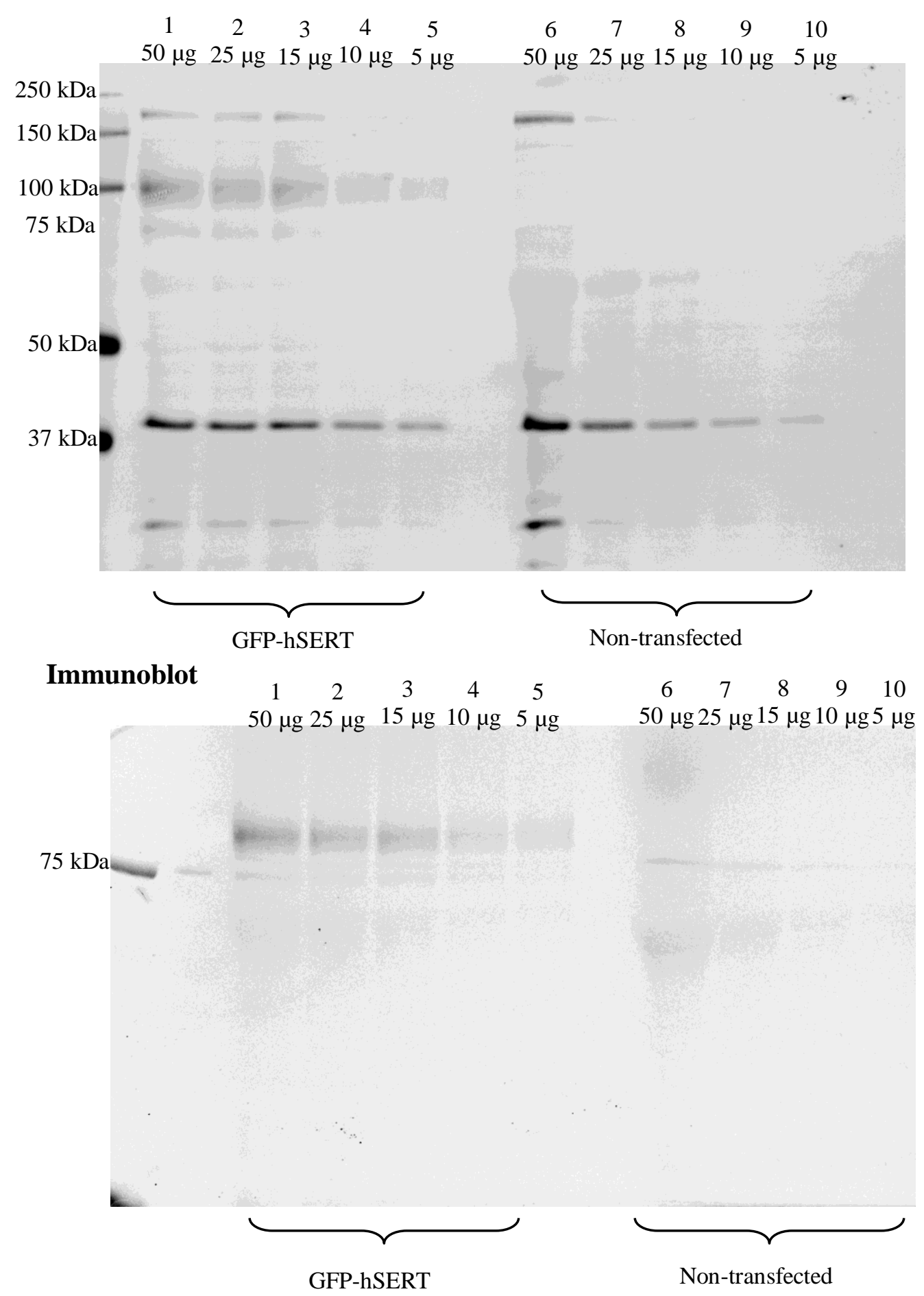

Figure 3:3: Western blot of $\mathrm{N}_{2} \mathrm{~A}$ cells transfected with GFP-hSERT and probed with Antibody 2 at a dilution of 1:1000.

Lanes are indicated with numbers (1-10) with the amount of protein loaded denoted underneath. Both non-transfected and GFP-hSERT transfected $\mathrm{N}_{2} \mathrm{~A}$ cells were loaded. Pictured is the fluorescent gel corresponding to the immunoblot. 


\subsection{Discussion}

Initial experiments were performed to investigate if any difference in the pattern of GFPhSERT expression could be seen when immunolabeled with two different anti-SERT antibodies. We chose widely used commercially available antibodies directed at both the $\mathrm{C}$ terminal (antibody 1) and the $\mathrm{N}$ terminal (antibody 2). It was advantageous to be able to validate the cellular model utilized throughout this project by comparison of the pattern of SERT expression using antibodies versus the detection of the GFP-tag attached to hSERT.

What is most intriguing about this experiment was that non-transfected HEK-293 and $\mathrm{N}_{2} \mathrm{~A}$ cells showed a similar staining pattern to GFP-hSERT transfected cells. A study carried out by Chamba et al. (2008) reported that HEK-293 cells contain endogenous SERT. This finding was supported by a study which carried out a Clonetech gene array platform confirming that SERT mRNA is abundantly expressed in wild-type HEK-293 cells (Shaw et al. 2002). Bands appear at 45, 60 and $70 \mathrm{kDa}$ in wild-type and SERT transfected HEK-293 cells and have been labeled the major SERT protein species. The diffuse 85-95 kDa band is most dominant in the SERT transfectants (Chamba et al. 2008). This is in partial agreement with our study where our two dominant diffuse bands are seen at $103 \mathrm{kDa}$ and $75 \mathrm{kDa}$ in GFP-hSERT transfected HEK-293 cells. Whether the staining pattern observed in the nontransfected lanes is residual non-specific antibody binding, or whether there is SERT present in these cells is unclear.

Due to the difficulty in transfection efficiency being poor of $\mathrm{N}_{2} \mathrm{~A}$ cells with GFP-hSERT, it was not possible to probe with both antibodies. Some difficulty was encountered with transfer of protein from the gel to the PVDF membrane, and after optimization of the transfer buffer, only the membrane from Figure 3:3 was successfully able to be blotted with Antibody 2. Since our lab and further experiments from this study concentrates on a cell system where hSERT is tagged with GFP, it would have been interesting to show what an antibody directed to GFP identified compared to what the fluorescent gels of GFP-hSERT showed. It would have been a good method validation to show that a GFP-specific antibody identifies the same pattern of SERT expression that is seen after reading the gels on the laser scanner. A comparison of this to the SERT-specific antibodies would be the next step in validating the specificity debate over the identification of SERT. Unfortunately due to time constraints and trouble-shooting, the GFP-specific antibody was not able to yield a successful Western blot. 
In an attempt to identify the dominant bands appearing in the above Western blots, a review of the literature reporting different SERT molecular sizes was carried out (Table 3:1). It is clear that there are various patterns of SERT expression depending on whether it is expressed in cell lines or endogenously in brain tissue or platelets. However there is no consensus over the SERT protein size or isoform regardless of the background or species it is expressed in (Table 3:1) (Chamba et al. 2008). Indeed, in this project we find two bands from the transfected cell lines with molecular weights of $103 \mathrm{kDa}$ and $75 \mathrm{kDa}$ which we identify as SERT, however it is worth mentioning that the manufacturers state the expected molecular size for SERT is $70 \mathrm{kDa}$ (antibody 1) and $83 \mathrm{kDa}$ (antibody 2). Discrepancy could arrive from differences in experimental protocols; the amount of protein loaded in gels can alter protein migration, and storage and batches of antibodies tend to vary between studies and can affect reported results. Post-translational modification can be attributed for differences in SERT mobility, and with the knowledge that the SERT protein exists in N-glycosylated and un-glycosylated forms, this helps in identifying the different forms of SERT in a gel. Chamba et al. (2008) report that the broad 85-95 kDa band appearing in their blots is a heavily N-glycosylated form of SERT in transfected HEK-293 cells. Removal of the Nglycans achieve bands that appear at 60 and $70 \mathrm{kDa}$ which correspond to those found expressed constitutively in non-transfected cells, leading this group to conclude that nonglycosylated SERT exists in HEK-293 cells. Keeping the results from the literature in mind and combining them with our previous knowledge of SERT characteristics, this study concluded that in the above Western blots, the diffuse band found at $103 \mathrm{kDa}$ in HEK-293 cells and $\mathrm{N}_{2} \mathrm{~A}$ cells transfected with hSERT is the N-glycosylated form of SERT. The smaller band found at $75 \mathrm{kDa}$ in HEK-293 cells and in $\mathrm{N}_{2} \mathrm{~A}$ cells we suggest could be the nonglycosylated form. We are hesitant to suggest what the band identified at $75 \mathrm{kDa}$ in the nontransfected cell lanes could be; whether it non-specific binding or a form of SERT is not clear. Further research into SERT antibody specificity is required before more conclusions is made. 


\section{Chapter 4: Investigating the effects of MDMA on SERT function in a cell model}

\subsection{Introduction}

It is commonly known that SERT function is regulated by trafficking between the plasma membrane and intracellular compartment through a series of post-translational modifications (Ramamoorthy et al. 1998; Howell and Kimmel 2008; Kivell et al. 2010). Studies carried out in our laboratory have shown that MDMA is able to rapidly internalize SERT from the plasma membrane into the cytosol in HEK-293 and $\mathrm{N}_{2} \mathrm{~A}$ cells (Kivell et al. 2010). What is not clear, however, is the mechanism by which this internalization occurs. PKC is an intracellular protein known to be involved in regulating SERT expression and function (Jayanthi and Ramamoorthy 2005). The question this chapter sought to investigate was whether changes in SERT function caused by MDMA were via PKC-dependent signaling pathways.

Cell models have been utilized throughout this study as they allow for greater manipulation when studying the effects of drugs on monoamine transporters than is possible in a whole animal or tissue samples. HEK-293 cells are a well-established cell model used to investigate monoamine transporter regulation and have been shown to contain many of the relevant cell signaling pathways. HEK-293 cells are derived from cells transfected with adenovirus 5, and despite being from a kidney origin have been shown to possess proteins from a neuronal background (Shaw et al. 2002). $\mathrm{N}_{2} \mathrm{~A}$ cells are also from a neuronal origin and therefore contain many of the relevant signaling pathways (Klebe and Ruddle 1969).

Traditional methods for studying SERT function in the brain include radioactive 5-HT uptake (Ramamoorthy et al. 1998), high-speed chronoamperometry (HSC) (Perez and Andrews 2005) and fast scan cyclic voltammetry (FSCV) (John and Jones 2007; Hashemi et al. 2009). These techniques have been used to measure SERT function in cells, synaptosomes and in vivo tissue systems. Another technique used to measure neurotransmitter transporter function is called rotating disc electrode voltammetry (RDEV) (Earles and Schenk 1998). This electrochemical technique is widely used in studies investigating the release and uptake of norepinephrine and dopamine by the neuronal monoamine transporters in both cell and brain tissue models (Burnette et al. 1996; Earles and Schenk 1998; Chen et al. 1999). Recently, RDEV has been validated for the measurement of SERT function in synaptosomes (Hagan et 
al. 2010; Hagan et al. 2011). The rotation of the glassy carbon electrode at $2000 \mathrm{rpm}$ allows for the solution in the chamber to remain well-mixed throughout the experimental time and the voltage applied is specific to oxidize the monoamines present in the chamber. The rotation of the electrode draws neurotransmitters towards the submerged electrode surface where they oxidize, releasing 1 or 2 electrons which produce the resulting current (Earles and Schenk 1998; Hagan et al. 2010). The magnitude of the current is directly related to the concentration of free monoamine substrate in the sample. Therefore, as monoamines are transported into the cells or tissue preparations in the chamber, the current will decrease accordingly due to the decrease in free monoamine able to be oxidized (Earles and Schenk 1998). The magnitude of the current measured at the solid electrode surface can be defined by the Levich equation:

$I_{L}=0.62 n F A C D^{2 / 3} v^{-1 / 6} \omega^{1 / 2}$

Where $I_{L}$ is the limiting current, $\mathrm{n}$ is the number of electrons transferred per mole, $F$ is the Faradays constant, $A$ is the area of the electrode in $\mathrm{cm}^{2}, D$ is the diffusion coefficient of the electroactive substrate in $\mathrm{cm}^{2} / \mathrm{s}, C$ is the concentration of the electroactive substrate in the sample solution in mM, $v$ is the kinematic viscosity of the solution in $\mathrm{cm}^{2} / \mathrm{sec}, \omega$ is the singular velocity of rotation in $\mathrm{rad} / \mathrm{sec}$, where $\omega=2 \pi N$, and $N$ is the number of rotations per second (Earles and Schenk 1998).

At the time of this study, there was no published data using RDEV to measure SERT function in cultured cells. Therefore, much of the protocol carried out for this project is based upon a recently published $\mathrm{PhD}$ thesis completed in our lab (Simonson 2011). Simonson (2011) sought to characterize SERT function in HEK-293 cells expressing GFP-hSERT, and the same experimental set-up was used in this study for the two cell lines being investigated, $\mathrm{N}_{2} \mathrm{~A}$ and HEK-293 cells. RDEV was used to investigate changes in SERT function after MDMA treatment by measuring 5-HT uptake. PKC activation by $\beta$-PMA causes a down-regulation in SERT function (Jayanthi et al. 2005). To establish whether MDMA works through a PKCdriven signaling system to alter SERT function, cells expressing SERT were pre-treated with a PKC inhibitor, Bis I. Bis I is a potent and selective PKC inhibitor, and studies have shown that it blocks the activation of PKC by $\beta$-PMA in astrocytes (Yasuda et al. 2011). Previous studies in tissue and cell preparations have shown that pre-treatment with Bis I for 30-90 min (Nair and Gudelsky 2004; Ramamoorthy et al. 2007) is sufficient to inhibit PKC. In this chapter RDEV was used to measure any changes in 5-HT uptake in cells treated with MDMA 
in the presence or absence of Bis I. The ability of Bis I to block MDMA-induced effects on SERT function could signify that MDMA is targeting the PKC pathway to regulate SERT.

\subsection{Aim}

Using RDEV to measure SERT function in HEK-293 and $\mathrm{N}_{2} \mathrm{~A}$ cells transfected with GFPhSERT, we aim to determine if MDMA modulates SERT via a PKC-dependent pathway 


\subsection{Results}

\subsubsection{Effect of MDMA on SERT function}

MDMA is known to compete with 5-HT for uptake by SERT (Howell and Kimmel 2008). To ensure that changes in 5-HT uptake seen after MDMA treatment was not due to residual MDMA in the cell suspension competing for uptake, a wash-out control was performed (Figure 4:1). MDMA $(10 \mu \mathrm{g} / \mathrm{mL})$ was added to a $35 \mathrm{~mm}$ dish containing GFP-hSERT transfected cells for $30 \mathrm{~s}$ and then removed. 5-HT uptake was then measured using RDEV with a single addition of 5-HT at $1.5 \mu \mathrm{M}$. No change in 5-HT uptake was observed compared to control (Figure 4:1). This shows that MDMA is able to be washed away and is no longer present to compete for uptake at SERT. The short time course used for this experiment (10 s) was not sufficient to measure changes in SERT trafficking which typically occurs after at least $5 \mathrm{~min}$.

To determine whether MDMA causes a down-regulation of SERT function we measured SERT function using RDEV in HEK-293 and $\mathrm{N}_{2} \mathrm{~A}$ cells transiently transfected with GFPhSERT. Cells were incubated with $10 \mu \mathrm{g} / \mathrm{mL}$ of MDMA for 5, 10, 30, 60 and $90 \mathrm{~min}$.

HEK-293 cells incubated with MDMA for 5 min show that 5-HT uptake is significantly decreased compared to controls (Figure 4:2A), with MDMA reducing uptake by 47\% $(\mathrm{p}<0.01)$. After a $10 \mathrm{~min}$ incubation with MDMA, uptake was reduced by $63 \%(\mathrm{p}<0.001)$. This decrease in 5-HT uptake persisted until the $90 \mathrm{~min}$ time point $(\mathrm{p}<0.01)$. This demonstrates that MDMA is able to cause a functional down-regulation due to the significant decrease seen in 5-HT uptake compared to vehicle-treated cells.

The same experiment was repeated in $\mathrm{N}_{2} \mathrm{~A}$ cells transiently transfected with GFP-hSERT. Interestingly, a decrease in 5-HT uptake was only seen with cells incubated with MDMA for 5 and $10 \mathrm{~min}$ (Figure 4:2B). At $5 \mathrm{~min}$ and $10 \mathrm{~min}, 5$-HT uptake was significantly decreased, with $43 \%$ decreased uptake ( $<<0.01$ and $p<0.05$ respectively), suggesting a reversible, more transient decrease in SERT function. 
A

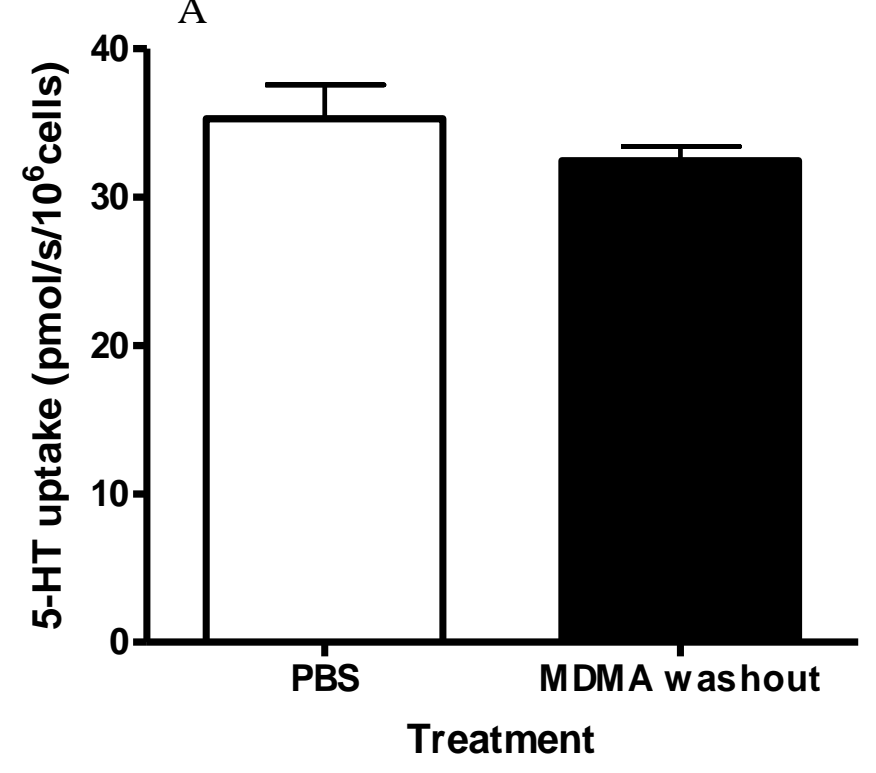

$\mathrm{B}$

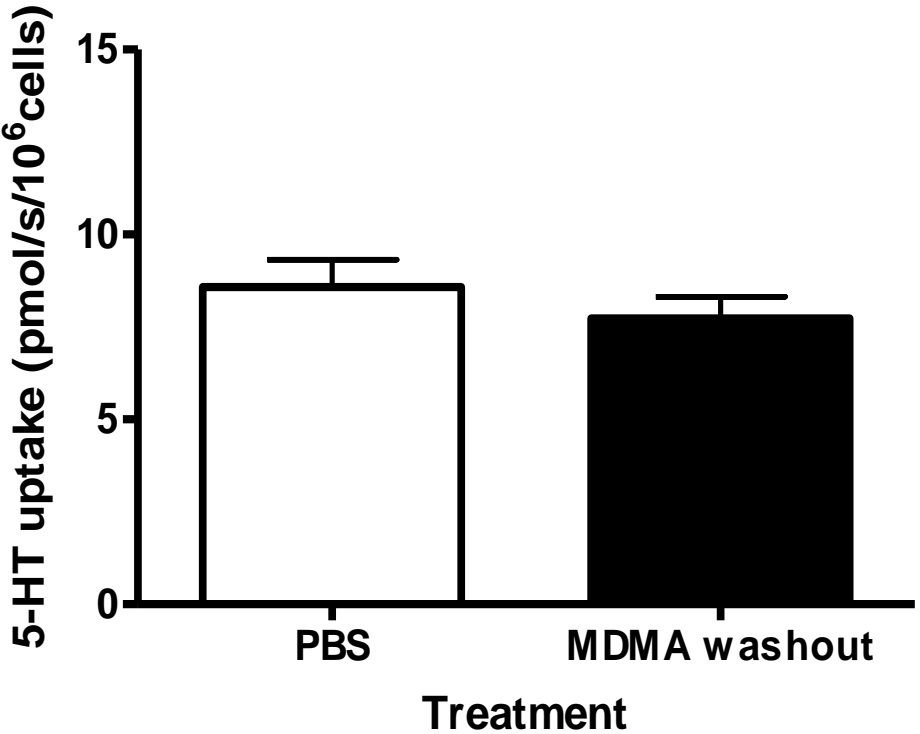

Figure 4:1: MDMA wash-out control.

HEK-293 (A) and $\mathrm{N}_{2} \mathrm{~A}$ (B) cells transfected with GFP-hSERT were incubated with MDMA $(10 \mu \mathrm{g} / \mathrm{mL})$ for $30 \mathrm{~s}$ and then washed with $1 \mathrm{x}$ PBS before a single 5-HT (1.5 $\mu \mathrm{M})$ addition. There was no significant difference in 5-HT uptake between control-treated (PBS) preparations and MDMA wash-out treatments, $(n=4$ preparations $)$. Student t-test used for statistical analysis. 

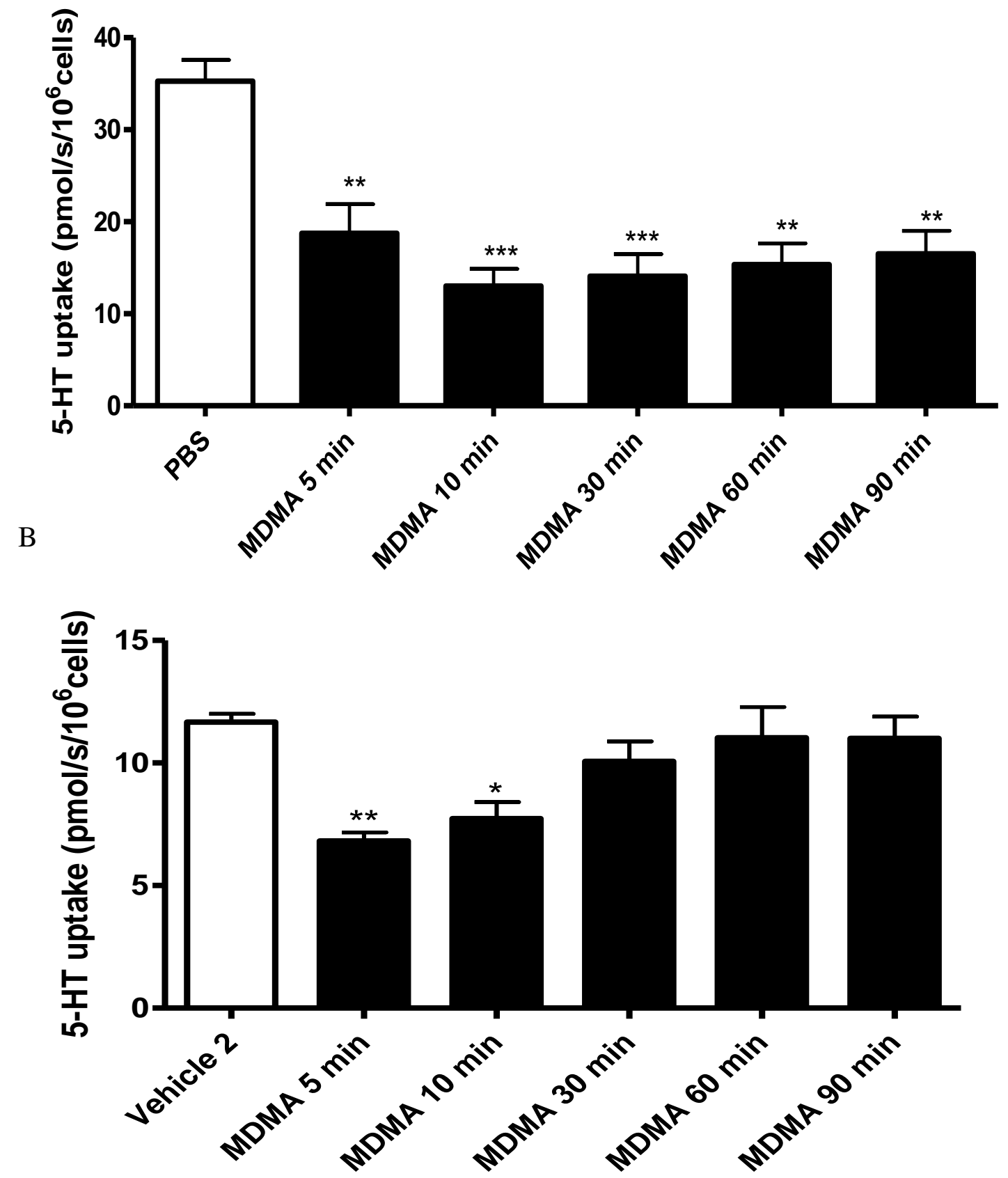

Figure 4:2: Effect of MDMA on 5-HT uptake in HEK-293 and $\mathrm{N}_{2} \mathrm{~A}$ cells transfected with GFP-hSERT.

HEK-293 cells (A) and $\mathrm{N}_{2}$ A cells (B) were incubated with MDMA (10 $\left.\mu \mathrm{g} / \mathrm{mL}\right)$ for 5-90 min before 5-HT $(1.5 \mu \mathrm{M})$ addition. MDMA caused a decrease in 5-HT uptake within 5 min for both cell lines when measured using RDEV. However, only HEK-293 cells showed a significant decrease in 5-HT uptake for the time period of 90 min. ( $\mathrm{n}=3-4$ preparations). Data points represent mean \pm SEM. One-way ANOVA followed by Bonferroni post test, $* \mathrm{p}<0.05, * * \mathrm{p}<0.01, * * * \mathrm{p}<0.001$. 


\subsubsection{Effect of PKC activator $\beta$-PMA on SERT function}

Once we established that MDMA caused a functional down-regulation of SERT through RDEV methods (Figure 4:2), the next step was to investigate whether it was caused by activation of PKC. Inhibition of SERT function occurs upon PKC activation, causing a reduction in 5-HT uptake (indicated by a decrease in $\mathrm{V}_{\max }$ ) with little or no change in the affinity of SERT for 5-HT (no change in $\mathrm{K}_{\mathrm{m}}$ ) (Qian et al. 1997). Addition of $1 \mu \mathrm{M} \beta$-PMA has been previously shown to decrease SERT function in HEK-293 cells within 20-60 min (Qian et al. 1997; Kivell et al. 2010). In this study, HEK-293 and $\mathrm{N}_{2} \mathrm{~A}$ cells transiently transfected with GFP-hSERT were pretreated with $1 \mu \mathrm{M} \beta$-PMA for 30 or $60 \mathrm{~min}$, followed by analysis of 5-HT uptake by RDEV. In HEK-293 cells, the 30 min pre-treatment with $\beta$ PMA significantly decreased uptake by $35 \%$ compared to controls $(\mathrm{p}<0.05)$ (Figure 4:3A). Treatment for 60 min reduced uptake by $45 \%(\mathrm{p}<0.01)$ (Figure 4:3A). Interestingly, $\mathrm{N}_{2} \mathrm{~A}$ cells did not show a significant decrease in 5-HT uptake after incubation with $\beta$-PMA for either $30 \mathrm{~min}$ or $60 \mathrm{~min}$ (Figure 4:3B). However it should be noted that there is a trend towards a decrease in 5-HT uptake after a $30 \mathrm{~min}$ incubation with $\beta$-PMA ( $\mathrm{p}=0.07$, Student ttest). 
A
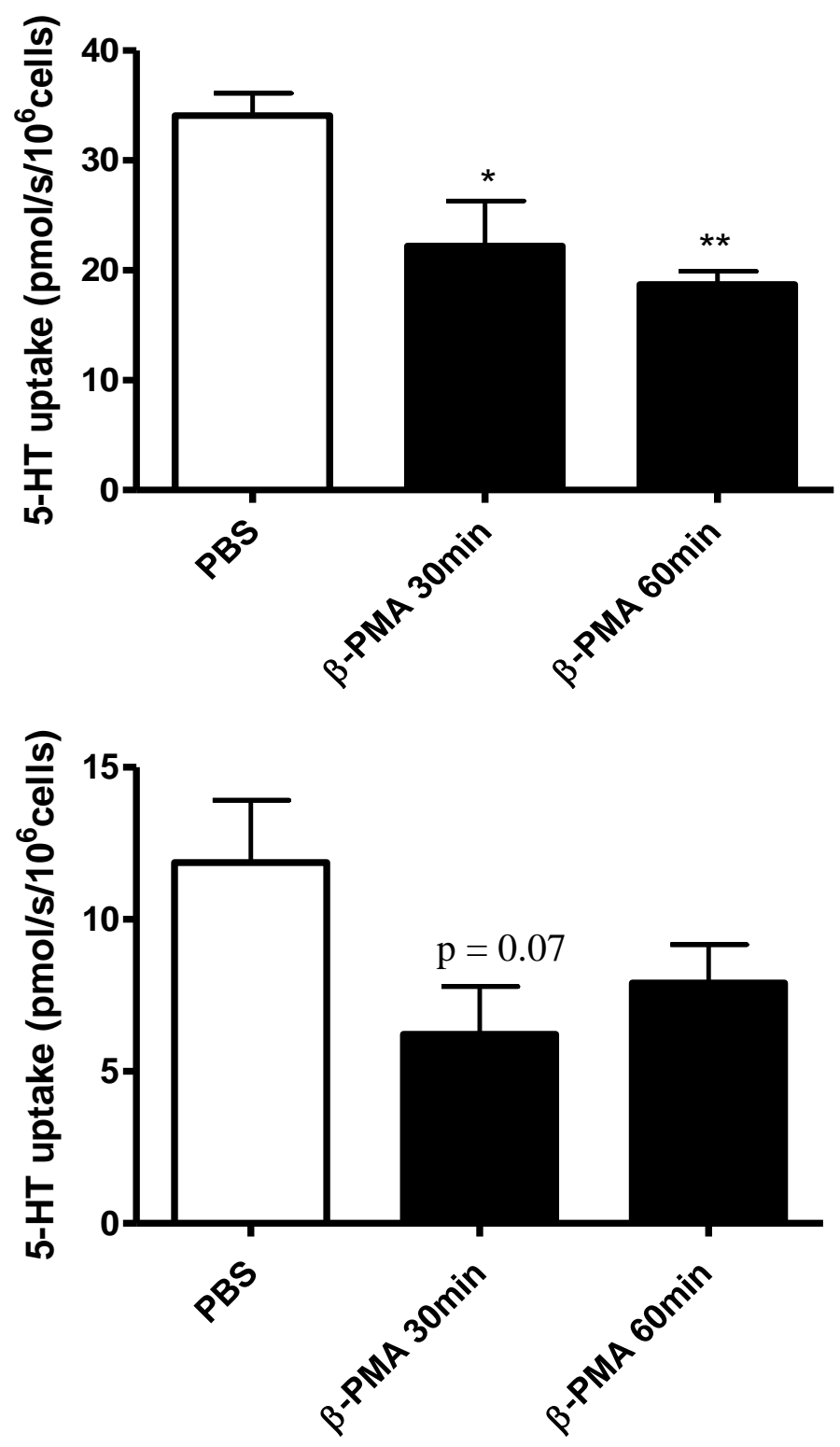

Figure 4:3: The effect of the PKC activator $\beta$-PMA on 5-HT uptake in HEK-293 and $\mathrm{N}_{2} \mathrm{~A}$ cells transfected with GFP-hSERT.

HEK-293 (A) and $\mathrm{N}_{2} \mathrm{~A}(\mathrm{~B})$ cells were incubated with $1 \mu \mathrm{M}$ of $\beta$-PMA for 30 or $60 \mathrm{~min}$ before 5-HT addition $(1.5 \mu \mathrm{M})$. A significant decrease in 5-HT uptake was seen in HEK-293 cells after 30 and 60 min $\beta$-PMA incubation ( $\mathrm{n}=4$ preparations). In $\mathrm{N}_{2} \mathrm{~A}$ cells there is a trend towards a decrease in 5-HT uptake after a 30 min incubation with $\beta$-PMA $(\mathrm{p}=0.07$, Student t-test) $(\mathrm{n}=5-7$ preparations $) .{ }^{*} \mathrm{p}<0.05, * * \mathrm{p}<0.01$. 


\subsubsection{Effect of MDMA on 5-HT uptake after PKC inhibition}

Results presented in Figure 4:2A and Figure 4:3A show that both MDMA treatment and PKC activation significantly decreased 5-HT uptake by SERT in HEK-293 cells. In $\mathrm{N}_{2} \mathrm{~A}$ cells, MDMA causes a significant decrease in 5-HT uptake, with $\beta$-PMA treatment showing a trend towards a decrease in 5-HT uptake (Figure 4:2B and Figure 4:3B). To establish whether MDMA is causing this down-regulation through PKC, Bis I pre-treatment was used to inhibit PKC. In this study, HEK-293 and $\mathrm{N}_{2} \mathrm{~A}$ cells transiently transfected with GFP-hSERT were pretreated with $200 \mathrm{nM}$ of Bis I for $30 \mathrm{~min}$. MDMA $(10 \mu \mathrm{g} / \mathrm{mL})$ was then added for 5 min and 5-HT uptake measured. Pre-treatment with Bis I show that in both HEK-293 cells (Figure 4:4A) and $\mathrm{N}_{2} \mathrm{~A}$ cells (Figure 4:4B), 5-HT uptake was not reduced after MDMA treatment. However cells in the absence of Bis I show a significant decrease in 5-HT uptake after MDMA treatment (Figure 4:4). This suggests that PKC inhibition prevents the effects MDMA has on SERT function. 


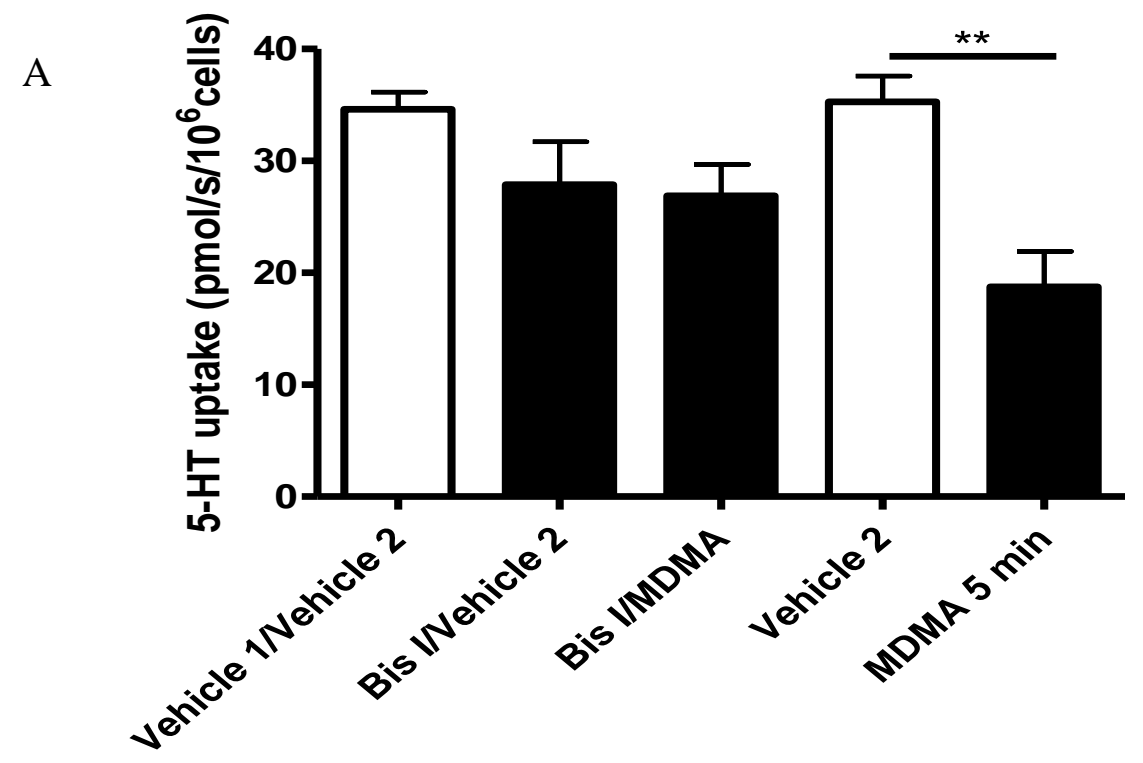

B

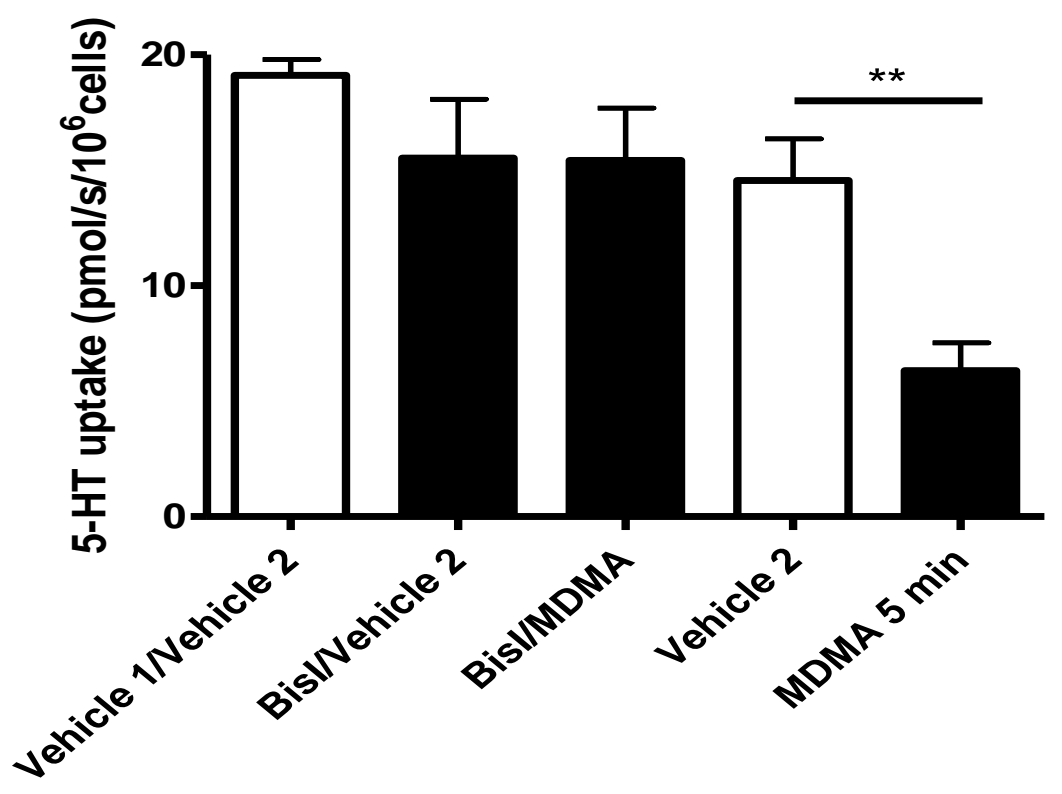

Figure 4:4: Effect of MDMA on 5-HT uptake after PKC inhibition by Bis I in HEK-293 and $\mathrm{N}_{2} \mathrm{~A}$ cells transfected with GFP-hSERT.

HEK-293 (A) and $\mathrm{N}_{2} \mathrm{~A}$ (B) cells transfected with GFP-hSERT were incubated with either 200 $\mathrm{nM}$ of Bis I for $30 \mathrm{~min}$, or incubated with $200 \mathrm{nM}$ of Bis I for $30 \mathrm{~min}$ followed by incubation with $10 \mu \mathrm{g} / \mathrm{mL}$ of MDMA for $5 \mathrm{~min}$ before 5-HT addition $(1.5 \mu \mathrm{M})$. 5-HT uptake levels were compared to vehicle-treated controls (vehicle 1 is DMSO, vehicle 2 is PBS). Transfected cells were also incubated with $10 \mu \mathrm{g} / \mathrm{mL}$ of MDMA for 5 min before 5-HT addition $(1.5 \mu \mathrm{M})$. Both cell lines show that pre-treatment with Bis I prevents the decrease in 5-HT uptake that MDMA causes, with 5-HT uptake levels comparable to vehicle treated control levels. ( $n=4-7$ for $\mathrm{N}_{2} \mathrm{~A}$ cell preparations, $n=3-5$ for HEK-293 cell preparations). Data points represent the mean \pm SEM. One-way ANOVA followed by Bonferroni post test, $* * \mathrm{p}<0.01$. 


\subsection{Discussion}

At the beginning of this project there were no published reports using RDEV methods to measure SERT function in transfected cell lines. The experimental parameters used in this study are based upon unpublished data from our laboratory which established RDEV techniques to measure SERT function in both HEK-293 cells transfected with hSERT, and rat brain tissue samples. Since this time, two very recent publications by Hagan et al. (2010) and Hagan et al. (2011) have provided the first use of RDEV to measure SERT. This study used whole mouse brain synaptosomes. The protocol established by Hagan et al. is very similar to that used in the current study. The main difference is that we measured 5-HT oxidation at $+450 \mathrm{mV}$ in isolated cell cultures, where Hagan et al. measured the current produced at +550 $\mathrm{mV}$. The values from the study by Hagan et al. and this study are both within the measurable range, but because we used a lower voltage, our 5-HT signal was 2.5 times lower $(0.084 \pm$ $0.004 \mathrm{nA} / \mathrm{nM}$ compared to $0.21 \pm 0.01 \mathrm{nA} / \mathrm{nM})$.

The principal aim of this experiment was to identify the cellular signaling pathway responsible for the decrease in SERT function following exposure to MDMA. Previous studies have shown that MDMA causes a release of 5-HT into the extracellular space and promotes an increase in activity of PKC (Kramer et al. 1997; Kramer et al. 1998). To investigate the time of maximal effect on SERT function, MDMA was incubated for $90 \mathrm{~min}$ with the two cell lines transiently transfected with GFP-hSERT, with initial 5-HT uptake measured at 5, 10, 30, 60 and $90 \mathrm{~min}$. It was expected that MDMA would cause a rapid and sustained decrease in 5-HT uptake as previous cell surface biotinylation and a microscopy technique called Total Internal Reflection Fluorescence microscopy (TIRFM) studies have shown that SERT is internalized after MDMA treatment (Kivell et al. 2010). Indeed, HEK293 cells transfected with GFP-hSERT displayed a significant decrease in 5-HT uptake (4763\%) following MDMA treatment in a rapid (within $5 \mathrm{~min}$ ) and sustained (up to $90 \mathrm{~min}$ ) manner. However $\mathrm{N}_{2} \mathrm{~A}$ cells transiently transfected with GFP-hSERT, MDMA treatment caused a significant decrease in 5-HT uptake compared to vehicle treated cells (43\%) at 5 and 10 minute (Figure 4:2B). 5-HT uptake was returned to levels comparable to vehicle treated cells with longer incubation times (30,60 and $90 \mathrm{~min}$ ). It is unclear why $\mathrm{N}_{2} \mathrm{~A}$ cells only show a change in SERT function after a short incubation with MDMA whereas HEK-293 cells show a sustained decrease in SERT function after MDMA treatment. This suggests that SERT may be differentially regulated in $\mathrm{N}_{2} \mathrm{~A}$ cells compared to HEK-293 cells with the activation of certain signaling cascades having variable sensitivity for MDMA. The level of 
5-HT uptake in $\mathrm{N}_{2} \mathrm{~A}$ cells compared to HEK-293 cells is also markedly different. The amount of 5-HT uptake in $\mathrm{N}_{2} \mathrm{~A}$ cells is apparently half of that that is seen in HEK-293 cells. $\mathrm{N}_{2} \mathrm{~A}$ cells do not transfect with GFP-hSERT to the same expression levels. These differences of 5-HT uptake in the cell lines may be due to the expression of less functional SERT on the cell surface.

Previous studies carried out by our lab have attempted to identify the pathway responsible for MDMA-induced regulation of SERT (Kivell et al. 2010). In particular p38 MAPK was investigated as to its role in MDMA-induced SERT down-regulation. Several studies have identified p38 MAPK as a known regulator of SERT membrane expression (Samuvel et al. 2005; Zhu et al. 2005; Oz et al. 2010). However it was found that p38 MAPK was not activated in response to MDMA treatment in GFP-hSERT transfected HEK-293 cells (Kivell et al. 2010).

There are several studies that show PKC is a regulator of SERT function and that activation of PKC by $\beta$-PMA leads to a decrease in SERT activity (Jayanthi and Ramamoorthy 2005; Jayanthi et al. 2005). Here we show that treatment with $\beta$-PMA for 30 or 60 min causes a decrease in 5-HT uptake in HEK-293 cells transfected with GFP-hSERT. What is interesting is that the same treatment with $\beta$-PMA did not cause a significant decrease in 5-HT uptake in $\mathrm{N}_{2} \mathrm{~A}$ cells expressing GFP-hSERT ( $\mathrm{p}<0.07$ at $30 \mathrm{~min}$ ). It is unclear why $\mathrm{N}_{2} \mathrm{~A}$ cells respond differently to $\beta$-PMA and MDMA treatment, it suggests that these cells are regulated in a different manner compared to HEK-293 cells. Pre-treatment with the PKC inhibitor, Bis I was able to block the decrease in 5-HT uptake caused by MDMA in both cell lines. These preliminary results suggest that MDMA may be regulating SERT function through a PKC signaling system in transfected cell cultures. 


\section{Chapter 5: Investigating the effect MDMA has on the surface expression of SERT in a cell model}

\subsection{Introduction}

In Chapter 4 we present evidence to suggest that MDMA causes a functional down-regulation of SERT in both $\mathrm{N}_{2} \mathrm{~A}$ and HEK-293 cells using RDEV methods. With pre-treatment of a PKC inhibitor, however, this functional down-regulation was blocked. To the best of our knowledge PKC is part of the first signaling pathway to be identified in playing a role in MDMA-mediated SERT regulation. Previous studies have shown that MDMA treatment and PKC activation results in a down-regulation of SERT function. This has been shown to be by a decrease in SERT surface expression through internalization (Jayanthi et al. 2005; Kivell et al. 2010). Kinetic data obtained using RDEV techniques gives detailed information about Michaelis-Menton kinetics. RDEV is able to show whether a change in 5-HT uptake is due to a change in affinity of a substrate for a transporter $\left(\mathrm{K}_{\mathrm{m}}\right)$ or due to a change in cell surface expression or modulation of the transporter by post-translational modifications $\left(\mathrm{V}_{\max }\right)$ (Earles and Schenk 1998; Chen et al. 1999).

Radioactive uptake studies are commonly used to provide information on transporter kinetics and densities, however limitations of using such a technique include the inability to measure monoamine uptake in real time or provide data on initial uptake kinetics. High-speed chronoamperometry (HSC) and fast scan cyclic voltammetry (FSCV) are able to provide kinetically resolved, real-time information for both in vivo and in vitro neurotransmitter events; however, they are technically challenging and require expensive, specialized equipment. RDEV is able to provide real-time, high temporal resolution measurements (can take up to 1000 measurements per second) in both cell suspensions and tissue homogenates expressing monoamine transporters. A very recent study published during the course of this study characterized RDEV technique for the measurement of SERT function. Mouse whole brain synaptosomes were used to show the difference in SERT kinetics between wild-type and SERT-knock-out mice. Wild-type mice displayed a higher uptake rate than the homozygous or heterozygous knockouts, with uptake being inhibited by the selective serotonin reuptake inhibitor (SSRI) paroxetine hydrochloride (Hagan et al. 2010). This study elegantly showed that in tissue samples, RDEV can be used to sensitively measure the difference in 5-HT uptake rate between the three mouse genotypes. Radioactive uptake 
methods could not distinguish differences in SERT function between heterozygous SERT knockout mice and wild-type mice (Bengel et al. 1998).

In this study we use cell surface biotinylation and Total Internal Reflection Fluorescence microscopy techniques (TIRFM) in conjunction with functional kinetic data to establish whether the MDMA-induced down-regulation of SERT seen in Chapter 4 was due to changes in cell surface expression.

Cell surface biotinylation is an established biochemical technique routinely used to measure the change in cell surface expression of monoamine transporters (Bolan et al. 2007; Zapata et al. 2007). Recently, published data from our lab used cell surface biotinylation techniques to show that MDMA (10 $\mu \mathrm{g} / \mathrm{mL}$ ) induces a rapid (within $5 \mathrm{~min}$ ) and sustained (up to $90 \mathrm{~min}$ ) decrease of GFP-hSERT from the cell surface fraction (24\%) with a corresponding increase in the intracellular fraction (30\%). Activation of PKC by $1 \mu \mathrm{M}$ of $\beta$-PMA for 30 min was sufficient to cause a $23 \%$ decrease in the cell surface fraction with a corresponding increase of $30 \%$ in the intracellular fraction. This was shown in both $\mathrm{N}_{2} \mathrm{~A}$ and HEK-293 cells (Kivell et al. 2010). Using biotinylated whole cell extracts of transfected HeLa cells it has been shown that $\beta$-PMA is able to alter SERT cell surface density (Prasad et al. 2005). HeLa cells transiently expressing hSERT with $10 \mu \mathrm{M}$ of $\beta$-PMA for 15 min was sufficient to cause a $40 \%$ down-regulation of 5-HT transport activity (Prasad et al. 2005). This down-regulation was also blocked with the PKC inhibitor Bis I. Cell surface biotinylation of SERT from rat platelets has also shown that a 30 min exposure to $\beta$-PMA causes a $80 \%$ reduction in surface SERT, with a corresponding increase in the intracellular fraction (Jayanthi et al. 2005). This effect was blocked by $250 \mathrm{nM}$ of the PKC inhibitor Bis I.

Even though cell surface biotinylation studies have been successfully used to investigate cell surface changes, as outlined above, it must be recognized that there are limitations to this technique. Cell surface biotinylation measures changes in a pool of heterologous cells, and so the sensitivity of this technique can be questioned if the cells are not all consistently expressing the same amount of SERT protein. This can lead to variable results over different dishes and between different cell lines. A study conducted by Furman et al. (2009) illustrated that as biotin has access to only the proteins found on the outer cell surface membrane and any protein located within cell membrane invaginations would be left unbound. This could invariably lead to the internal fraction of the biotinylation being larger than what it really is, 
as the proteins would be counted as intracellular rather than cell surface. This is why this technique is often partnered with sensitive microscopy techniques, such as TIRFM.

Previous studies with HEK-293 cells have successfully used TIRFM to show that GFPhSERT cell surface expression is decreased upon MDMA exposure (Kivell et al. 2010). Furman et al. (2009) have also shown that $\mathrm{N}_{2} \mathrm{~A}$ cells stably expressing a yellow fluorescent tagged- dopamine transporter (DAT) respond to dopamine and amphetamine by increasing cell surface expression of YFP-hDAT. These studies demonstrate how TIRFM can be used as a sensitive technique to measure and monitor cell surface expression of fluorescentlytagged proteins in live cells. TIRFM is a microscopy technique where the laser beam used to excite the fluorescent tag is bent greater than the critical angle of the sample. This results in an evanescent field of $100 \mathrm{~nm}$ from the point of laser-focus which excites any fluorescent molecules within it. This represents the proteins found at the cell surface. The critical angle is defined by:

$\theta_{\mathrm{c}}=\sin ^{-1}\left(\mathrm{n}_{1} / \mathrm{n}_{3}\right)$

From this equation, the critical angle is given by $\theta_{c}$, where the refractive index of the liquid is $\mathrm{n}_{1}$ and the refractive index of the solid is $\mathrm{n}_{3}$ (the solid is taken as the glass bottom of the dish) (Axelrod 2001). When the TIRF angle is greater than the critical angle the laser beam is entirely internally reflected rather than refracted through the sample. This generates images that have very low background fluorescence (compared to images acquired with just epifluorescence) and much greater detail. The unique features of TIRFM allow it to be a useful technique for measuring changes in cell surface expression of live cells that contain fluorescent membrane proteins. Since the evanenscent field is only set to a $100 \mathrm{~nm}$ penetration depth, this allows visualization of any trafficking/movement of the fluorophores from the membrane to the cytosol, or vice versa.

The aim of using this technique was to exploit the high temporal and spatial resolution of TIRFM in order to investigate the dynamics of SERT trafficking upon MDMA and $\beta$-PMA application. This technique was used as a more sensitive measure to couple with the results gained from the cell surface biotinylation experiments. 


\subsection{Aim}

We hypothesize that the MDMA-induced down-regulation of SERT is PKC-dependent. To test this we treated HEK-293 and $\mathrm{N}_{2} \mathrm{~A}$ cells transfected with GFP-hSERT with a PKC inhibitor, Bis I, and measured changes in cell surface expression using RDEV kinetic data, cell surface biotinylation and TIRFM. 


\subsection{Results}

\subsubsection{Determination of SERT kinetics in cells transfected with GFP-hSERT following MDMA treatment.}

Control experiments were carried out using non-transfected HEK-293 (Figure 5:1) and $\mathrm{N}_{2} \mathrm{~A}$ cells (Figure 5:3). These experiments help to determine the non-specific decay or uptake of 5-HT in the system. For HEK-293 cells, the baseline uptake was linear, with the slope of the line equaling $6.31 \mathrm{pmol} / \mathrm{s} / 10^{6}$ cells $\left(\mathrm{r}^{2}=0.9235\right)$. Kinetic data obtained for HEK-293 cells expressing GFP-hSERT subsequently had the non-specific baseline uptake subtracted. The specific uptake curve for these cells followed Michaelis-Menten kinetics (Figure 5:2) with an average $\mathrm{V}_{\max }$ of $108.3 \pm 33.5 \mathrm{pmol} / \mathrm{s} / 10^{6}$ cells and a $\mathrm{K}_{\mathrm{m}}$ of $3.3 \pm 1.6 \mu \mathrm{M}$ (Table $5: 1$ ).

Kinetic data was obtained from HEK-293 cells transfected with GFP-hSERT following a 5 min incubation with MDMA $\left(10 \mu \mathrm{g} / \mathrm{mL}\right.$ ) (Figure 5:2) and gave an average $V_{\max }$ of $87.6 \pm$ $43.1 \mathrm{pmol} / \mathrm{s} / 10^{6}$ cells and $\mathrm{a} \mathrm{K}_{\mathrm{m}}$ of $5.7 \pm 3.7 \mu \mathrm{M}$ (Table $5: 1$ ). Surprisingly there was no significant difference between the $\mathrm{K}_{\mathrm{m}}$ and $\mathrm{V}_{\max }$ values between the controls vs. MDMAtreated cells. This suggests that change in 5-HT transport was not due to a cell surface downregulation of SERT.

In non-transfected $\mathrm{N}_{2} \mathrm{~A}$ cells, the baseline decay slope to determine the non-specific uptake of the system was unusual in that it generated a sigmoidal curve rather than the linear uptake seen in HEK-293 cells (Figure 5:3). Interestingly when kinetic data was gathered for GFPhSERT transfected $\mathrm{N}_{2} \mathrm{~A}$ cells, 5-HT uptake did not follow the Michaelis-Menton curve as is expected for monoamine transporters (Figure 5:3). Again this data was better fitted to a sigmoidal curve rather than the traditional Michaelis-Menten hyperbole curve. This sigmoidal curve was also found for transfected $\mathrm{N}_{2} \mathrm{~A}$ cells treated with MDMA for 5 min (Figure 5:4). This was an interesting finding, and due to lack of previous studies carried out in $\mathrm{N}_{2} \mathrm{~A}$ cells using RDEV techniques, $\mathrm{V}_{\max }$ and $\mathrm{K}_{\mathrm{m}}$ values could not be obtained. 
จ Transfected

- Specific

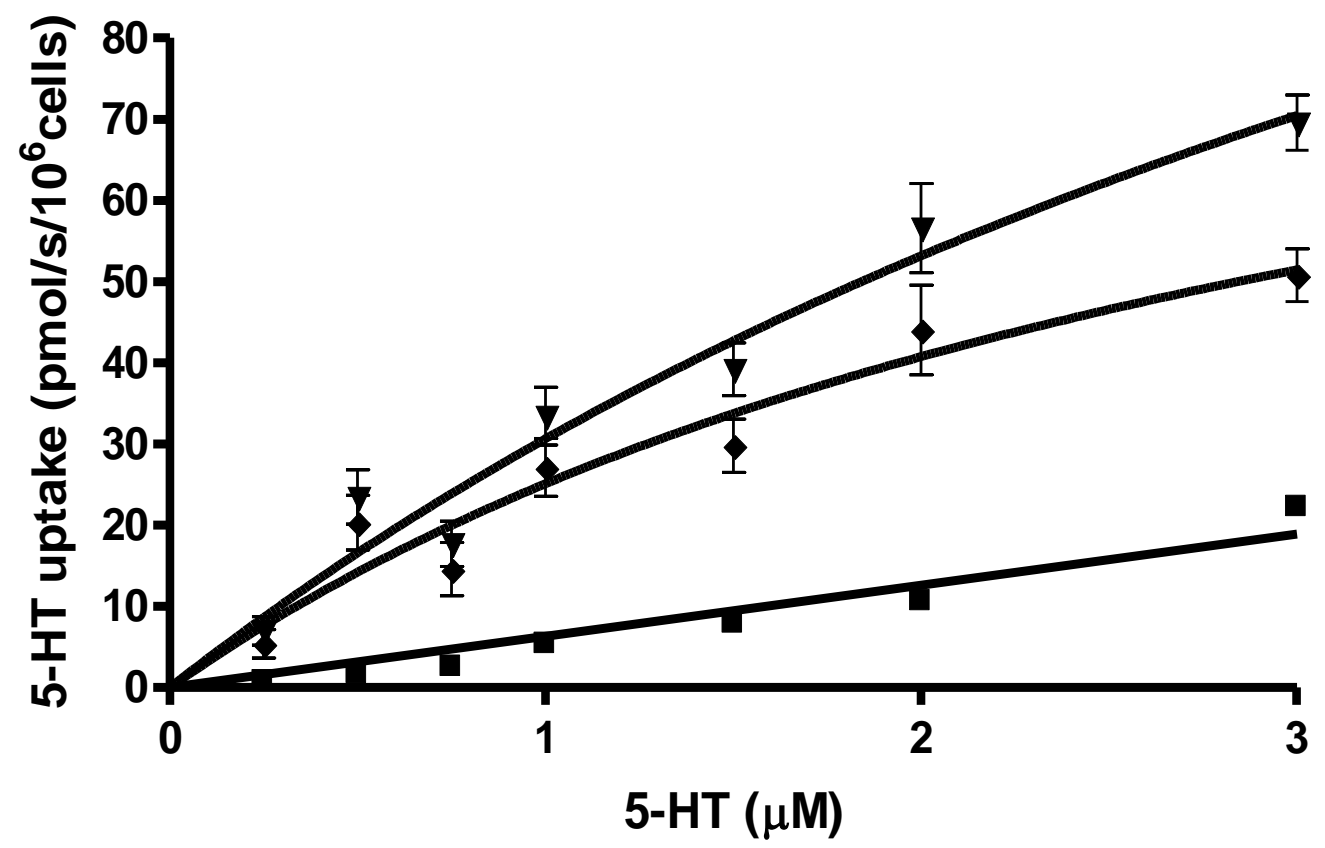

- Non-transfected

Figure 5:1: Uptake of 5-HT in non-transfected and GFP-hSERT transfected HEK-293 cells.

Single additions of 5-HT were used to treat non-transfected and GFP-hSERT transfected HEK-293 cells. The initial uptake was then measured. Uptake from non-transfected cells (non-specific uptake) was subtracted from transfected cells to give specific 5-HT uptake by GFP-hSERT. Data points represent the mean \pm SEM $(n=1$, non-transfected, $n=3-5$, transfected cell preparations). 


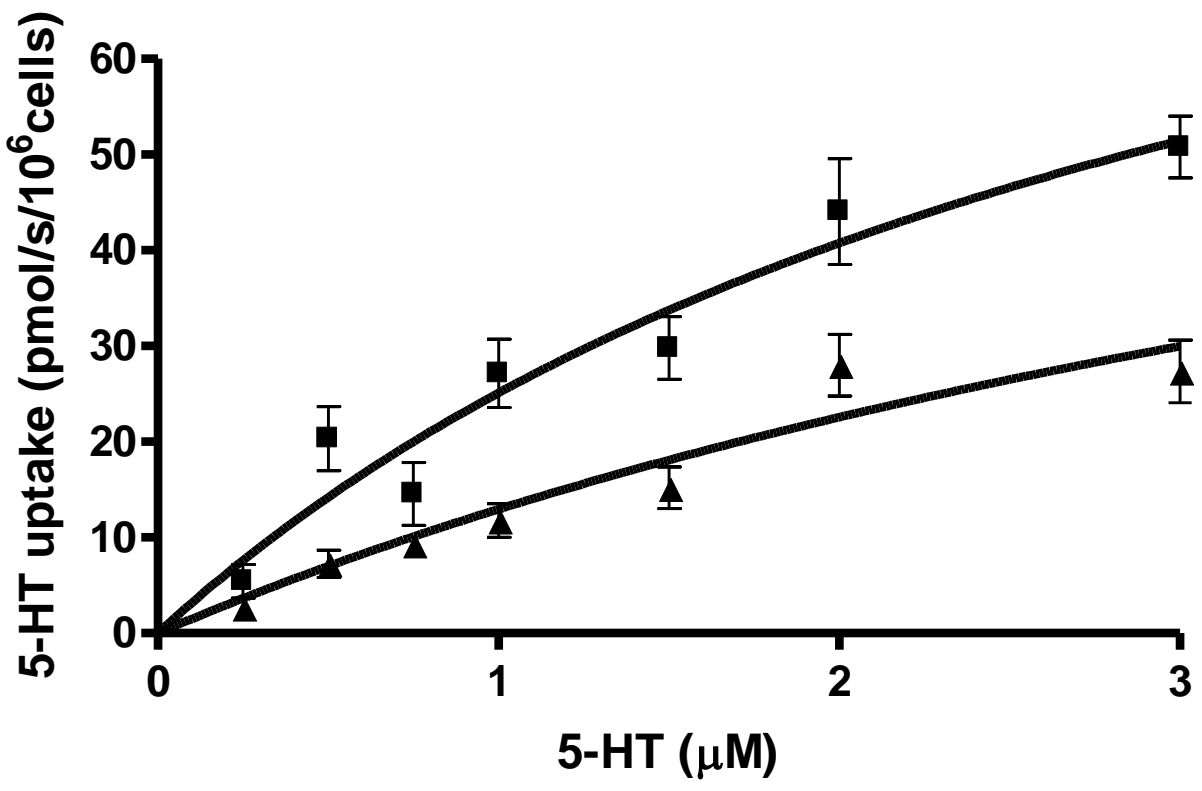

- Control

$\triangle$ MDMA

Figure 5:2: The effect of MDMA on SERT function in HEK-293 cells transiently transfected with GFP-hSERT.

MDMA $(10 \mu \mathrm{g} / \mathrm{mL})$ was added to cells 5 min before 5-HT uptake was measured by RDEV. Single additions of 5-HT were used to treat GFP-hSERT HEK-293 cells. Data points are mean $\pm \operatorname{SEM}(n=3-5$ preparations $)$.

Table 5:1: Kinetic data from RDEV for control and MDMA treated cells.

Values are the mean \pm SEM ( $\mathrm{n}=3-5$ preparations). No significant difference was found in the values between control vs. MDMA-treated cells as shown by Student t-test.

\begin{tabular}{lll}
\hline Treatment & $\mathbf{V}_{\max }\left(\mathbf{p m o l} / \mathbf{s} / \mathbf{1 0}^{\mathbf{6}}\right.$ cells $)$ & $\mathbf{K}_{\mathbf{m}}(\boldsymbol{\mu} \mathbf{M})$ \\
\hline Control & $108.3 \pm 33.5$ & $3.3 \pm 1.6$ \\
MDMA & $87.6 \pm 43.1$ & $5.7 \pm 3.7$
\end{tabular}


- Transfected

- Specific

- Non-transfected

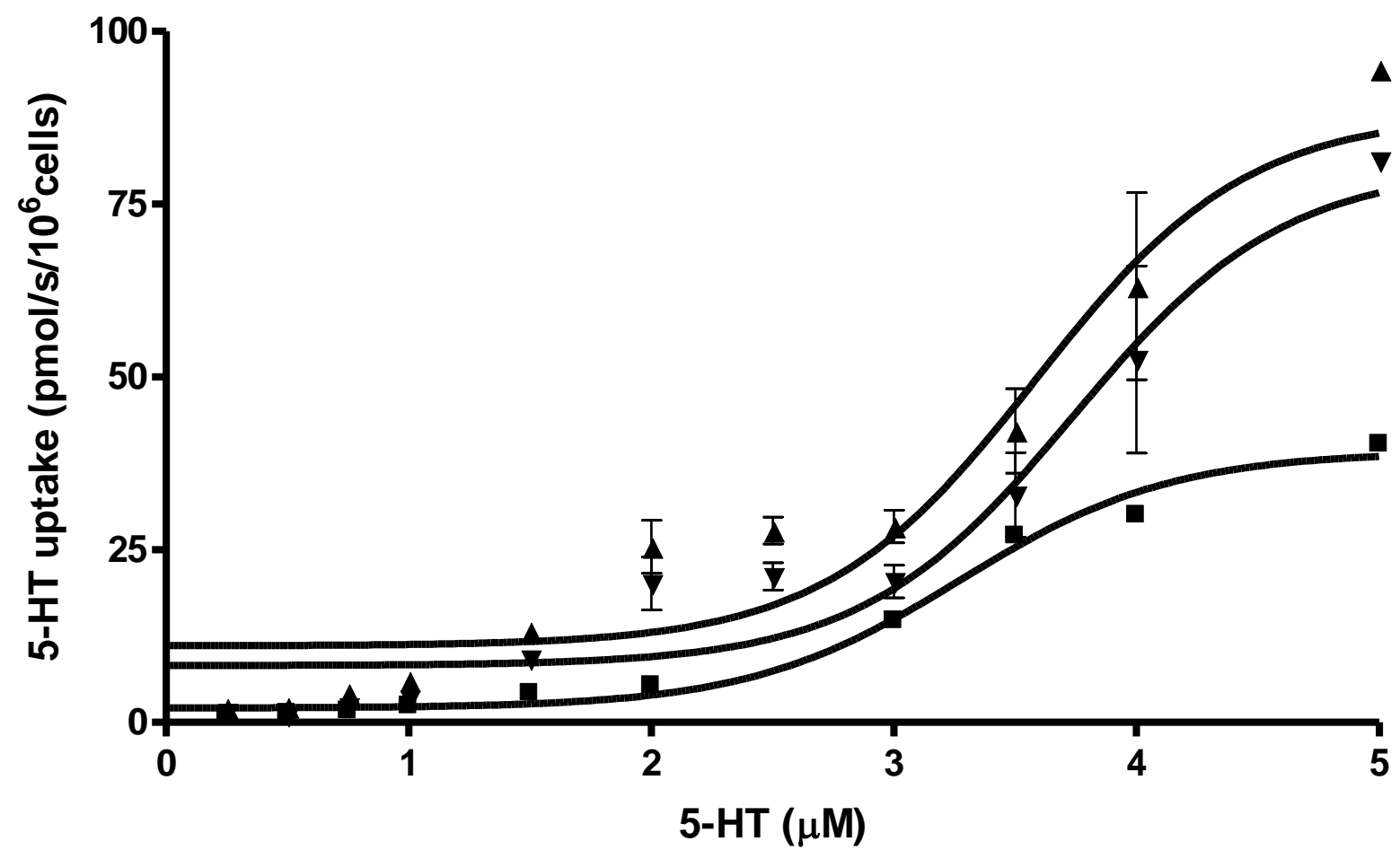

Figure 5:3: Uptake of 5-HT in non-transfected and GFP-hSERT transfected $\mathrm{N}_{2} A$ cells.

Single additions of 5-HT were used to treat non-transfected and GFP-hSERT transfected $\mathrm{N}_{2} \mathrm{~A}$ cells. The initial decay/uptake was then measured. Uptake from non-transfected cells (nonspecific decay) was subtracted from transfected cells to give the specific initial uptake of 5HT by GFP-hSERT. Data points represent the mean \pm SEM $(n=1-2$, non-transfected, $n=3$ 6 , transfected cell preparations). 


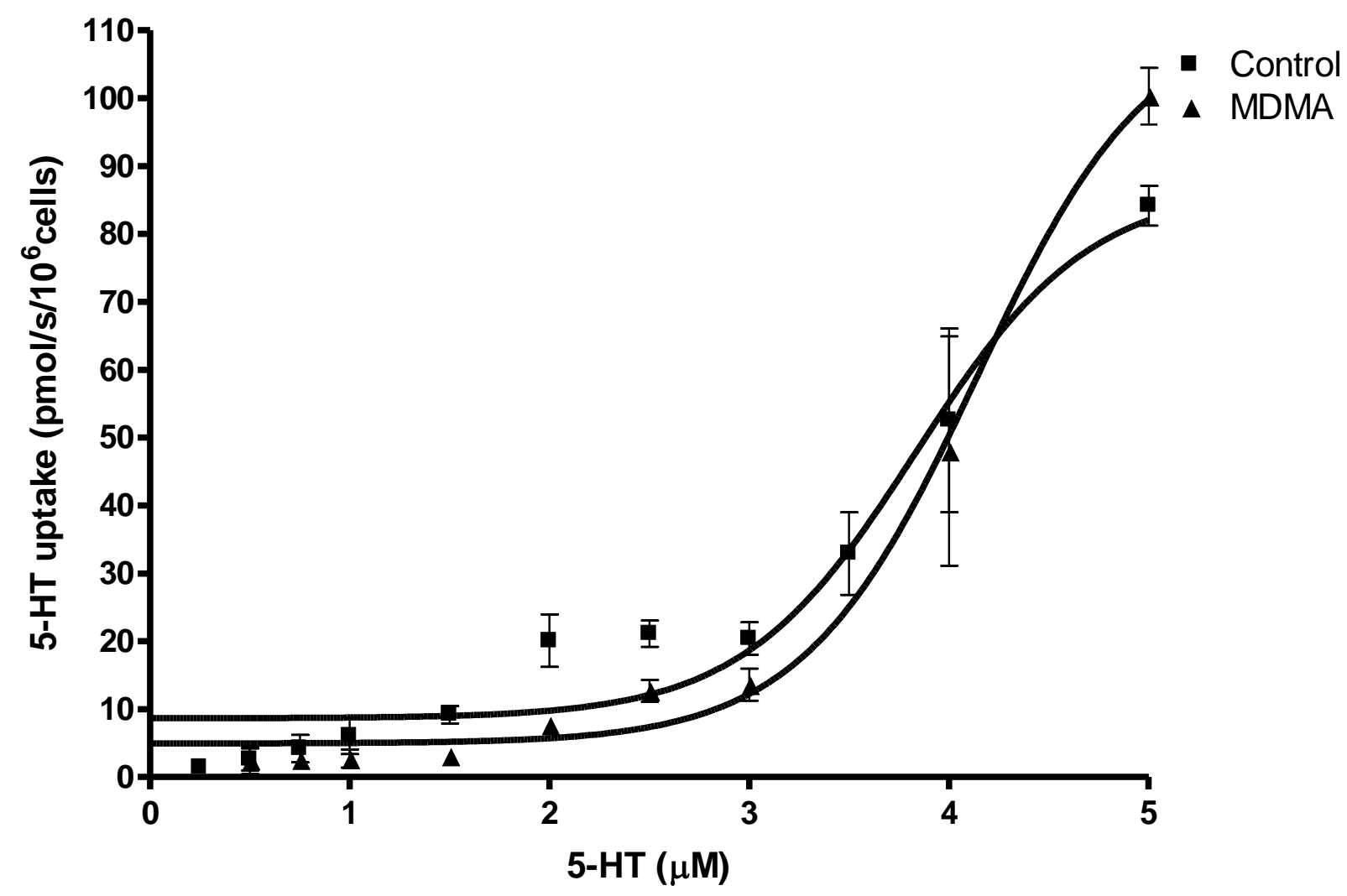

Figure 5:4: The effect of MDMA on SERT function in $\mathrm{N}_{2} \mathrm{~A}$ cells transiently transfected with GFP-hSERT.

MDMA $(10 \mu \mathrm{g} / \mathrm{mL})$ was added to cells 5 min before uptake was measured by RDEV. Single additions of 5-HT were used to treat GFP-hSERT $\mathrm{N}_{2}$ A cells Data points are mean \pm SEM ( $\mathrm{n}$ $=2-6$ preparations). 


\subsubsection{Cell surface biotinylation}

\subsubsection{SERT Trafficking in Response to MDMA and PKC Activation}

HEK-293 and $\mathrm{N}_{2}$ A cells transfected with GFP-hSERT were incubated with $10 \mu \mathrm{g} / \mathrm{mL}$ of MDMA to investigate changes in cell surface expression of SERT. The mean band intensity was measured for each fraction to give a value for GFP-hSERT. The values for each treatment were then normalized back to the vehicle-treated control, with the results shown as a fold change compared to vehicle.

HEK-293 cells transfected with GFP-hSERT were treated with $10 \mu \mathrm{g} / \mathrm{mL}$ of MDMA for either 10 or $60 \mathrm{~min}$ (Figure 5:5). As shown by RDEV in the previous chapter, there is a functional down-regulation of SERT at these time points. It is surprising then, that cell surface biotinylations did not show a significant decrease in the cell surface fraction of GFPhSERT as predicted, indicating that SERT was not being internalized.

Previous work from our lab showed that, in $\mathrm{N}_{2} \mathrm{~A}$ cells, MDMA is able to cause a rapid (with $5 \mathrm{~min}$ ) and sustained (up to $90 \mathrm{~min}$ ) decrease of GFP-hSERT (Kivell et al. 2010). Interestingly, functional data obtained from RDEV in the previous chapter shows that there is only a significant change in SERT function with a 5 or 10 min incubation with MDMA. Dishes were therefore incubated with $10 \mu \mathrm{g} / \mathrm{mL}$ of MDMA for 5, 10 or $60 \mathrm{~min}$ in order to see if there would be difference in surface expression of SERT at these time points. Surprisingly, cell surface biotinylations did not show a significant change in GFP-hSERT at any of the time points (Figure 5:6). 

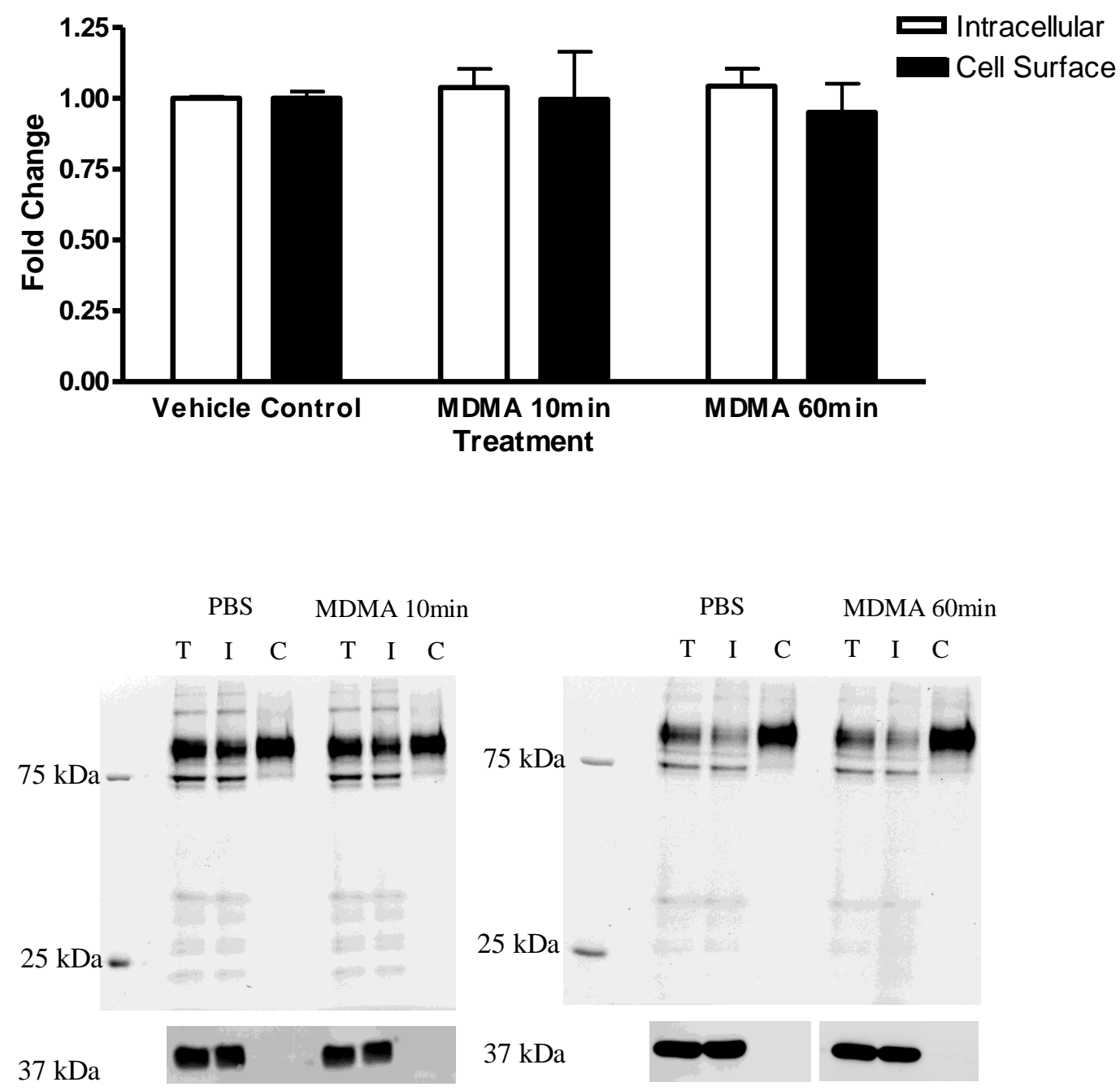

Figure 5:5: No change seen in GFP-hSERT cell surface fraction following MDMA treatment in HEK-293 cells.

HEK-293 cells were treated with $10 \mu \mathrm{g} / \mu \mathrm{L}$ of MDMA for $10 \mathrm{~min}$ or $60 \mathrm{~min}$. There was no detectable change in cell surface expression after either MDMA treatment. The vehicle control used was PBS. Shown is a representative gel and Western blot for GFP-hSERT and GAPDH respectively. $\mathrm{T}=$ total fraction, $\mathrm{I}=$ intracellular fraction, $\mathrm{C}=$ cell surface fraction $(\mathrm{n}$ = 4-24). Data is presented as average \pm SEM. One-way ANOVA followed by Bonferroni post test showed no significant differences from the control. 

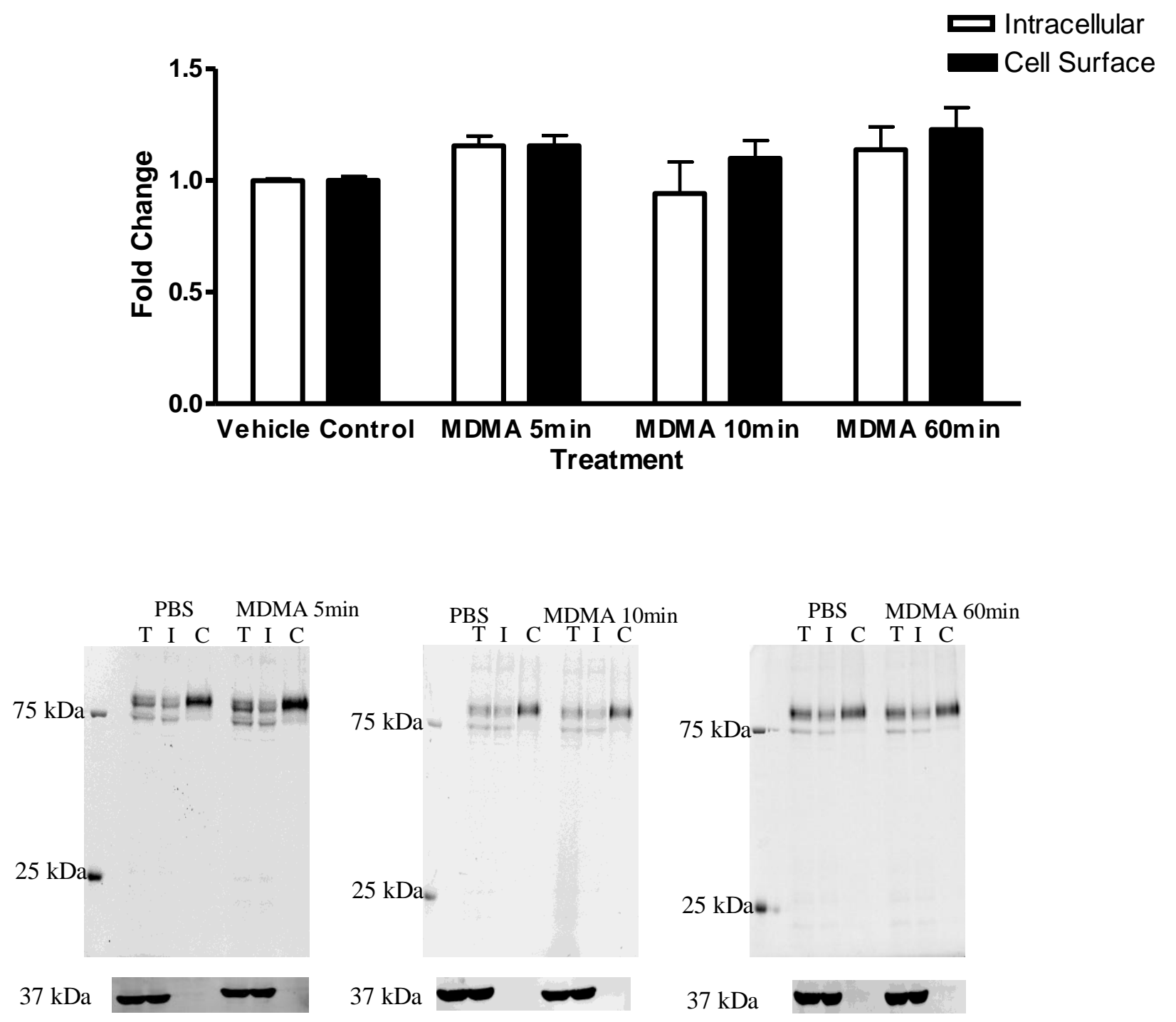

Figure 5:6: No change seen in GFP-hSERT cell surface fraction after MDMA treatment in $\mathbf{N}_{2} \mathrm{~A}$ cells.

$\mathrm{N}_{2} \mathrm{~A}$ cells were treated with $10 \mu \mathrm{g} / \mathrm{mL}$ of MDMA for 5,10 or $60 \mathrm{~min}$. There was no detectable change in cell surface expression with any of the treatments. The vehicle control used was PBS. Shown is a representative gel for GFP-hSERT with an accompanying Western blot for GAPDH below. $\mathrm{T}=$ total fraction, $\mathrm{I}=$ intracellular fraction, $\mathrm{C}=$ cell surface fraction $(n=4-17)$. Data is presented as average \pm SEM. One-way ANOVA followed by Bonferroni post test showed no significant differences from the control. 
Cell surface biotinylation of transfected HEK-293 and $\mathrm{N}_{2}$ A cells treated with the PKC activator $\beta$-PMA for $30 \mathrm{~min}$ did not show a significant decrease of GFP-hSERT from the cell surface fraction (Figure 5:7 and Figure 5:8 respectively). Multiple batches of $\beta$-PMA were tested as concern arose over the integrity of the stock solution. However no significant decrease was seen of GFP-hSERT from the cell surface for either HEK-293 or $\mathrm{N}_{2} \mathrm{~A}$ cells after treatment with new $\beta$-PMA for 30 min (Figure 5:7 and Figure 5:8 respectively). $\mathrm{N}_{2} \mathrm{~A}$ cells transfected with GFP-hSERT were treated for 20 min with $\beta$-PMA in case the time point of maximal activity was being missed, and was occurring earlier. Figure 5.8 shows that no significant change in GFP-hSERT cell surface expression was seen.

Activation of PKC by $\beta$-PMA requires an increased level of intracellular calcium (Samuvel et al. 2005). $\mathrm{N}_{2} \mathrm{~A}$ cells expressing GFP-hSERT were treated with $5 \mu \mathrm{M}$ of ionomycin and $1 \mu \mathrm{M}$ of $\beta$-PMA for $30 \mathrm{~min}$. Ionomycin is a compound that increases the levels of intracellular calcium. This treatment caused a significant $(\mathrm{p}<0.001) 35 \%$ decrease of GFP-hSERT from the cell surface fraction compared to control (Figure 5.8).

Due to time constraints, ionomycin and $\beta$-PMA treatment was not carried out on HEK-293 cells. 

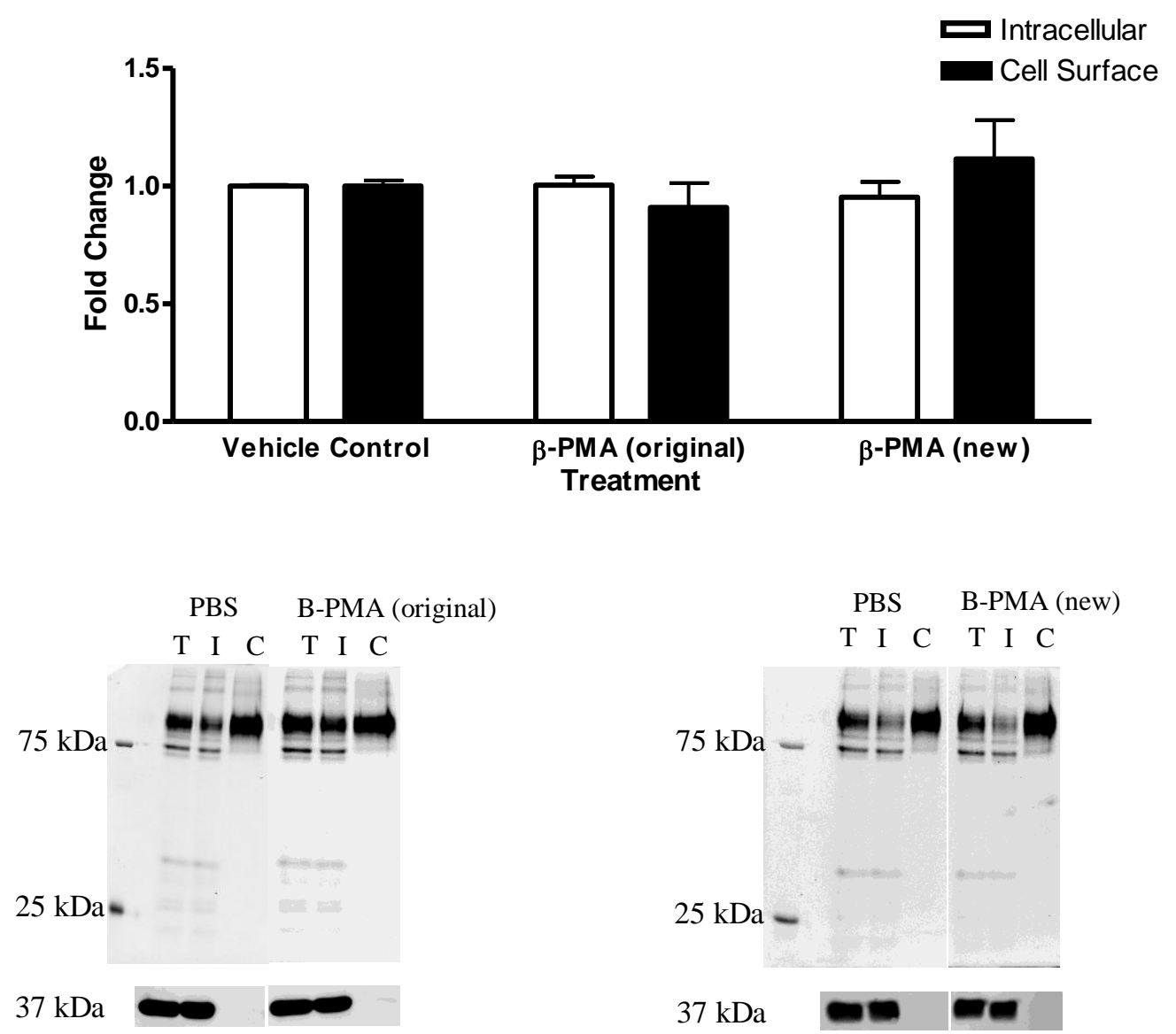

Figure 5:7: No change seen in GFP-hSERT cell surface fraction after $\beta$-PMA treatment in HEK-293 cells.

HEK-293 cells were treated with $1 \mu \mathrm{M}$ of either original or new $\beta$-PMA solution for $30 \mathrm{~min}$. There was no detectable change in cell surface expression after either $\beta$-PMA treatment compared to vehicle (PBS) treated controls. Shown is a representative gel for GFP-hSERT and Western blot of GAPDH below. $\mathrm{T}=$ total fraction, $\mathrm{I}=$ intracellular fraction, $\mathrm{C}=$ cell surface fraction $(n=4-24)$. Data is presented as average \pm SEM. One-way ANOVA followed by Bonferroni post test showed no significant differences from the control. 


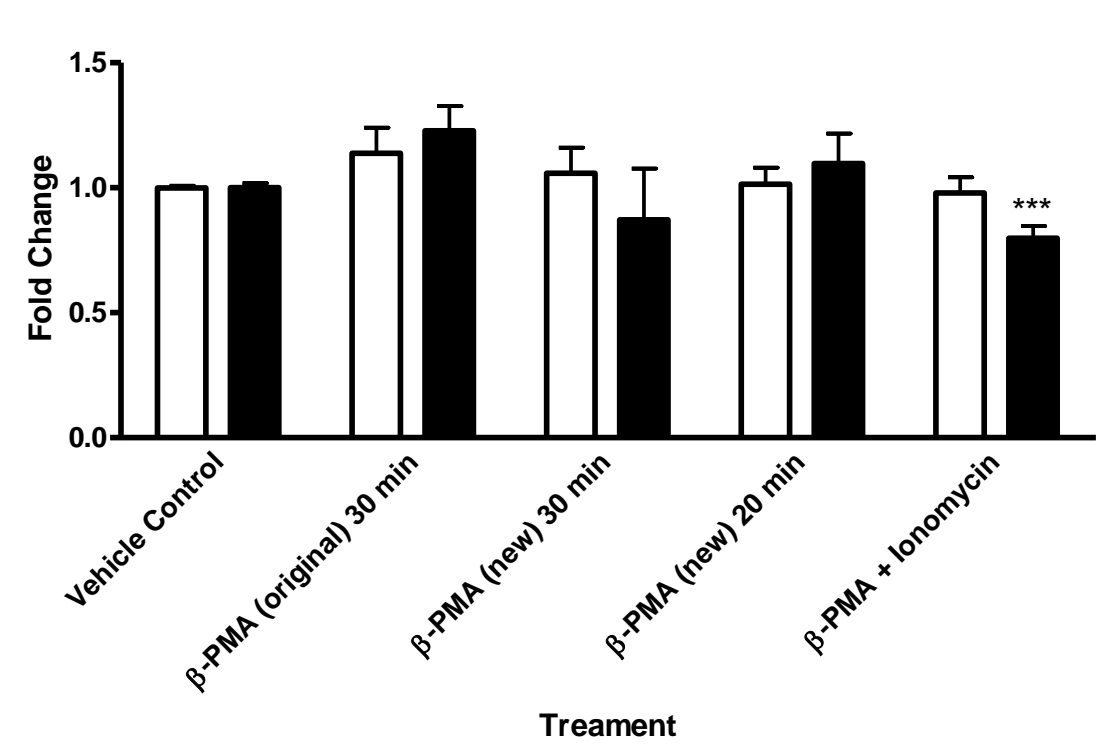

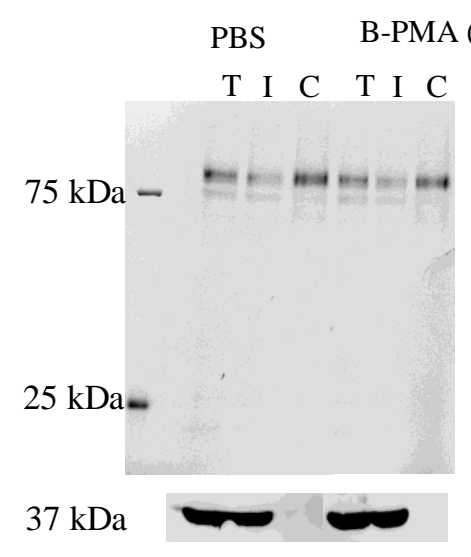

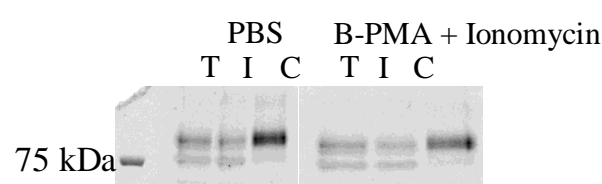

$37 \mathrm{kDa}$

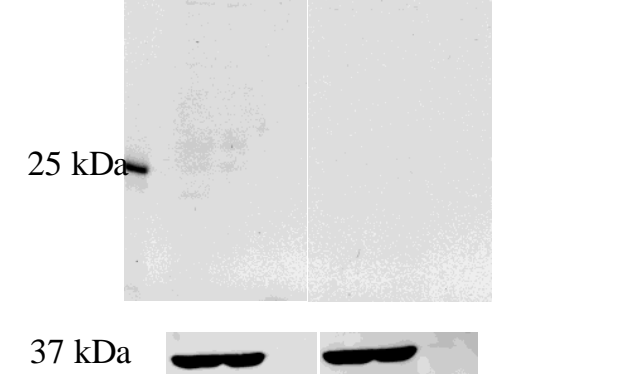

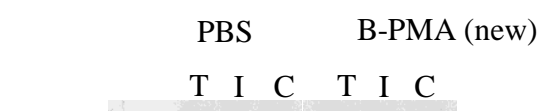

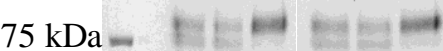

$25 \mathrm{kDa}-$

$37 \mathrm{kDa}$

PBS B-PMA (new) $20 \mathrm{~min}$

T I C $\quad \mathrm{T}$ I $\mathrm{C}$

$75 \mathrm{kDa}-$

$25 \mathrm{kDa}$

$37 \mathrm{kDa}$

-

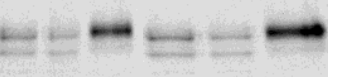

Intracellular

Cell Surface 
Figure 5:8: No change in GFP-hSERT cell surface fraction after $\beta$-PMA treatment in $\mathrm{N}_{2} \mathrm{~A}$ cells but significant decrease after treatment with Ionomycin and $\beta$-PMA.

A significant decrease in GFP-hSERT surface expression was seen upon treatment with Ionomycin and $\beta$-PMA. $\mathrm{N}_{2} \mathrm{~A}$ cells were treated with $1 \mu \mathrm{M}$ of either two batches (original and new) $\beta$-PMA solution for $20 \mathrm{~min}$ or $30 \mathrm{~min}$. There was no detectable change in cell surface expression with any $\beta$-PMA treatment. $\mathrm{N}_{2} \mathrm{~A}$ cells were also treated simultaneously with 5 $\mu \mathrm{M}$ of Ionomycin and $1 \mu \mathrm{M}$ of $\beta$-PMA for $30 \mathrm{~min}$. There was a significant $35 \%$ decrease of GFP-hSERT from the cell surface fraction using a One-way ANOVA followed by Bonferroni post test. The vehicle control used was PBS. Shown is a representative gel for GFP-hSERT and Western blot of GAPDH below. $\mathrm{T}=$ total fraction, $\mathrm{I}=$ intracellular fraction, $\mathrm{C}=$ cell surface fraction $(\mathrm{n}=4-17)$. Data is presented as average \pm SEM. $* * * \mathrm{p}<0.001$. 


\subsubsection{SERT Trafficking in Response to Simultaneous PKC Inhibition and MDMA}

To determine if MDMA works through a PKC-dependent pathway, both HEK-293 and $\mathrm{N}_{2} \mathrm{~A}$ cells expressing GFP-hSERT were treated for 30 min with the PKC inhibitor, Bis I (200 nM), prior to a 5 min treatment with MDMA $(10 \mu \mathrm{g} / \mathrm{mL})$. No change in GFP-hSERT in either the cell surface or intracellular fraction was seen in HEK-293 cells after treatment with Bis I. Similarly there was no change in GFP-hSERT after $30 \mathrm{~min}$ with Bis I, followed by a $60 \mathrm{~min}$ with MDMA (10 $\mu \mathrm{g} / \mathrm{mL})$ (Figure 5:9).

$\mathrm{N}_{2} \mathrm{~A}$ cells expressing GFP-hSERT were also treated with the PKC inhibitor, Bis I. Pretreatment with Bis I for 30 min was followed by of MDMA $(10 \mu \mathrm{g} / \mathrm{mL})$ treatment for 5 or 60 min showed no detectable change in GFP-hSERT cell surface expression (Figure 5:10). 

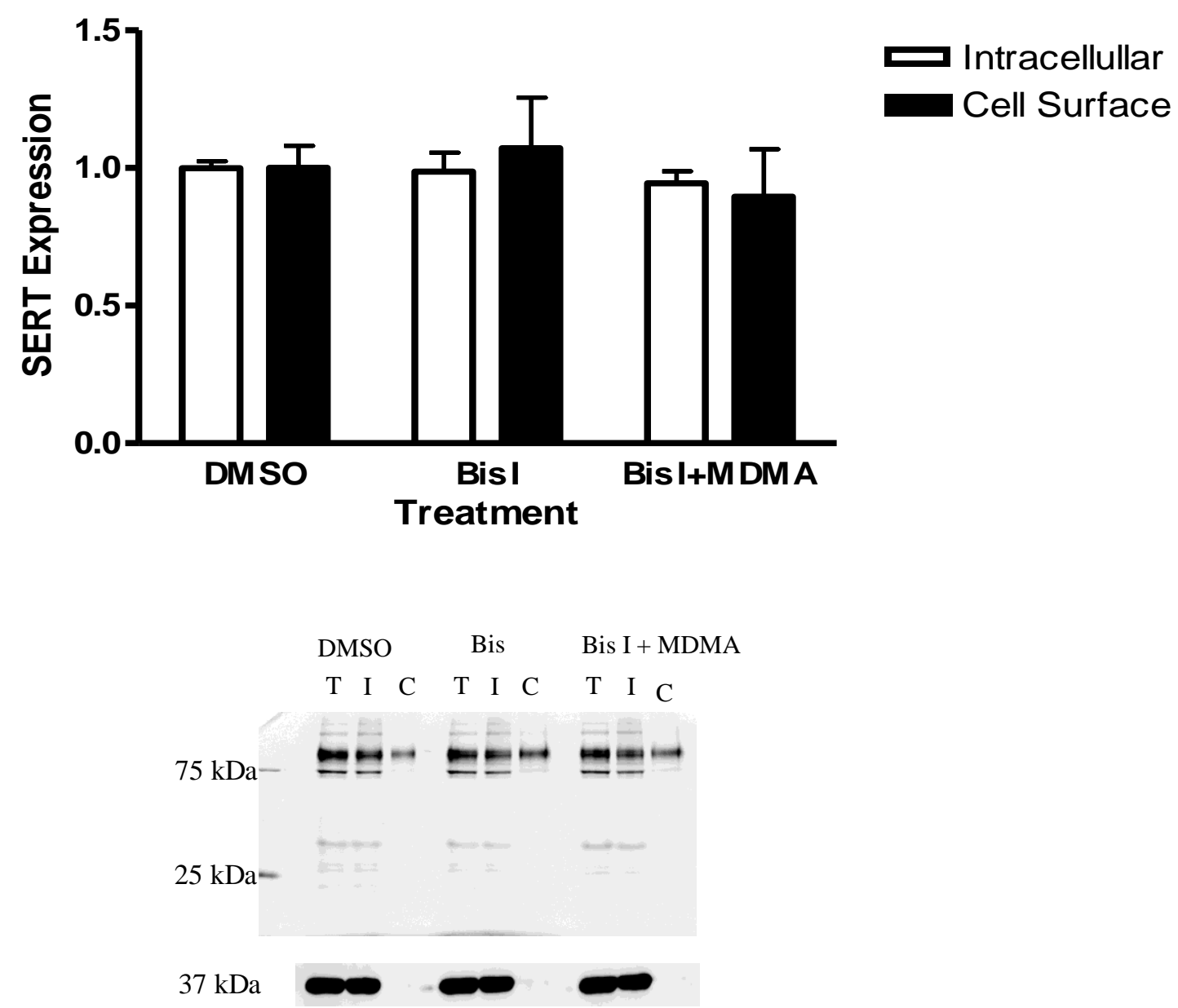

Figure 5:9: No change seen in GFP-hSERT expression after BisI and/or MDMA treatment in HEK-293 cells.

HEK-293 cells were treated with either $200 \mathrm{nM}$ BisI for $30 \mathrm{~min}$, or treated with Bis I followed by MDMA $(10 \mu \mathrm{g} / \mathrm{mL})$ for $60 \mathrm{~min}$. There was no detectable change in cell surface expression after treatment with any of the compounds. DMSO was used as the vehicle control. Shown is a representative gel for GFP-hSERT and Western blot for GAPDH below. $\mathrm{T}=$ total fraction, $\mathrm{I}=$ intracellular fraction, $\mathrm{C}=$ cell surface fraction $(\mathrm{n}=8)$. Data is presented as average \pm SEM. One-way ANOVA followed by Bonferroni post test showed no significant differences from the control. 

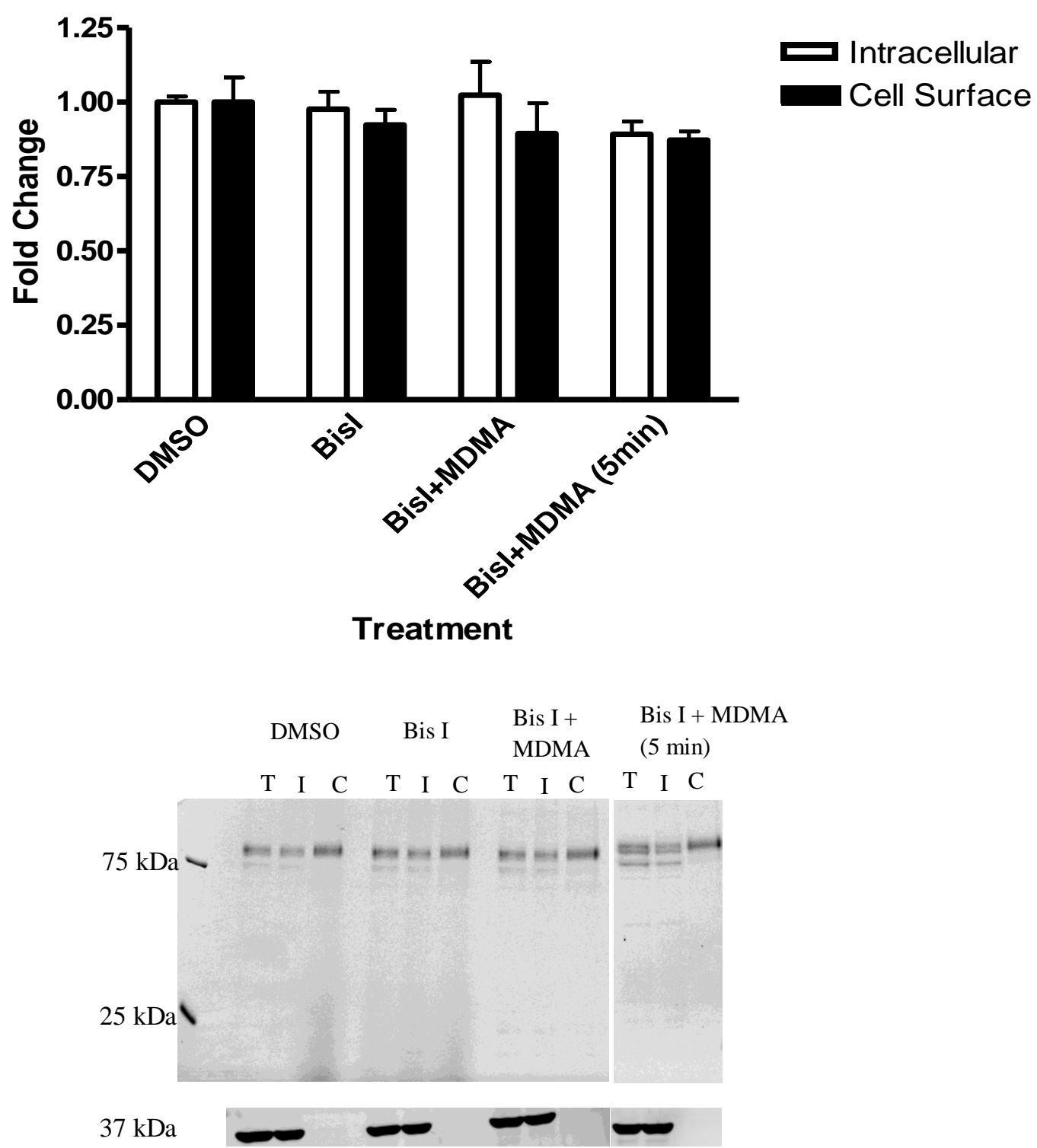

Figure 5:10: No change seen in GFP-hSERT expression following Bis I and/or MDMA treatment in $\mathbf{N}_{2} A$ cells.

$\mathrm{N}_{2}$ A cells were treated with either $200 \mathrm{nM}$ Bis I for $30 \mathrm{~min}$, or with Bis I followed by MDMA $(10 \mu \mathrm{g} / \mathrm{mL})$ for $60 \mathrm{~min}$. There was no detectable change in cell surface expression after treatment with any of the compounds. DMSO was used as the vehicle control. Shown is a representative gel for GFP-hSERT and Western blot for GAPDH below. $\mathrm{T}=$ total fraction, $\mathrm{I}$ $=$ intracellular fraction, $\mathrm{C}=$ cell surface fraction $(\mathrm{n}=4-9)$. Data is presented as average \pm SEM. One-way ANOVA followed by Bonferroni post test showed no significant differences from the control. 


\subsubsection{Total Internal Reflection Fluorescence Microscopy (TIRFM)}

\subsubsection{HEK-293}

\subsection{SERT Trafficking in Response to MDMA}

Due to the limitation regarding the sensitivity of cell surface biotinylation techniques a more sensitive technique was employed called TIRFM. TIRFM experiments were initially carried out for $300 \mathrm{~s}(5 \mathrm{~min})$ with addition of MDMA $(10 \mu \mathrm{g} / \mathrm{mL})$ occurring at $50 \mathrm{~s}$ and images taken every $5 \mathrm{~s}$. Results show that MDMA had no immediate effect on SERT re-distribution during this time course as no change in surface expression was seen after MDMA treatment (Figure $5: 11)$.

\subsubsection{2 $\quad \mathrm{N}_{2} \mathrm{~A}$}

\subsection{SERT Trafficking in Response to MDMA and PKC Activation}

TIRFM experiments were extended to cover a time course of $600 \mathrm{~s}(10 \mathrm{~min})$ to ensure that the time point where MDMA exerts its maximal effect was not being missed. Results obtained from these experiments show that there is a trend towards a decrease in SERT surface expression following MDMA treatment $(10 \mu \mathrm{g} / \mathrm{mL})$ (Figure 5:12). Two-way ANOVA showed that interaction was at statistical significance $(\mathrm{p}<0.0001)$, but time and treatment were both non-significant $(\mathrm{p}<0.7108$ and $\mathrm{p}<0.1208$ respectively). It is interesting that cell surface biotinylation experiments did not show this trend.

Due to the trend seen after MDMA treatment, $\mathrm{N}_{2} \mathrm{~A}$ cells expressing GFP-hSERT were treated with $\beta$-PMA for $30 \mathrm{~min}$. This experiment was carried out before cell surface biotinylation showed that co-treatment with ionomycin and $\beta$-PMA causes a decrease in SERT surface expression (Figure 5.8). TIRFM experiments were carried out for $40 \mathrm{~min}$, with either vehicle or $1 \mu \mathrm{M}$ of $\beta$-PMA added at $10 \mathrm{~min}$ and treatment lasting for $30 \mathrm{~min}$. The results show that there was no significant change in cell surface fluorescence of GFP-hSERT following $\beta$ PMA treatment (Figure 5:13). 

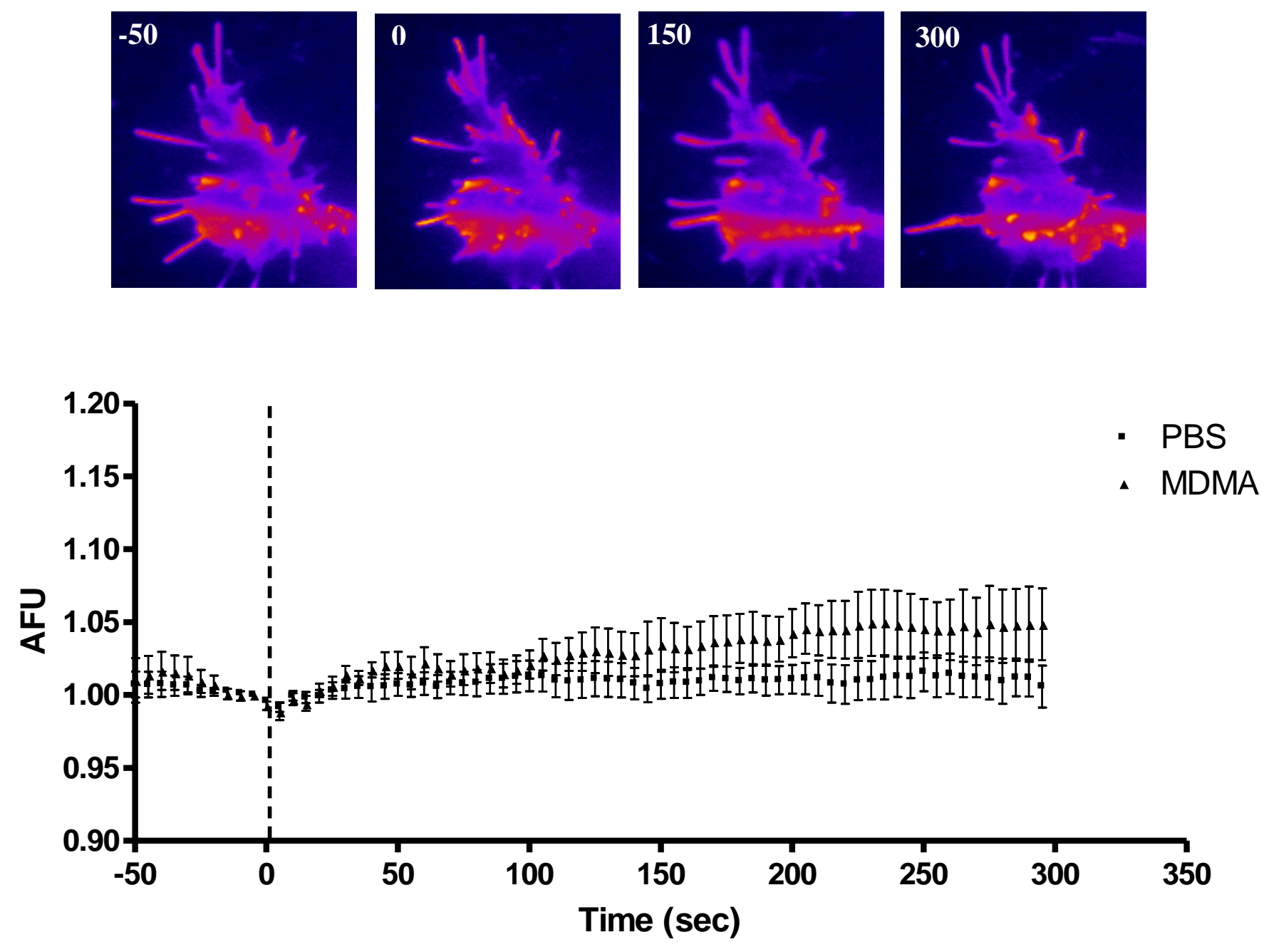

Figure 5:11: MDMA does not significantly alter cell surface expression of GFP-hSERT expressed in HEK-293 cells.

TIRFM was conducted on HEK-293 cells expressing GFP-hSERT. 70 images were taken, 5 $\mathrm{s}$ apart, with MDMA $(10 \mu \mathrm{g} / \mathrm{mL})$ or vehicle being added at time 0 . No detectable changes in cell surface expression was seen $(n=8-9)$. Average fluorescence was measured for each cell captured at each image and normalized back to the image taken at time 0 . Vehicle used was PBS. Data is plotted as the average \pm SEM. Two-way ANOVA followed by Bonferroni post test. Shown is a representative MDMA-treated cell with images taken at -50, 0, 150 and 300 s. $\mathrm{AFU}=$ Arbitrary fluorescence units. 

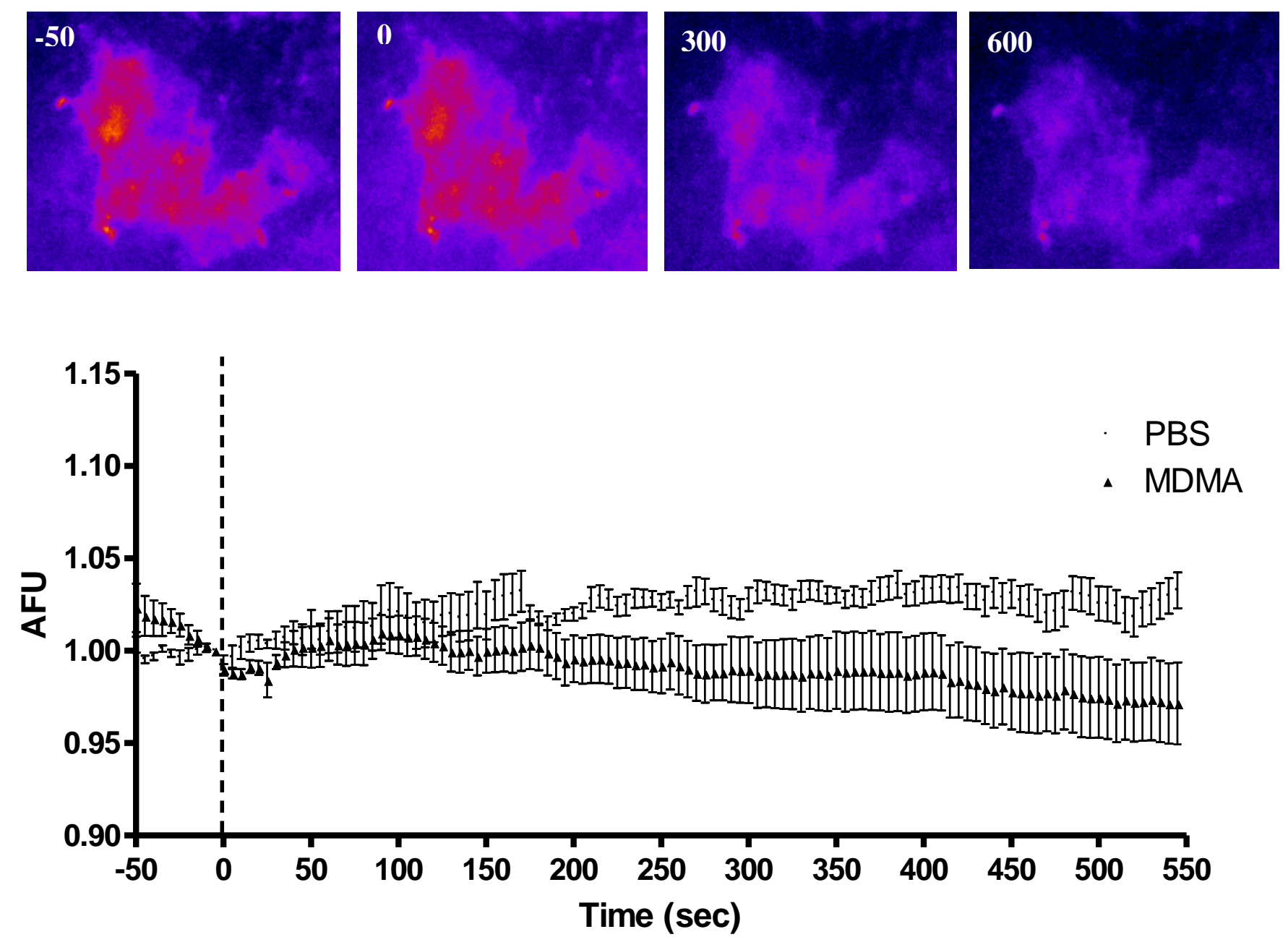

Figure 5:12: Cell Surface Expression of GFP-hSERT during $10 \mathrm{~min}$ incubation with MDMA in $\mathbf{N}_{2} \mathrm{~A}$ cells.

TIRFM was conducted with $\mathrm{N}_{2} \mathrm{~A}$ cells expressing GFP-hSERT. 120 images were taken $5 \mathrm{~s}$ apart, with MDMA $(10 \mu \mathrm{g} / \mathrm{mL})$ or vehicle added at time 0 . There was a trend towards a decrease of GFP-hSERT at the cell surface after MDMA treatment $(n=5-7)$. Average fluorescence was measured for each cell at each image captured and normalized back to the image taken at time 0. Vehicle used was PBS. Data is plotted as the average \pm SEM. Twoway ANOVA followed by Bonferroni post test was. Shown is a representative MDMAtreated cell with images taken at $-50,0,300$ and $600 \mathrm{~s}$. 

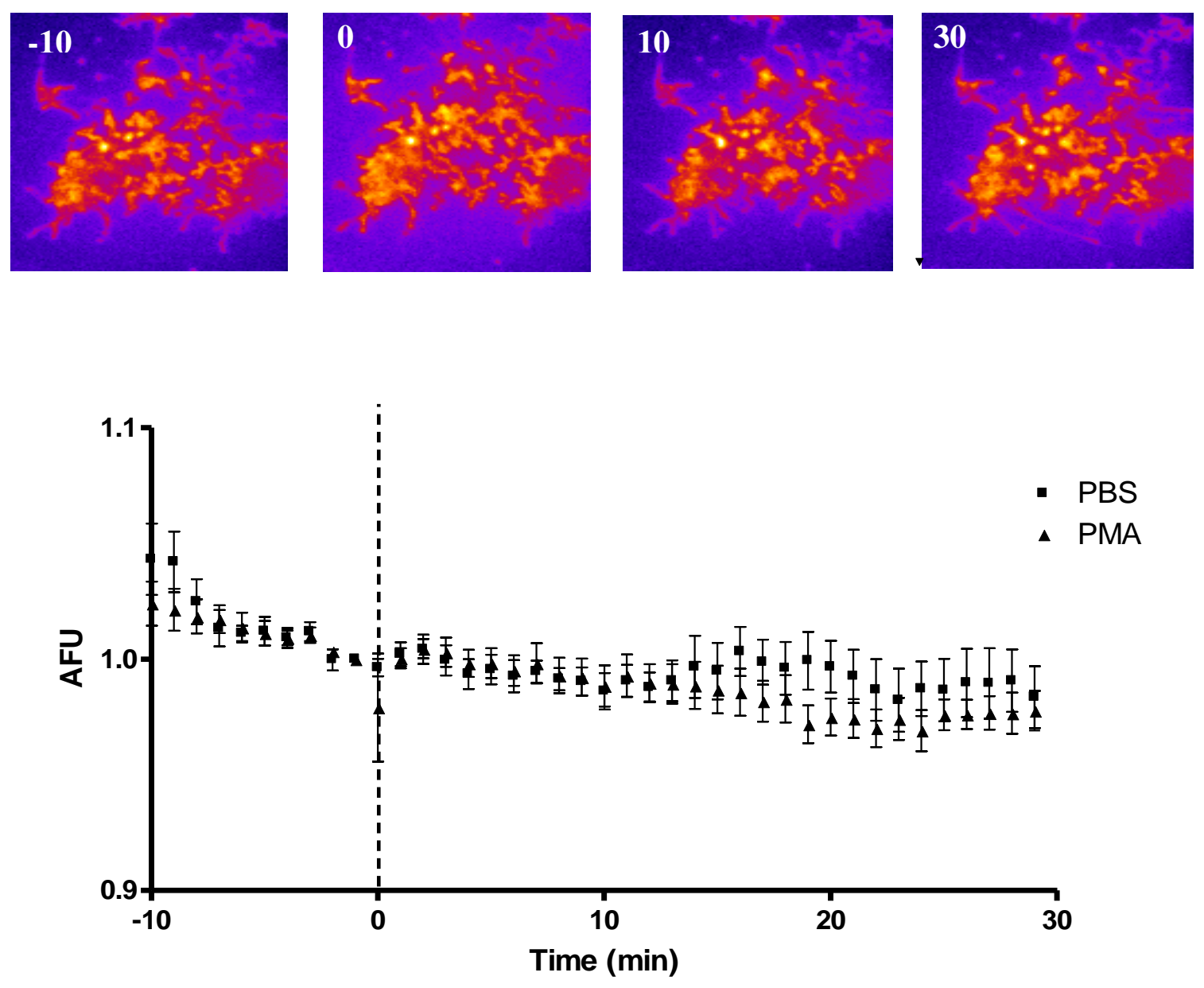

Figure 5:13: Cell Surface Expression of GFP-hSERT during a $30 \mathrm{~min}$ incubation with $\beta$-PMA in $\mathbf{N}_{2} A$ cells.

TIRFM was conducted on $\mathrm{N}_{2} \mathrm{~A}$ cells expressing GFP-hSERT. 40 images were taken 1 min apart, with vehicle or $\beta$-PMA $(1 \mu \mathrm{M})$ being added after $10 \mathrm{~min}$. No change was detectable in cell surface expression with $\beta$-PMA. ( $n=5-12$ cells from 4 separate transfections). Average fluorescence was measured for each cell at each image captured and normalized back to the image taken at time 0. Data is plotted as the average +/- SEM. Two-way ANOVA followed by Bonferroni post test was carried out for statistical significance. Shown is a representative $\beta$-PMA-treated cell with images taken at $-10,0,10$ and $30 \mathrm{~min}$. 


\subsection{Discussion}

Previous studies have shown that PKC activation (Jayanthi et al. 2005) and MDMA treatment (Battaglia et al. 1987) decreases SERT function in cultured cells and rat brain tissue. One way in which decreases in transporter function can occur is through decreased cell surface expression. It has already been shown that activation of PKC by $\beta$-PMA leads to a decrease in surface expression of SERT both in vivo (Jayanthi et al. 2005) and in vitro (Bauman et al. 2000). Previous findings from our lab (Kivell et al. 2010) have identified that SERT cell surface expression is also decreased by application of MDMA in cultured cells. We hypothesized that MDMA activates PKC, therefore causing an increase in SERT phosphorylation, leading to a decrease in 5-HT transport due to internalization of the transporter into the intracellular compartment.

Neurochemistry experiments from Chapter 4 show a significant decrease in SERT function after both MDMA and $\beta$-PMA treatment in transfected HEK-293 and $\mathrm{N}_{2} \mathrm{~A}$ cells. RDEV can be used for kinetic studies, providing additional information on how SERT is being modulated by MDMA. A decrease in $\mathrm{V}_{\max }$ with little or no change in $\mathrm{K}_{\mathrm{m}}$ indicates a decrease in cell surface expression. For GFP-hSERT transfected HEK-293 cells, initial velocities were kinetically resolved with $\mathrm{V}_{\max }$ values for MDMA treated and vehicle treated calculated as $87.6 \pm 43.1 \mathrm{pmol} / \mathrm{s} / 10^{6}$ cells and $108.3 \pm 33.5 \mathrm{pmol} / \mathrm{s} / 10^{6}$ cells, respectively (Table $5: 1$ ). However the statistical analysis on these values showed that this was a non-significant decrease in SERT surface expression after MDMA treatment compared to control. Statistical analysis was carried out on the $\mathrm{K}_{\mathrm{m}}$ values obtained for each treatment $(3.3 \pm 1.6$ for control treated cells and $5.7 \pm 3.7$ for MDMA treated cells) with no significant difference calculated. However the size of the standard error for all of these values is quite large which could contribute to the lack of statistical significance. Further repeats of the data would be ideal as this would resolve the error size, creating a tighter data set. The values obtained for both $\mathrm{V}_{\max }$ and $\mathrm{K}_{\mathrm{m}}$ still fall within the range of values reported in the literature for transfected cell preparations. $\mathrm{K}_{\mathrm{m}}$ values have been shown to fall between $0.3 \mu \mathrm{M}$ (Zhu et al. 2005; Mao et al. 2008; Tsuruda et al. 2010) and 21.8 $\mu \mathrm{M}$ (Mochizuki et al. 2005) which is quite a large range. This could be due partly to the various cell types used and different SERT plasmid expressed in the cell lines, as well as the different techniques used to generate kinetic data.

The most puzzling aspect of this study is the kinetic data generated for the non-transfected and hSERT transfected $\mathrm{N}_{2} \mathrm{~A}$ cells. There is no current literature published for the use of RDEV in investigating SERT function in $\mathrm{N}_{2} \mathrm{~A}$ cells. This makes it challenging to interpret 
the sigmoidal nature of the kinetic data set obtained. One hypothesis is that we are measuring a mixture of SERT and non-SERT mediated 5-HT uptake. In a recent publication carried out by Hagan et al. (2011), they focused on the contribution of low-affinity, high-capacity transport mechanisms for 5-HT clearance in synaptosomes using RDEV. Through the use of a specific SERT blocker (paroxetine) and an inhibitor of low-affinity, high-capacity transporters (decynium-22, D-22), they found that at high 5-HT concentrations $(>300 \mathrm{nM}$ there was a large amount of non-SERT mediated uptake. At low 5-HT concentrations $(<300$ $\mathrm{nM}$ ), both SERT- and non-SERT mediated mechanisms were observed for 5-HT uptake. They suggest that there may be low-affinity, high-capacity transporters present that may play a role in 5-HT uptake. As $\mathrm{N}_{2} \mathrm{~A}$ cells are neuronally derived it is possible that they express these other transporters, and they are contributing to 5-HT uptake as measured by our RDEV experiments. This could help explain the non-saturated region of the curve, leading to a sigmoidal shape. Further investigation into this possibility was beyond the scope of this project but it is a very important future direction and would help support the conclusion that non-SERT mediated 5-HT uptake may have a significant biological importance. There are several other studies that support the existence of alternative mechanisms of 5-HT uptake besides SERT. For example, Grundemann and colleagues were the first to clone the organic cation transporters (OCTs) in the early 1990s. These transporters are widely distributed in the brain and belong to the SLC22 family and act to take up cations and regulate salt intake. OCTs are capable of 5-HT uptake at high substrate concentrations such as the ones used in our study, and they have also been shown to be sensitive to MDMA (Amphoux et al. 2006; Koepsell et al. 2007; Daws 2009). The OCTs have a much lower affinity for 5-HT compared to SERT; however, they are capable of high-capacity 5-HT transport (Busch et al. 1996; Daws et al. 2005). The affinity of MDMA for the OCTs has been reported to be comparable to its affinity for SERT (Mortensen et al. 1999; Amphoux et al. 2006). This raises the possibility that some of the effect MDMA has may be mediated by the OCT transporter, and until their role is further investigated in $\mathrm{N}_{2} \mathrm{~A}$ cells, we cannot conclude that the kinetic data generated in this study is solely due to SERT-mediated 5-HT uptake. Another transporter capable of taking up monoamines is the plasma membrane monoamine transporter, PMAT (Engel et al. 2004; Dahlin et al. 2007). Although it is not homologous with the other monoamine transporters, it does have capability for 5-HT uptake. As reported by Engel et al. 2004, the transport efficiency of PMAT $\left(K_{m}\right.$ and $\left.V_{\max }\right)$ in cell expression systems is only slightly different to that of SERT (2-3 magnitudes lower for $\mathrm{K}_{\mathrm{m}}$ but 2-3 magnitudes higher for $\mathrm{V}_{\max }$ ). This suggests that PMAT is a low affinity transporter but has high capacity for 5- 
HT uptake. Presence of low-affinity, high-capacity 5-HT transporters could shift the $\mathrm{K}_{\mathrm{m}}$ value higher (Daws 2009; Hagan et al. 2011).

Since the kinetic data from the RDEV experiments do not show a significant change in $\mathrm{V}_{\max }$ values, we cannot confirm that the functional change seen in Chapter 4 with MDMA treatment is due to a change in cell surface expression. Two other techniques that provide detail on surface expression changes are cell surface biotinylation and TIRFM. Cell model studies published from our lab show that cell surface biotinylations and TIRFM experiments have been used successfully to show that treatment with MDMA causes an internalization of SERT from the cell surface in transfected HEK-293 and $\mathrm{N}_{2} \mathrm{~A}$ cells (Kivell et al. 2010). Similarly, this study showed that PKC activation by $\beta$-PMA causes an internalization of SERT from the cell surface in transfected in HEK-293 cells. The cell surface biotinylation results showed that MDMA and $\beta$-PMA down-regulates SERT from the plasma membrane of HEK-293 cells by $24 \%$ and $23 \%$ respectively. TIRFM studies show that MDMA has a rapid effect on SERT surface expression in HEK-293 cells, with a significant decrease seen at 290 s and sustained until $420 \mathrm{~s}$ with a $13 \%$ decrease (Kivell et al. 2010). Unexpectedly, in this study, no change in cell surface expression of SERT was detectable with cell surface biotinylations in the HEK-293 cell line after a 60 min treatment with MDMA (Figure 5:5). A 10 min treatment with MDMA was also investigated with no significant change in cell surface expression of SERT (Figure 5:5). The TIRFM experiments confirmed that MDMA was not having an effect on SERT surface expression in HEK-293 as no change in surface fluorescence was observed (Figure 5:11). This became of some concern that HEK-293 cells were not responding to MDMA treatment in the predicted manner, so experimental focus was shifted to $\mathrm{N}_{2} \mathrm{~A}$ cells. An explanation for this possibility is that HEK-293 cells of varying passage numbers (up to 100 passages) were utilized throughout the experiments which may affect the stability of the cell and cause them to be significantly diverged from their parent line. Three time points for MDMA treatment were investigated (5, 10 and $60 \mathrm{~min}$ ). Even though RDEV results from Chapter 4 show that MDMA has a functional effect on SERT after 5 and $10 \mathrm{~min}$, a $60 \mathrm{~min}$ time point was included in the cell surface biotinylation experiments in this study. This is due to the fact that findings from our lab show that MDMA has a sustained effect on decreasing cell surface expression of SERT and to ensure that time of maximal activity of MDMA on SERT was not being missed unexpectedly. When no significant change was observed in cell surface expression of SERT in the cell biotinylations in any of the time points (Figure 5:6), TIRFM experiments were carried out. From these 
results it appears that there is a trend towards a decrease in cell surface expression of SERT after MDMA $(10 \mu \mathrm{g} / \mathrm{mL}$ ) treatment for $10 \mathrm{~min}$ (Figure 5:12). Due to time constraints this trend could not be investigated further; however, it would be ideal to gather a larger data set to confirm the trend. The main concern when choosing representative cells to analyze in the TIRFM experiments is the amount of cell movement that is encountered due to drifting. Since the evanescent field was set to only $100 \mathrm{~nm}$ from the coverslip, if the cell was not adhered properly to the bottom of the dish, it had the tendency to drift either away or closer to the surface throughout the time course. This is a concern as it could create false impressions of the fluorescence measured for SERT trafficking. For HEK-293 cells especially, this was a significant problem encountered. Coating the glass-covered dishes with poly-d-lysine helped to eliminate some of this movement by improving the adherence of cells to the culture dish.

Treatment with $1 \mu \mathrm{M} \beta$-PMA did not cause any detectable change in cell surface expression of SERT as indicated by cell surface biotinylation experiments in HEK-293 (Figure 5:7) or $\mathrm{N}_{2}$ A cells (Figure 5:8) transfected with GFP-hSERT. Testing a new solution of $\beta$-PMA also did not show a significant change in cell surface expression as indicated by cell surface biotinylation experiments for the two cell lines (Figure 5:7 and Figure 5:8) and TIRFM for $\mathrm{N}_{2} \mathrm{~A}$ cells (Figure 5:13). This was the most surprising result, as it is well published that $\beta$ PMA activates PKC which causes an internalization of SERT (Jayanthi et al. 2005; Samuvel et al. 2005; Kivell et al. 2010). For $\mathrm{N}_{2} \mathrm{~A}$ cells, when ionomycin was applied in conjunction with $\beta$-PMA, there was a significant decrease (35\% compared to control-treated cells) in cell surface expression of SERT ( $\mathrm{p}<0.001$ ) (Figure 5:8). Ionomycin is known to cause an increase in intracellular calcium levels, and for $\beta$-PMA-induced activation of PKC, it is necessary to have calcium present (Samuvel et al. 2005). Previous studies have shown that the presence of intracellular calcium is essential for the amphetamine-mediated stimulation of PKC activity in the dopaminergic system. Rat synaptosomes treated with a calcium chelator showed that a depletion of intracellular calcium resulted in the attenuation of dopamine release induced by amphetamine treatment (Giambalvo 2003). Further studies using ionomycin in conjunction with $\beta$-PMA in TIRFM experiments would be essential to investigate this trend further. Unfortunately due to product availability and time constraints further investigation into treatment with ionomycin could not be carried out.

There is no clear explanation for why these two techniques, cell surface biotinylation and TIRFM, did not show a detectable change in cell surface expression of SERT after MDMA or $\beta$-PMA treatment. For cell surface biotinylation it must be emphasized that the sensitivity of 
the technique may not be high enough to detect possible changes in surface expression of SERT in this particular study. As mentioned before, the intracellular fraction can be overestimated due to biotin not being able to bind proteins found in membrane invaginations (Furman et al. 2009). For TIRFM experiments it must be pointed out that, depending on where the SERT is located on the surface of the cell, it can be differentially modulated (A.Sorkin, personal communication). SERT located on the filopodia of the cell is modulated rapidly, compared to SERT located on the surface of the cell body. Expression levels varied between individual cells even in the same transfection and though efforts were made to choose cells for analysis that displayed similar expression levels of SERT, variation in expression could have an effect on the level of regulation. It must be kept in mind that presence of 5-HT attenuates $\beta$-PMA-induced activation of PKC. While HEK-293 and $\mathrm{N}_{2} \mathrm{~A}$ cells are not commonly reported to contain endogenous 5-HT, it must be stated that there is one report which indicates that immunoblots of HEK-293 cells show that have been identified as positive for the presence of the SERT gene and 5-HT (Shaw et al. 2002). The amounts found were of minimal concentrations and there have been no further studies to suggest the presence of 5-HT in HEK-293 or $\mathrm{N}_{2} \mathrm{~A}$ cells.

There is one previous study carried out by Wang et al. (2005) that did not report any change in expression levels between the cell surface and intracellular compartments of SERT after MDMA administration. They suggest that MDMA exposure may result in less SERT being associated with lipid rafts. SERT that are not associated with lipid rafts are non-functional and this could account for the results showing that MDMA is able to decrease SERT function without altering expression levels. However this study was carried out with antibodies to the SERT protein, and identification of SERT from the immunoblots must be carried out with caution as SERT antibodies have been shown to be non-specific (refer to Chapter 3 for detailed discussion).

Whether MDMA targets a PKC-dependent pathway to exert its effect on SERT is still unknown. PKC inhibition by Bis I treatment was carried out in parallel on GFP-hSERT transfected HEK-293 and N2A cells. This was in the hopes to see if Bis I could prevent the predicted internalization of SERT from the cell surface into the intracellular fraction after MDMA treatment. Unfortunately, since the cell surface biotinylations and TIRFM results are not conclusive about whether MDMA or PKC activation causes a decrease in SERT cell surface expression in this study, we cannot state that PKC inhibition prevents MDMAinduced internalization. The kinetic information gathered from the RDEV experiment in this 
chapter are also inconclusive about whether the down-regulation in SERT function seen in Chapter 4 after MDMA treatment and PKC activation in HEK-293 cells is due to a change in cell surface expression. An increase in $K_{m}$ normally suggests a decrease in monoamine uptake, where a decrease in $\mathrm{K}_{\mathrm{m}}$ suggests an increase in uptake. Decreases in $\mathrm{V}_{\max }$ without a significant change in $\mathrm{K}_{\mathrm{m}}$ signifies that the transporter is down-regulated from the cell surface, either by a decrease in cell surface expression, or modulation by post-translational modifications, similarly an increase in $\mathrm{V}_{\max }$ suggests an up-regulation of the transporter. However a combined increase in both $\mathrm{K}_{\mathrm{m}}$ and $\mathrm{V}_{\max }$ can signify an up-regulation of the transporter in some circumstances (Meiergerd et al. 1994). It is not clear whether a combined decrease in the kinetic values could be indicative of a down-regulation of the transporter. There is a non-significant decrease in the $\mathrm{V}_{\max }$ value for MDMA-treated HEK-293 cells compared to control without a significant change in $K_{m}$ values. Since the cell surface biotinylations nor TIRFM experiments suggest a change in cell surface expression, it could be concluded that that SERT is being functionally altered rather than through a traffickingdependent mechanism such as internalization in this particular study. 


\section{Chapter 6: Final Discussion}

SERT is an important part of the brains natural reward pathway and is a major target for drugs of abuse such as MDMA. Previous studies have shown that SERT expression on the cell membrane is down-regulated after exposure to MDMA (Kivell et al. 2010). SERT regulation is tightly controlled by a large network of kinases which cross-talk with each other, creating an efficient 5-HT signaling system. Changes in the phosphorylation state of SERT have been shown to trigger internalization from the plasma membrane, leading to changes in trafficking and function of the transporter. Dysregulation of this system is implicated in disease states such as depression and anxiety and SERT is known to be involved in substance abuse (Green et al. 2003). How MDMA interacts and exerts its effects on the signaling molecules responsible for the regulation of SERT at the cell membrane would help to narrow the gap in scientists' current knowledge about how drugs of abuse act on the monoamine systems. The neurotoxic action of MDMA is highly disputed throughout the literature, and although this subject was not a key focus in this study, advances in information about how MDMA targets SERT for down-regulation may provide a stepping stone for further investigation into its mechanism of action. This is important for understanding how drugs of abuse are able to modulate their targets and could lead to pharmacotherapies for reversing the effects of drugs of abuse or preventing drug-induced cellular changes.

p38 MAPK is a well-known regulator of SERT, however previous research from our laboratory has suggested that MDMA does not exert its effects on SERT through this particular kinase (Kivell et al. 2010). This was shown through a series of experiments which demonstrated activation of p38 MAPK was not related to MDMA-induced SERT downregulation from the cell membrane. This has led to investigation of other well-known regulatory proteins of SERT. PKC is known to directly regulate SERT through phosphorylation, causing a loss of cell surface expression and corresponding decrease in 5HT uptake (Jayanthi et al. 2005). Studies using the PKC activator, $\beta$-PMA, have shown that SERT is regulated in a biphasic manner, with short treatments of less than 30 min causing a decrease in 5-HT transport. Longer treatments exceeding 30 min result in a loss of SERT expression from the cell surface (Jayanthi et al. 2005). This phosphorylation event occurs on as-yet unknown serine and threonine residues. The RDEV technique that was utilized in this study allowed for an in-depth investigation into whether MDMA was targeting a PKCdependent pathway in order to down-regulate SERT. RDEV data from HEK-293 cells 
expressing GFP-hSERT has suggested that MDMA is able to activate PKC and cause a down-regulation in SERT function by decreasing 5-HT uptake (Figure 4:4). Further investigation using RDEV into whether MDMA was causing SERT internalization in a similar PKC-dependent manner resulted in a non-significant change in $\mathrm{V}_{\max }$ and $\mathrm{K}_{\mathrm{m}}$ values for control-treated vs. MDMA-treated HEK-293 cells expressing GFP-hSERT (Table 5:1). Since one of the major ways SERT is regulated is through changes in cell surface expression, this data is surprising. Both cell surface biotinylation and TIRFM experiments did not show a significant change in SERT surface expression after PKC activation (Figure 5:7, Figure 5:8 and Figure 5:13) or MDMA treatment (Figure 5:5, Figure 5:6, Figure 5:11 and Figure 5:12), contrary to previous studies (Jayanthi and Ramamoorthy 2005; Kivell et al. 2010). It was through trouble-shooting that addition of ionomycin with $\beta$-PMA to $\mathrm{N}_{2} \mathrm{~A}$ cells expressing GFP-hSERT caused a significant 35\% decrease in the cell surface expression of SERT (Figure 5:8). Unfortunately due to time constraints and product availability, further experiments could not be carried out with TIRFM or RDEV using ionomycin. This suggests that these cell lines are dependent on the presence of intracellular calcium in order to carry out correct regulation of SERT.

Unfortunately there were unexpected results arising from this study, one including the 5-HT uptake sigmoidal dose-response curve generated by $\mathrm{N}_{2} \mathrm{~A}$ cells expressing GFP-hSERT (Figure 5:3). This experiment needs further investigation to validate the results presented here and for a more in-depth understanding of the cellular system that was studied. For now, we hypothesize that $\mathrm{N}_{2} \mathrm{~A}$ cells generate both SERT-mediated and non-SERT mediated 5-HT uptake. The redundancy and plasticity of the SERT uptake system is well-known. The ability of transporters to take up other molecules beside their cognate substrates was highlighted in the 1960's when studies confirmed that catecholaminergic neurons were able to accumulate 5-HT (Daws 2009). Later studies showed that DAT was able to take up and release 5-HT (Stamford et al. 1990; Wightman and Zimmerman 1990). While there is no doubt that SERT is the primary regulator for 5-HT uptake, it must be noted that alternative mechanisms do play a role, and can come into play when 5-HT levels are high or when SERT function or expression is impaired or absent (Daws 2009). OCTs and PMATs are two classes of alternative transporters that have the ability to transport 5-HT. Whether these transporters are present in $\mathrm{N}_{2} \mathrm{~A}$ cells and are involved in 5-HT uptake is unclear and requires further investigation. 
Using the information found in the literature and combining it with the data from this study, we make an attempt to propose a model for how MDMA regulates SERT. After translation SERT starts off in a non-glycosylated, non-phosphorylated form at an unidentified molecular weight. N-glycosylation begins in the Endoplasmic Reticulum and is completed in the Golgi apparatus. This is followed by phosphorylation carried out by at least p38 MAPK which provides the basal phosphorylation level to trigger the SERT to insert into the membrane. As seen by cell surface biotinylation experiments in this study (see Chapter 5), we identify this as the $103 \mathrm{kDa}$ band. Upon MDMA exposure, PKC is activated and phosphorylates SERT on a serine residue. This is aided by a rise in intracellular calcium levels and causes a conformational change in SERT, leading to a decrease in 5-HT transport. This conformational change has been identified through studies investigating 5-HT binding (Murphy et al. 2004), and so is possible that MDMA causes a similar conformational change. It is possible that the $75 \mathrm{kDa}$ band seen solely in the intracellular compartment of the biotinylation experiments is a non-glycosylated non-functional form of SERT. The $103 \mathrm{kDa}$ band however, is found in both the intracellular and cell surface fractions. It is possible that it is this form of SERT which becomes internalized after further phosphorylation on a threonine residue by PKC.

\subsection{Future directions:}

Further investigation into the relationship between MDMA and PKC and how they affect SERT function is needed before certain conclusions can be drawn. If indeed MDMA targets PKC to cause a down-regulation in SERT function it would be intriguing to use a biochemical colourimetric assay kit to determine the level of activity MDMA induces in PKC. Transfecting a cell line such as HEK-293 cells would be ideal as they are easy to manipulate and they express the necessary signaling pathways. Basal activity levels of PKC could be compared to the PKC activity after cells expressing SERT are exposed to MDMA. If MDMA is working through a PKC-dependent pathway then it would be expected that PKC activity increases in order to target SERT for internalization and subsequently decreasing 5HT transport.

Another angle that could be pursued is the generation of SERT mutants. Knockout of specific residues such as serine or threonines could provide information on the site that MDMA targets which triggers the functional down-regulation and internalization of SERT. 
Identification of the SERT bands could be an alternative future direction. By using mass spectrometry it would be possible to elucidate the primary sequence of the two major bands $(103 \mathrm{kDa}$ and $75 \mathrm{kDa})$ that we identify as SERT. This could help identify areas of posttranslational modification, and differences in glycosylation or phosphorylation between the two SERT forms.

What would be intriguing to further investigate is the presence of low-affinity high-capacity transporter systems that may exist in both HEK-293 cells and N2A cells. Treatment using D22 as an inhibitor of low-affinity, high-capacity transporters would provide further insight into the presence of transporters such as OCT's and PMAT. This would be interesting to explore to what extent the role they play in 5-HT uptake. Determining the biological significance of these alternative transporters could provide insight on how they function as novel mediators of 5-HT uptake which would be important for developing further understanding of human disease. 


\section{Appendix 1: Solutions}

\section{$\underline{\text { Biotinylations }}$}

10x Phosphate Buffered Saline (PBS) pH 7.4

\begin{tabular}{ll}
\hline Reagents & $\mathrm{g} / \mathrm{L}$ \\
\hline $\mathrm{NaCl}$ & 80 \\
$\mathrm{KCl}$ & 2 \\
$\mathrm{Na}_{2} \mathrm{HPO}_{4}$ & 26.8 \\
$\mathrm{KH}_{2} \mathrm{PO}_{4}$ & 2.4 \\
\hline
\end{tabular}

PBS was made by dissolving the salts into $900 \mathrm{ml}$ of $\mathrm{ddH}_{2} \mathrm{O}$. The solution was then adjusted to $\mathrm{pH} 7.4$ by addition of concentrated $\mathrm{HCl}$ or $\mathrm{NaOH}$. 1x $\mathrm{PBS}(0.15 \mathrm{M})$ was prepared from this stock and autoclaved as required.

\section{1x PBS Ca/Mg pH 8.0}

\begin{tabular}{ll}
\hline Reagents & $\mathrm{g} / \mathrm{L}$ \\
\hline $\mathrm{CaCl}_{2}$ & 0.111 \\
$\mathrm{MgCl}_{2} \cdot 6 \mathrm{H}_{2} \mathrm{O}$ & 0.203 \\
\hline
\end{tabular}

Salts were dissolved in 1x PBS, with the $\mathrm{pH}$ being adjusted to $\mathrm{pH} 8.0$ using concentrated $\mathrm{HCL}$ or $\mathrm{NaOH}$.

\section{1x PBS Ca/Mg/Glycine}

\begin{tabular}{ll}
\hline Reagents & $\mathrm{g} / \mathrm{L}$ \\
\hline $\mathrm{CaCl}_{2}$ & 0.111 \\
$\mathrm{MgCl}_{2} \cdot 6 \mathrm{H}_{2} \mathrm{O}$ & 0.203 \\
Glycine & 75 \\
\hline
\end{tabular}




\section{Westerns}

Radio-immuno-precipitation assay (RIPA) buffer $(100 \mathrm{~mL})$ pH 7.5

\begin{tabular}{ll}
\hline Reagents & $\mathrm{mg} / 100 \mathrm{~mL}$ \\
\hline Tris-HCl & 121.1 \\
$\mathrm{NaCl}$ & 876.6 \\
EDTA & 37.22 \\
TritonX-100 & $1 \mathrm{~mL}$ \\
SDS & 100 \\
Sodium deoxycholate & 1000 \\
\hline
\end{tabular}

Ingredients were mixed to final volume of $100 \mathrm{~mL}$ using $\mathrm{ddH}_{2} \mathrm{O}$, and $\mathrm{pH}$ was adjusted to 7.5 with $1 \mathrm{M} \mathrm{HCl}$.

10x Tris Buffered Saline (TBS)

\begin{tabular}{ll}
\hline Reagents & $\mathrm{g} / \mathrm{L}$ \\
\hline Tris & 60.5 \\
$\mathrm{NaCl}$ & 87.6 \\
\hline
\end{tabular}

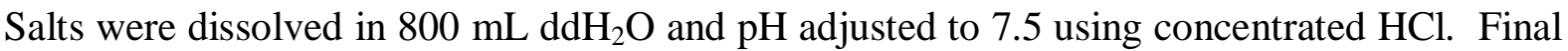
volume was made up to $1 \mathrm{~L}$ using $\mathrm{ddH}_{2} \mathrm{O}$.

\section{1x Tris Buffered Saline-Tween 20 (TBST)}

TBST was prepared by addition of $1 \mathrm{~mL}$ Tween-20 to $1 \mathrm{~L}$ of $1 \mathrm{x}$ TBS buffer.

\section{Western Blot Transfer Buffer}

\begin{tabular}{ll}
\hline Reagents & $\mathrm{g} / \mathrm{L}$ \\
\hline Tris & 3.03 \\
Glycine & 14.4 \\
SDS & 0.38 \\
Methanol & $150 \mathrm{~mL}$ \\
\hline
\end{tabular}


Ingredients were mixed in $850 \mathrm{~mL}$ of $\mathrm{ddH}_{2} \mathrm{O}$ and chilled in $4^{\circ} \mathrm{C}$. Methanol was added directly before use.

\section{Stripping Buffer}

\begin{tabular}{ll}
\hline Reagents & $\mathrm{g} / 500 \mathrm{~mL}$ \\
\hline SDS & 10 \\
$0.05 \mathrm{M}$ Tris-HCl & $496.25 \mathrm{~mL}$ \\
$\beta$-Mercaptoethanol & $3.75 \mathrm{~mL}$ \\
\hline
\end{tabular}

Ingredients were mixed together with $\mathrm{pH}$ adjusted to 6.8 with concentrated $\mathrm{HCl}$.

10x SDS Running Buffer

\begin{tabular}{ll}
\hline Reagents & $\mathrm{g} / \mathrm{L}$ \\
\hline SDS & 10 \\
Tris & 30.3 \\
Glycine & 144.1 \\
\hline
\end{tabular}

Ingredients were dissolved in $1 \mathrm{~L}$ of $\mathrm{ddH}_{2} \mathrm{O}$.

5x Reducing Buffer (10 mL)

\begin{tabular}{ll}
\hline Reagents & \\
\hline $1.5 \mathrm{M}$ Tris pH 6.8 & $1 \mathrm{~mL}$ \\
$10 \%$ SDS & $5 \mathrm{~mL}$ \\
$80 \%$ Glycerol & $3.2 \mathrm{~mL}$ \\
$1 \%$ Bromphenol Blue & $0.8 \mathrm{~mL}$ \\
\hline
\end{tabular}

Ingredients were mixed together and $1 \mathrm{~mL}$ aliquots were stored at $-20^{\circ} \mathrm{C}$. 
$10 \%$ SDS Polyacrylamide Separating Gels

(2 gels- $1.5 \mathrm{~mm}$ thick)

\begin{tabular}{ll}
\hline Reagents \\
\hline ddH2O \\
$1.5 \mathrm{M}$ Tris-HCL pH 6.8 \\
$10 \%$ SDS in ddH ${ }_{2} \mathrm{O}$ \\
Acrylamide/Bis & \\
$10 \%$ Ammonium persulphate (APS) & $6.66 \mathrm{~mL}$ \\
TEMED & $100 \mu \mathrm{L}$ \\
\hline
\end{tabular}

Ingredients were added in order shown. 10\% APS and TEMED were added last to initiate polymerisation of acrylamide. The gel solution was then used to fill the gel casting apparatus and overlaid with $100 \%$ isopropanol. The gel was left to set for a minimum of 45 minutes. A $4 \%$ stacking gel was then placed on top after removal of the isopropanol.

\section{4\% SDS Stacking Gel}

\begin{tabular}{ll}
\hline Reagents \\
\hline $\mathrm{ddH}_{2} \mathrm{O}$ \\
$1.5 \mathrm{M}$ Tris-HCL pH 8.8 \\
$10 \%$ SDS in $\mathrm{ddH}_{2} \mathrm{O}$ \\
Acrylamide/Bis \\
$10 \%$ Ammonium persulphate (APS) & $1.33 \mathrm{~mL}$ \\
TEMED & $50 \mu \mathrm{L}$ \\
\hline
\end{tabular}

\section{Plasmid Preparation}

\section{LB-Broth}

\begin{tabular}{ll}
\hline Reagents & $\mathrm{g} / \mathrm{L}$ \\
\hline Tryptone & 10 \\
$\mathrm{NaCl}$ & 10 \\
Yeast Extract & 5 \\
\hline
\end{tabular}

Ingredients were mixed together to a final volume of $1 \mathrm{~L}$ in $\mathrm{ddH}_{2} \mathrm{O}$. 


\section{LB-Agar (200 mL)}

\begin{tabular}{ll}
\hline Reagents & $\mathrm{g} / 200 \mathrm{~mL}$ \\
\hline Tryptone & 2 \\
$\mathrm{NaCl}$ & 2 \\
Yeast Extract & 1 \\
Agar & 2 \\
\hline
\end{tabular}

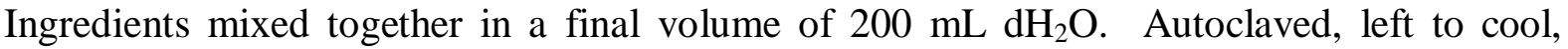
addition of antibiotic, pour plates, $12.5 \mathrm{ml}$ each plate, left to set for a minimum of $45 \mathrm{~min}$.

\section{Kanamycin $(50 \mathrm{mg} / \mathrm{mL})$}

To make a $50 \mathrm{mg} / \mathrm{ml}$ stock of Kanamycin, add $0.5 \mathrm{~g}$ of Kanamycin to $10 \mathrm{ml}$ of $\mathrm{ddH}_{2} \mathrm{O}$. Aliquot out in $1 \mathrm{~mL}$ and store at -20C. Working solution in experiments is $50 \mu \mathrm{g} / \mu \mathrm{l}$.

\section{RDEV}

\section{KREB Buffer}

\begin{tabular}{ll}
\hline Reagents & $\mathrm{g} / \mathrm{L}$ \\
\hline $\mathrm{NaCl}$ & 7.6 \\
$\mathrm{KCl}$ & 0.10 \\
$\mathrm{CaCl}_{2}$ & 0.24 \\
$\mathrm{MgSO}_{4} \cdot 6 \mathrm{H}_{2} \mathrm{O}$ & 0.27 \\
$\mathrm{KH}_{2} \mathrm{PO}_{4}$ & 0.16 \\
$\mathrm{HEPES}$ & 2.6 \\
D-Glucose & 1.8 \\
\hline
\end{tabular}




\section{Appendix 2: BCA Protein Assay}

To determine the amount of protein to load for the SDS-PAGE gels, protein assays were carried out on all samples for the Western blot experiments. A set of BSA (bovine serum albumin) standards were diluted so that the absorbance of a range of concentrations were measured to create a standard curve. A sample from either transfected or non-transfected lysates were taken from each cell line and diluted either 1:10 or 1:100 and the absorbance measured along with the standards. A representative curve is shown below where the absorbance value for each lysate is compared to that of the standard curve so the concentration can be calculated using the equation derived from the graph. A range of 2.5 $50 \mu \mathrm{g} / 20 \mu \mathrm{L}$ well was loaded on an SDS-PAGE gel.

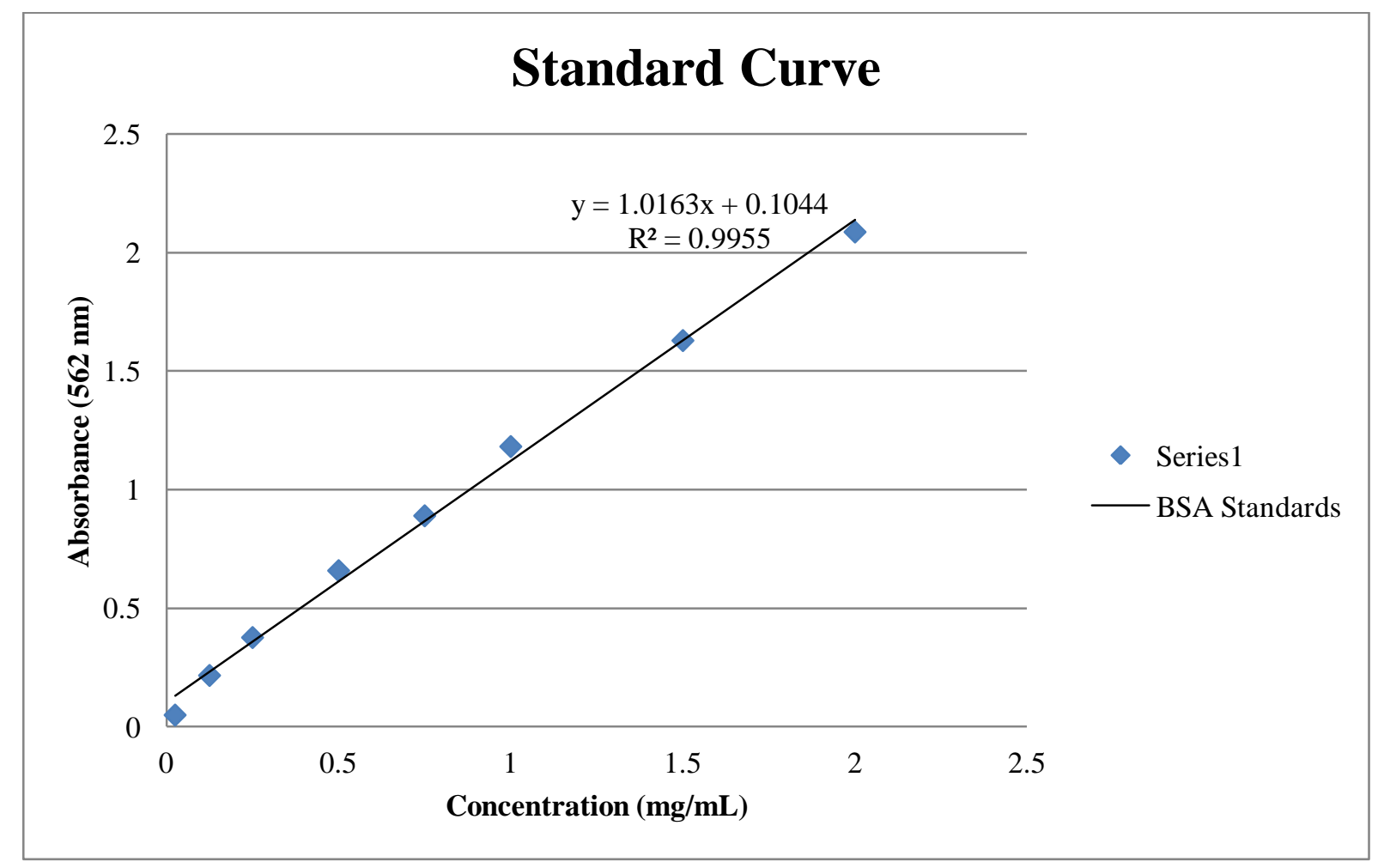

\section{Figure 8:1 Standard curve for BCA assay.}

The equation derived from the standard curve generated by the BSA standards was used to determine the unknown protein concentration of the lysate samples. The absorbance (denoted by y) of all samples was measured at $562 \mathrm{~nm}$, with the values being plotted against the protein concentration of the BSA standards (denoted by $\mathrm{x}$ ). 


\section{References}

Adinoff, B. (2004). "Neurobiologic processes in drug reward and addiction." Harvard Review of Psychiatry 12(6): 305-320.

Aguirre, N., M. Barrionuevo, et al. (1999). "alpha-lipoic acid prevents 3,4methylenedioxymethamphetamine (MDMA)-induced neurotoxicity." Neuroreport 10(17): 3675-3680.

Amphoux, A., V. Vialou, et al. (2006). "Differential pharmacological in vitro properties of organic cation transporters and regional distribution in rat brain." Neuropharmacology 50(8): 941952.

Axelrod, D. (2001). "Total internal reflection fluorescence microscopy in cell biology." Traffic 2(11): 764-774.

Bai, F. J., D. C. Jones, et al. (2001). "Serotonergic neurotoxicity of $3,4-(+/-)$ methylenedioxyamphetamine and 3,4-(+/-)-methylendioxymethamphetamine (ecstasy) is potentiated by inhibition of gamma-glutamyl transpeptidase." Chemical Research in Toxicology 14(7): 863-870.

Battaglia, G., S. Y. Yeh, et al. (1987). "3,4-Methylenedioxymethamphetamine and 3,4methylenedioxyamphetamine destroy serotonin terminals in rat-brain - quantification of neurodegeneration by measurement of $\mathrm{H}-3$ paraoxetine-labeled serotonin uptake sites." Journal of Pharmacology and Experimental Therapeutics 242(3): 911-916.

Bauman, A. L., S. Apparsundaram, et al. (2000). "Cocaine and antidepressant-sensitive biogenic amine transporters exist in regulated complexes with protein phosphatase $2 \mathrm{~A}$." Journal of Neuroscience 20(20): 7571-7578.

Baumann, M. H., X. Y. Wang, et al. (2007). "3,4-Methylenedioxymethamphetamine (MDMA) neurotoxicity in rats: a reappraisal of past and present findings." Psychopharmacology 189(4): 407-424.

Bengel, D., D. L. Murphy, et al. (1998). "Altered brain serotonin homeostasis and locomotor insensitivity to 3,4-methylenedioxymethamphetamine ("ecstasy") in serotonin transporterdeficient mice." Molecular Pharmacology 53(4): 649-655.

Blakely, R. D., L. J. Defelice, et al. (1994). "Molecular physiology of norepinephrine and serotonin transporters." Journal of Experimental Biology 196: 263-281.

Bolan, E. A., B. Kivell, et al. (2007). "D-2 receptors regulate dopamine transporter function via an extracellular signal-regulated kinases 1 and 2-dependent and phosphoinositide 3 kinaseindependent mechanism." Molecular Pharmacology 71(5): 1222-1232.

Burnette, W. B., M. D. Bailey, et al. (1996). "Human norepinephrine transporter kinetics using rotating disk electrode voltammetry." Analytical Chemistry 68(17): 2932-2938.

Busch, A. E., S. Quester, et al. (1996). "Monoamine neurotransmitter transport mediated by the poly-specific cation transporter rOCT1." Febs Letters 395(2-3): 153-156.

Cai, G. Q., P. S. Salonikidis, et al. (2005). "The role of N-glycosylation in the stability, trafficking and GABA-uptake of GABA-transporter 1 - Terminal N-glycans facilitate efficient GABA-uptake activity of the GABA transporter." Febs Journal 272(7): 1625-1638.

Capela, J. P., H. Carmo, et al. (2009). "Molecular and Cellular Mechanisms of Ecstasy-Induced Neurotoxicity: An Overview." Molecular Neurobiology 39(3): 210-271.

Chamba, A., M. J. Holder, et al. (2008). "Characterisation of the endogenous human peripheral serotonin transporter SLC6A4 reveals surface expression without N-glycosylation." Journal of Neuroimmunology 204(1-2): 75-84.

Chamberlain, L. H. and G. W. Gould (2002). "The vesicle- and target-SNARE proteins that mediate Glut4 vesicle fusion are localized in detergent-insoluble lipid rafts present on distinct intracellular membranes." Journal of Biological Chemistry 277(51): 49750-49754. 
Chen, N. H., C. G. Trowbridge, et al. (1999). "Cationic modulation of human dopamine transporter: Dopamine uptake and inhibition of uptake." Journal of Pharmacology and Experimental Therapeutics 290(3): 940-949.

Commins, D. L., G. Vosmer, et al. (1987). "Biochemical and histological evidence that methylenedioxymethylamphetamine (MDMA) is toxic to neurons in the rat-brain." Journal of Pharmacology and Experimental Therapeutics 241(1): 338-346.

Dahlin, A., L. Xia, et al. (2007). "Expression and immunolocalization of the plasma membrane monoamine transporter in the brain." Neuroscience 146(3): 1193-1211.

Daws, L. C. (2009). "Unfaithful neurotransmitter transporters: Focus on serotonin uptake and implications for antidepressant efficacy." Pharmacology \& Therapeutics 121(1): 89-99.

Daws, L. C., S. Montanez, et al. (2005). "Transport mechanisms governing serotonin clearance in vivo revealed by high-speed chronoamperometry." Journal of Neuroscience Methods 143(1): 4962.

Earles, C. and J. O. Schenk (1998). "Rotating disk electrode voltammetric measurements of dopamine transporter activity: An analytical evaluation." Analytical Biochemistry 264(2): 191-198.

Engel, K., M. Y. Zhou, et al. (2004). "Identification and characterization of a novel monoamine transporter in the human brain." Journal of Biological Chemistry 279(48): 50042-50049.

Frankhauser, P., Y. Grimmer, et al. (2006). "Characterization of the neuronal dopamine transporter DAT in human blood platelets." Neuroscience Letters 399(3): 197-201.

Furman, C. A., R. Chen, et al. (2009). "Dopamine and Amphetamine Rapidly Increase Dopamine Transporter Trafficking to the Surface: Live-Cell Imaging Using Total Internal Reflection Fluorescence Microscopy." Journal of Neuroscience 29(10): 3328-3336.

Giambalvo, C. T. (1992). "Protein-kinase-C and dopamine transport .1. Effects of amphetamine in vivo." Neuropharmacology 31(12): 1201-1210.

Giambalvo, C. T. (1992). "Protein-kinase-C and dopamine transport .2. Effects of amphetamine in vitro." Neuropharmacology 31(12): 1211-1222.

Giambalvo, C. T. (2003). "Differential effects of amphetamine transport vs. dopamine reverse transport on particulate PKC activity in striatal synaptoneurosomes." Synapse 49(2): 125133.

Green, A. R., A. O. Mechan, et al. (2003). "The pharmacology and clinical pharmacology of 3,4methylenedioxymethamphetamine (MDMA, "ecstasy")." Pharmacological Reviews 55(3): 463-508.

Hagan, C. E., J. F. Neumaier, et al. (2010). "Rotating disk electrode voltammetric measurements of serotonin transporter kinetics in synaptosomes." Journal of Neuroscience Methods 193(1): 29-38.

Hagan, C. E., J. O. Schenk, et al. (2011). "The Contribution of Low-Affinity Transport Mechanisms to Serotonin Clearance in Synaptosomes." Synapse 65(10): 1015-1023.

Hashemi, P., E. C. Dankoski, et al. (2009). "Voltammetric Detection of 5-Hydroxytryptamine Release in the Rat Brain." Analytical Chemistry 81(22): 9462-9471.

Hensler, J. G. (2006). "Serotonergic modulation of the limbic system." Neuroscience and Biobehavioral Reviews 30(2): 203-214.

Hoffman, B. J., S. R. Hansson, et al. (1998). "Localization and dynamic regulation of biogenic amine transporters in the mammalian central nervous system." Frontiers in Neuroendocrinology 19(3): 187-231.

Howell, L. L. and H. L. Kimmel (2008). "Monoamine transporters and psychostimulant addiction." Biochemical Pharmacology 75(1): 196-217.

Hoyer, D., J. P. Hannon, et al. (2002). "Molecular, pharmacological and functional diversity of 5-HT receptors." Pharmacology Biochemistry and Behavior 71(4): 533-554.

Ichijo, H. (1999). "From receptors to stress-activated MAP kinases." Oncogene 18(45): 6087-6093.

Jayanthi, L. D. and S. Ramamoorthy (2005). "Regulation of monoamine transporters: Influence of psychostimulants and therapeutic antidepressants." Aaps Journal 7(3): E728-E738. 
Jayanthi, L. D., D. J. Samuvel, et al. (2005). "Evidence for biphasic effects of protein kinase C on serotonin transporter function, endocytosis, and phosphorylation." Molecular Pharmacology 67(6): 2077-2087.

John, C. E. and S. R. Jones (2007). "Voltammetric characterization of the effect of monoamine uptake inhibitors and releasers on dopamine and serotonin uptake in mouse caudate-putamen and substantia nigra slices." Neuropharmacology 52(8): 1596-1605.

Jorgensen, H. S. (2007). "Studies on the neuroendocrine role of serotonin." Danish Medical Bulletin 54(4): 266-288.

Kilic, F. and G. Rudnick (2000). "Oligomerization of serotonin transporter and its functional consequences." Proceedings of the National Academy of Sciences of the United States of America 97(7): 3106-3111.

Kittler, K., T. Lau, et al. (2010). "Antagonists and substrates differentially regulate serotonin transporter cell surface expression in serotonergic neurons." European Journal of Pharmacology 629(1-3): 63-67.

Kivell, B., D. Day, et al. (2010). "MDMA causes a redistribution of serotonin transporter from the cell surfaceto the intracellular compartment by a mechanism independent of phospho-p38mitogen activated protein kinase activation." Neuroscience 168(1): 82-95.

Klebe, R. J. and R. H. Ruddle (1969). "Neuroblastoma - cell culture analysis of a differentiating stem cell system." Journal of Cell Biology 43(2P2): A69-\&.

Koepsell, H., K. Lips, et al. (2007). "Polyspecific organic cation transporters: Structure, function, physiological roles, and biopharmaceutical implications." Pharmaceutical Research 24(7): 1227-1251.

Koob, G. F. (2001). "Drug addiction, reward dysregulation and allostasis." British Journal of Pharmacology 134.

Kramer, H. K., J. C. Poblete, et al. (1997). "Activation of protein kinase C (PKC) by 3,4methylenedioxymethamphetamine (MDMA) occurs through the stimulation of serotonin receptors and transporter." Neuropsychopharmacology 17(3): 117-129.

Kramer, H. K., J. C. Poblete, et al. (1998). "Characterization of the translocation of protein kinase C (PKC) by 3,4-methylenedioxymethamphetamine (MDMA/Ecstasy) in synaptosomes: Evidence for a presynaptic localization involving the serotonin transporter (SERT)." Neuropsychopharmacology 19(4): 265-277.

Lesch, K. P., D. Bengel, et al. (1996). "Association of anxiety-related traits with a polymorphism in the serotonin transporter gene regulatory region." Science 274(5292): 1527-1531.

Mao, Y. X., L. Mathewson, et al. (2008). "Involvement of serotonin transporter extracellular loop 1 in serotonin binding and transport." Molecular Membrane Biology 25(2): 115-127.

Marinissen, M. J. and J. S. Gutkind (2001). "G-protein-coupled receptors and signaling networks: emerging paradigms." Trends in Pharmacological Sciences 22(7): 368-376.

McLane, M. W., U. McCann, et al. (2011). "Identifying the Serotonin Transporter Signal in Western Blot Studies of the Neurotoxic Potential of MDMA and Related Drugs." Synapse 65(12): 1368-1372.

Meiergerd, S. M., S. M. Hooks, et al. (1994). "The striatal transporter for dopamine in the rat may be kinectically up-regulated following 3 weeks of withdrawl from cocaine self-administration." Journal of Neurochemistry 63(4): 1277-1281.

Melikian, H. E., S. Ramamoorthy, et al. (1996). "Inability to N-glycosylate the human norepinephrine transporter reduces protein stability, surface trafficking, and transport activity but not ligand recognition." Molecular Pharmacology 50(2): 266-276.

Melo, J. A., J. Shendure, et al. (1996). "Identification of sex specific quantitative trait loci controlling alcohol preference in C57BL/6 mice." Nature Genetics 13(2): 147-153.

Mochizuki, H., T. Amano, et al. (2005). "Role of C-terminal region in the functional regulation of rat serotonin transporter (SERT)." Neurochemistry International 46(2): 93-105. 
Mortensen, O. V., A. S. Kristensen, et al. (1999). "Molecular cloning, expression and characterization of a bovine serotonin transporter." Molecular Brain Research 71(1): 120-126.

Murphy, D. L., M. A. Fox, et al. (2008). "How the serotonin story is being rewritten by new genebased discoveries principally related to SLC6A4, the serotonin transporter gene, which functions to influence all cellular serotonin systems." Neuropharmacology 55(6): 932-960.

Murphy, D. L., A. Lerner, et al. (2004). "Serotonin transporter: Gene, genetic disorders, and pharmacogenetics." Molecular Interventions 4(2): 109-123.

Nair, S. G. and G. A. Gudelsky (2004). "Protein kinase C inhibition differentially affects 3,4methylenedioxymethamphetamine-induced dopamine release in the striatum and prefrontal cortex of the rat." Brain Research 1013(2): 168-173.

Nelson, N. (1998). "The family of $\mathrm{Na}+\mathrm{Cl}$ - neurotransmitter transporters." Journal of Neurochemistry 71(5): 1785-1803.

Nichols, D. E. and C. D. Nichols (2008). "Serotonin receptors." Chemical Reviews 108(5): 1614-1641.

O'Callaghan, J. P. and D. B. Miller (1993). "Quantification of reactive gliosis as an approach to neurotoxicity assessment." NIDA Res Monogr 136: 188-212.

Owens, M. J. and C. B. Nemeroff (1994). "Role of serotonin in the pathophysiology of depression focus on the serotonin transporter." Clinical Chemistry 40(2): 288-295.

Oz, M., T. Libby, et al. (2010). "Real-time, spatially resolved analysis of serotonin transporter activity and regulation using the fluorescent substrate, ASP(+)." Journal of Neurochemistry 114(4): 1019-1029.

Perez, X. A. and A. M. Andrews (2005). "Chronoamperometry to determine differential reductions in uptake in brain synaptosomes from serotonin transporter knockout mice." Analytical Chemistry 77(3): 818-826.

Prasad, H. C., C. B. Zhu, et al. (2005). "Human serotonin transporter variants display altered sensitivity to protein kinase $\mathrm{G}$ and p38 mitogen-activated protein kinase." Proceedings of the National Academy of Sciences of the United States of America 102(32): 11545-11550.

Pubill, D., A. M. Canudas, et al. (2003). "Different glial response to methamphetamine- and methylenedioxymethamphetamine-induced neurotoxicity." Naunyn-Schmiedebergs Archives of Pharmacology 367(5): 490-499.

Qian, Y., A. Galli, et al. (1997). "Protein kinase C activation regulates human serotonin transporters in HEK-293 cells via altered cell surface expression." Journal of Neuroscience 17(1): 45-57.

Qian, Y., H. E. Melikian, et al. (1995). "Identification and characterization of antidepressant-sensitive serotonin transporter proteins using site-specific antibodies." Journal of Neuroscience 15(2): 1261-1274.

Ramamoorthy, S., A. L. Bauman, et al. (1993). "Antidepressant-sensitive and cocaine-sensitive human serotonin transporter - molecular-cloning, expression, and chromosomal localization." Proceedings of the National Academy of Sciences of the United States of America 90(6): 2542-2546.

Ramamoorthy, S., E. Giovanetti, et al. (1998). "Phosphorylation and regulation of antidepressantsensitive serotonin transporters." Journal of Biological Chemistry 273(4): 2458-2466.

Ramamoorthy, S., D. J. Samuvel, et al. (2007). "Phosphorylation of threonine residue 276 is required for acute regulation of serotonin transporter by cyclic GMP." Journal of Biological Chemistry 282(16): 11639-11647.

Ramamoorthy, S., T. S. Shippenberg, et al. (2011). "Regulation of monoamine transporters: Role of transporter phosphorylation." Pharmacology \& Therapeutics 129(2): 220-238.

Robinson, T. E. and K. C. Berridge (2000). "The psychology and neurobiology of addiction: an incentive-sensitization view." Addiction 95(8): S91-S117.

Rothman, R. B., S. Jayanthi, et al. (2003). "High-dose fenfluramine administration decreases serotonin transporter binding, but not serotonin transporter protein levels, in rat forebrain." Synapse 50(3): 233-239. 
Rudnick, G. and J. Clark (1993). "From synapse to vesicle - the reuptake and storage of biogenicamine neurotransmitters." Biochimica Et Biophysica Acta 1144(3): 249-263.

Samuvel, D. J., L. D. Jayanthi, et al. (2005). "A role for p38 mitogen-activated protein kinase in the regulation of the serotonin transporter: Evidence for distinct cellular mechanisms involved in transporter surface expression." Journal of Neuroscience 25(1): 29-41.

Schmidt, C. J. and V. L. Taylor (1987). "Depression of rat-brain tryptophan-hydroxylase activity following the acute administration of methylenedioxymethamphetamine." Biochemical Pharmacology 36(23): 4095-4102.

Schmued, L. and L. Xu (2003). "Demonstration and localization of MDMA induced neuronal degeneration." Neurotoxicology 24(2): 54.

Scholze, P., M. Freissmuth, et al. (2002). "Mutations within an intramembrane leucine heptad repeat disrupt oligomer formation of the rat GABA transporter 1." Journal of Biological Chemistry 277(46): 43682-43690.

Shaw, G., S. Morse, et al. (2002). "Preferential transformation of human neuronal cells by human adenoviruses and the origin of HEK 293 cells." Faseb Journal 16(6): 869-+.

Simonson, B. (2011). Investigating the effects of novel kappa opiod receptor agonists on the dopamine transporter. School of Biological Sciences. Wellington, Victoria University. PhD.

Sitte, H. H., H. Farhan, et al. (2004). "Oligomerization as a determinant of transporter function and trafficking." Molecular Interventions 4(1): 38-47.

Sitte, H. H. and M. Freissmuth (2010). "The reverse operation of $\mathrm{Na}+\mathrm{Cl}$--coupled neurotransmitter transporters - why amphetamines take two to tango." Journal of Neurochemistry 112(2): 340-355.

Sorkina, T., S. Doolen, et al. (2003). "Oligomerization of dopamine transporters visualized in living cells by fluorescence resonance energy transfer microscopy." Journal of Biological Chemistry 278(30): 28274-28283.

Stamford, J. A., Z. L. Kruk, et al. (1990). "Striatal dopamine terminals release serotonin after 5-HTP pretreatment - in vivo voltammetric data." Brain Research 515(1-2): 173-180.

Steinkellner, T., M. Freissmuth, et al. (2011). "The ugly side of amphetamines: short- and long-term toxicity of 3,4-methylenedioxymethamphetamine (MDMA, 'Ecstasy'), methamphetamine and D-amphetamine." Biological Chemistry 392(1-2): 103-115.

Tate, C. G. and R. D. Blakely (1994). "The effects of N-linked glycosylation on activity of the Na+dependent and $\mathrm{Cl}$--dependent serotonin transporter expressed using recombinant baculovirus in insect cells." Journal of Biological Chemistry 269(42): 26303-26310.

Tsuruda, P. R., J. Yung, et al. (2010). "Influence of ligand binding kinetics on functional inhibition of human recombinant serotonin and norepinephrine transporters." Journal of Pharmacological and Toxicological Methods 61(2): 192-204.

UNODC (2010). World drug report 2010, United Nations Publication, Vienna.

Vaughan, R. A. (2004). "Phosphorylation and regulation of psychostimulant-sensitive neurotransmitter transporters." Journal of Pharmacology and Experimental Therapeutics 310(1): 1-7.

Wang, X., M. H. Baumann, et al. (2007). "Restoration of 3,4-methylenedioxymethamphetamineinduced 5-HT depletion by the administration of L-5-hydroxytryptophan." Neuroscience 148(1): 212-220.

Wang, X. Y., M. H. Baumann, et al. (2005). "(+/-)-3,4-Methylenedioxymethamphetamine administration to rats does not decrease levels of the serotonin transporter protein or alter its distribution between endosomes and the plasma membrane." Journal of Pharmacology and Experimental Therapeutics 314(3): 1002-1012.

Wightman, R. M. and J. B. Zimmerman (1990). "CONTROL OF DOPAMINE EXTRACELLULAR CONCENTRATION IN RAT STRIATUM BY IMPULSE FLOW AND UPTAKE." Brain Research Reviews 15(2): 135-144. 
Xie, T., L. Tong, et al. (2006). "Loss of serotonin transporter protein after MDMA and other ringsubstituted amphetamines." Neuropsychopharmacology 31(12): 2639-2651.

Yamashita, A., S. K. Singh, et al. (2005). "Crystal structure of a bacterial homologue of $\mathrm{Na}+\mathrm{Cl}--$ dependent neurotransmitter transporters." Nature 437(7056): 215-223.

Yamauchi, Y., T. Uumi, et al. (2007). "Acceleration of serotonin transporter transport-associated current by 3,4-methylenedioxymethanphetamine (MDMA) under acidic conditions." Neuroscience Letters 428(2-3): 72-76.

Yasuda, K., M. Itakura, et al. (2011). "PKC-Dependent Inhibition of Ca2+-Dependent Exocytosis from Astrocytes." Glia 59(1): 143-151.

Zapata, A., B. Kivell, et al. (2007). "Regulation of dopamine transporter function and cell surface expression by D3 dopamine receptors." Journal of Biological Chemistry 282(49): 3584235854.

Zhu, C. B., A. M. Carneiro, et al. (2005). "p38 MAPK activation elevates serotonin transport activity via a trafficking-independent, protein phosphatase 2A-dependent process." Journal of Biological Chemistry 280(16): 15649-15658.

Zhu, C. B., W. A. Hewlett, et al. (2004). "Adenosine receptor, protein kinase G and p38 mitogenactivated protein kinase-dependent up-regulation of serotonin transporters involves both transporter trafficking and activation." Molecular Pharmacology 65(6): 1462-1474. 